\title{
Deep infiltratingf endometriosis environment, genetics, epigenetics
}

Citation for published version (APA):

Kaam, K. J. A. F. (2012). Deep infiltratingf endometriosis environment, genetics, epigenetics. [Doctoral Thesis, Maastricht University]. Maastricht University. https://doi.org/10.26481/dis.20120524kk

Document status and date:

Published: 01/01/2012

DOI:

10.26481/dis.20120524kk

Document Version:

Publisher's PDF, also known as Version of record

\section{Please check the document version of this publication:}

- A submitted manuscript is the version of the article upon submission and before peer-review. There can be important differences between the submitted version and the official published version of record.

People interested in the research are advised to contact the author for the final version of the publication, or visit the DOI to the publisher's website.

- The final author version and the galley proof are versions of the publication after peer review.

- The final published version features the final layout of the paper including the volume, issue and page numbers.

Link to publication

\footnotetext{
General rights rights.

- You may freely distribute the URL identifying the publication in the public portal. please follow below link for the End User Agreement:

www.umlib.nl/taverne-license

Take down policy

If you believe that this document breaches copyright please contact us at:

repository@maastrichtuniversity.nl

providing details and we will investigate your claim.
}

Copyright and moral rights for the publications made accessible in the public portal are retained by the authors and/or other copyright owners and it is a condition of accessing publications that users recognise and abide by the legal requirements associated with these

- Users may download and print one copy of any publication from the public portal for the purpose of private study or research.

- You may not further distribute the material or use it for any profit-making activity or commercial gain

If the publication is distributed under the terms of Article $25 \mathrm{fa}$ of the Dutch Copyright Act, indicated by the "Taverne" license above, 


\title{
DEEP INFILTRATING ENDOMETRIOSIS
}

\author{
ENVIRONMENT, GENETICS, EPIGENETICS
}


C Copyright K J.A.F. van Kaam, Maastricht 2012

Cover design: Marjolein Pijnappels | Studio Lakmoes

Layout: Tiny Wouters

Production: GVO drukkers en vormgevers B.V. | Ponsen en Looijen

ISBN: 978-90-6464-552-5

The studies described in this thesis were financially supported by an unrestricted research grant from Ferring B.V., Hoofddorp, The Netherlands. This support is gratefully acknowledged.

Financial support for printing of this thesis was kindly provided by:

Bayer HealthCare, GOODLIFE Pharma, Endometriose Stichting, Ferring B.V. and MSD Nederland 


\title{
DEEP INFILTRATING ENDOMETRIOSIS
}

\author{
ENVIRONMENT, GENETICS, EPIGENETICS
}

\section{PROEFSCHRIFT}

ter verkrijging van de graad van doctor aan de Universiteit Maastricht, op gezag van de Rector Magnificus, Prof. mr. G.P.M.F. Mols, volgens het besluit van het College van Decanen, in het openbaar te verdedigen op donderdag 24 mei 2012 om 14:00 uur

door

Kim Josephine Agnes Francisca van Kaam

Geboren op 15 september 1977 te Sittard 
Promotor

Prof. dr. J.L.H. Evers

Copromotores

Dr. G.A.J. Dunselman

Dr. P.G. Groothuis

Beoordelingscommissie

Prof. dr. R.G.H. Beets-Tan (voorzitter)

Dr. C.E.M. de Die-Smulders

Prof. dr. M. van Engeland

Prof. dr. B.C.J.M. Fauser (Universitair Medisch Centrum Utrecht)

Dr. ir. J.W. Voncken 
Stel dat je niet naar huis gaat Je laat de laatste ronde gaan Je planned alleen de eerste meters De hardste hier vandaan

Stel dat je hoofd je hart volgt En je loopt naar het station En je leunt op de gedachte Terwijl je wacht op het perron

Het maakt niet uit wat je gisteren deed Het gaat om dat wat je morgen pas weet 



\section{Contents}

Abbreviations

Chapter 1 General Introduction

Chapter 2 Fibromuscular differentiation in deep infiltrating endometriosis is a reaction of resident fibroblasts to the presence of ectopic endometrium

Chapter 3 Transforming growth factor beta1 gene polymorphism -509C/T in deep infiltrating endometriosis

Chapter 4 Progesterone receptor polymorphism +331G/A is associated with a decreased risk of deep infiltrating endometriosis

Chapter 5 DNA methyltransferases and methyl-CpG binding domain proteins in human endometrium and endometriosis

Chapter 6 Is the extreme dysregulation of genes in eutopic endometrium of endometriosis patients the result of aberrant gene promoter methylation?

Chapter 7 General Discussion

Summary

Samenvatting

Dankwoord

Curriculum Vitae

Color figures 



\section{Abbreviations}

\begin{tabular}{|c|c|}
\hline ASMA & alpha-smooth muscle actin \\
\hline bp & base pair \\
\hline cDNA & complementary DNA \\
\hline $\mathrm{Cl}$ & confidence interval \\
\hline $\mathrm{CT}$ & comparative threshold \\
\hline DNMT & DNA methyltransferase \\
\hline DZ & dizygotic \\
\hline ECM & extracellular matrix \\
\hline ESC & embryonic stem cell \\
\hline E1 & estrone \\
\hline E2 & estradiol \\
\hline FM & fibromuscular \\
\hline HDAC & histone deacetylase \\
\hline he & heterozygous \\
\hline $\mathrm{hmC}$ & hydroxymethylation of cytosines \\
\hline ho & homozygous \\
\hline HSD & hydroxysteroid dehydrogenase \\
\hline HWE & Hardy-Weinberg equilibrium \\
\hline IBD & identity by descent \\
\hline $\lg$ & immunoglobulin \\
\hline IGFBP & insulin growth factor binding protein \\
\hline IL & interleukin \\
\hline IVD & in vitro methylated DNA \\
\hline LFC & Leuven Fertility Center \\
\hline LRES & long-range epigenetic silencing \\
\hline MBD & methyl-CpG-binding domain protein \\
\hline miRNA & micro-RNA \\
\hline mRNA & messenger RNA \\
\hline MSP & methylation specific PCR \\
\hline MUMC & Maastricht University Medical Center \\
\hline $\mathrm{MZ}$ & monozygotic \\
\hline NL & normal lymphocytes \\
\hline OR & odds ratio \\
\hline$P$ & progesterone \\
\hline pAbs & polyclonal antibodies \\
\hline PBS & phosphate-buffered saline \\
\hline PCR & polymerase chain reaction \\
\hline PR & progesterone receptor \\
\hline QTL & quantitative linkage analysis \\
\hline
\end{tabular}




$\begin{array}{ll}\text { rAFS } & \text { revised American Society for Reproductive Medicine } \\ \text { RFLP } & \text { restriction fragment length polymorphism } \\ \text { RT-PCR } & \text { real-time PCR } \\ \text { TGF- } \beta & \text { transforming growth factor- } \beta \\ \text { T } \beta \text { R } & \text { transforming growth factor- } \beta \text { receptor } \\ \text { SD } & \text { standard deviation } \\ \text { SEM } & \text { standard error of the mean } \\ \text { SI } & \text { staining index } \\ \text { SM } & \text { smooth muscle } \\ \text { SMM } & \text { smooth muscle metaplasia } \\ \text { SM-MHC } & \text { smooth muscle myosin heavy chain } \\ \text { SNP } & \text { single nucleotide polymorphism } \\ \text { TSS } & \text { transcription start site } \\ \text { T1 } & \text { wildtype allele } \\ \text { T2 } & \text { mutant allele } \\ \text { wt } & \text { wildtype }\end{array}$




\section{Chapter 1}

General Introduction 
Chapter 1 


\section{Endometriosis}

\section{Clinical Introduction}

Endometriosis is defined as the presence of functional endometrial glands and stroma at ectopic locations outside the uterine cavity. Ectopic endometrial implants are most often found on the ovaries, the fossa ovarica, the uterosacral ligaments and the posterior culde-sac. A proportion of women with this condition may be asymptomatic, but symptoms can be substantial and include dysmenorrhea, dyspareunia, chronic and severe pelvic pain throughout the menstrual cycle, and infertility. Endometriosis predominantly develops in women of reproductive age and regresses after menopause or after ovariectomy (1), suggesting that the establishment and growth of ectopic implants is dependent on ovarian steroids, similar to the situation encountered in eutopic endometrium. Being one of the most common benign gynecological conditions with an estimated prevalence of about $10 \%(2)$, endometriosis is a debilitating disease with detrimental effects on social, occupational and psychological functioning (3). The prevalence increases up to $30 \%$ in patients with infertility and up to $45 \%$ in patients with chronic pelvic pain $(2,4)$. At present, endometriosis can only be reliably diagnosed by laparoscopy, with subsequent biopsy of suspect lesions for histological confirmation. Because the symptomatology of endometriosis shows numerous commonalities with a wide range of diseases, a diagnostic delay of 5 to 10 years is not uncommon in some healthcare settings (3).

\section{Pathogenesis}

Although endometriosis stands as one of the most investigated disorders of gynecology, our current understanding of the pathogenesis of this disease remains limited. Theories that have been developed regarding this subject can be divided into three main concepts: 1) the in situ development theory, i.e. the concept that endometriosis develops in situ from local tissues, such as the germinal epithelium of the ovary, remnants of the Wolffian or Müllerian ducts or from metaplasia of totipotent mesothelial serosal cells, 2) the induction theory, i.e. the concept that endogenous substances released from degenerating menstrual endometrium induce a metaplastic process in undifferentiated mesenchyme to develop into endometrial tissue (5) and 3) the retrograde transplantation theory, which is currently the most widely accepted theory regarding the pathogenesis of endometriosis (6). According to this theory, reflux of viable endometrial cells takes place through the Fallopian tubes during menstruation, with subsequent adhesion, implantation and growth on and into the peritoneum and ovary. A large body of experimental and clinical observations add support to the Sampson hypothesis, such as the anatomical distribution of endometriosis lesions in the abdominal cavity (7), the demonstration of viable endometrial cells in the peritoneal fluid of women with endometriosis $(8,9)$ and characteristics of retrogradely shed endometrial fragments such as the ability to adhere to 
the peritoneal lining $(10)$, to invade the extracellular matrix $(11,12)$ and to produce angiogenic factors that can potentially induce local neovascularisation (13). However, research indicates that menstrual reflux is a common occurrence, and small endometriotic implants occur frequently in asymptomatic women of reproductive age $(14,15)$. This has led to the hypothesis that mild peritoneal endometriosis is a condition that occurs intermittently in most if not all menstruating women with patent tubes (16). As a consequence, there is a growing appreciation for the notion that mild peritoneal endometriosis should be considered a physiological phenomenon rather than a disease.

It has been proposed that viable endometrial fragments arriving in the peritoneal cavity through retrograde menstruation would normally be cleared by a cell-mediated immune response. The incapacity to clear the peritoneal cavity of endometrial cells may either result from innate properties of the endometrium itself, leading to increased survival, or from (immunological) aberrations in the local peritoneal environment, leading to decreased surveillance, recognition and destruction of the misplaced endometrial cells. When these local pelvic clearance mechanisms fail, endometriosis lesions may have the opportunity to adhere, vascularize, grow, and infiltrate, thus allowing the "phenomenon" endometriosis to progress into the "disease" endometriosis. Endometriotic disease was characterized by Koninckx and coworkers as the presence of either 1) considerable pelvic adhesions perturbing the local anatomical situation, 2) endometriotic ovarian cysts or 3 ) deep infiltrating endometriosis lesions (16). The question that has frustrated investigators for more than a century is: why does endometriosis develop into a pathological condition in some but not all women?

\section{Deep infiltrating endometriosis}

\section{Definition and pathogenesis}

In the early nineties of the past century, deep infiltrating endometriosis was introduced as a new distinct entity (17). Deep infiltrating endometriosis is defined as endometrial glands and stroma infiltrating $>5 \mathrm{~mm}$ under the peritoneal surface. The threshold of $5 \mathrm{~mm}$ was chosen because of several reasons. First, lesions infiltrating $>5 \mathrm{~mm}$ were shown to be the most active lesions from a morphological point of view (17). A second argument is derived from the frequency distribution of the depth of infiltration in women with pelvic pain and/or infertility, which shows a biphasic pattern with a nadir at 5-6 mm (18). Furthermore, of all lesion types, deep infiltrating endometriosis showed the strongest association with pelvic pain. Women with pain have larger and deeper lesions and very deep implants $(>10 \mathrm{~mm}$ ) were found exclusively in patients with pain. Therefore, it was suggested that in most women, peritoneal endometriosis lesions infiltrate only superficially, cause little or no symptoms and are eventually inactivated. Lesions that infiltrate deeper than $5 \mathrm{~mm}$ become a different condition. The disease becomes more 
active and aggressive, and develops into even deeper lesions causing pelvic distortion and severe pain. Deep infiltrating lesions are often symptomatic and are strongly associated with symptoms such as dysmenorrhea, deep dyspareunia, chronic pelvic pain and painful defecation (19) .

In recent years, the pathogenesis of deep endometriosis has also been the subject of another debate. It has been argued that deep infiltrating endometriosis may be a dissimilar disease entity, different from peritoneal and ovarian endometriosis. Several arguments exist supporting this notion. Deep infiltrating endometriosis lesions have a distinct histological appearance resembling adenomyosis (i.e. the presence of endometrial glands and stroma in the myometrium) of the uterine wall. They are nodular in appearance and mainly consist of fibromuscular tissue, interspersed with islands of endometrial glands and stroma (20). Moreover, deep infiltrating endometriosis lesions have a specific anatomical distribution, as they are mainly found in the pouch of Douglas and on the uterosacral ligaments. Therefore, it was hypothesized by some that this type of lesion is not caused by implantation of regurgitated endometrial tissue during menstruation (i.e. Sampson's theory), but rather develops from metaplasia of Müllerian remnants located in the rectovaginal septum, in line with the in situ metaplasia theory (21). Alternatively, there are those that believe that deep infiltrating endometriosis lesions develop from superficial peritoneal lesions in the pouch of Douglas (22).

\section{Fibrosis and smooth muscle metaplasia in deep infiltrating endometriosis}

Although the question whether deep endometriosis and adenomyosis represent the same disease entity is still a subject of debate, a certain histological distinction can be made between deep infiltrating endometriosis on the one hand, and peritoneal and ovarian endometriosis on the other hand. Deep endometriosis lesions are nodular in appearance and are histologically characterized by islands of endometrial glands and scanty stroma interlacing dense tissue composed of fibrous and smooth muscle cells, whereas peritoneal and ovarian endometriosis are characterized by a more glandular appearance surrounded by a cytogenic stroma. Strikingly, the major component of the deep infiltrating nodular lesion is not endometrial tissue but fibromuscular tissue $(20,21,23)$. Itoga and coworkers demonstrated that fibrosis was present in $89 / 90$ histological specimens of rectovaginal endometriotic nodules. Moreover, there was a significant correlation between the amount of fibrosis and the amount of endometrial tissue present in the lesion. Aggregated smooth muscles that were not associated with blood vessels, defined as smooth muscle metaplasia (SMM), were always present in fibrotic areas, and the degree of SMM in the entire tissue was significantly correlated with the degree of fibrosis. These authors were not the first to histologically characterize endometriosis lesions: in 2000 Anaf and coworkers demonstrated that smooth muscles are present in peritoneal, ovarian, uterosacral and rectovaginal lesions. Smooth muscle cells are absent in the unaffected peritoneum and in the eutopic endometrium of women with and without pelvic 
endometriosis (23), suggesting a role of the local environment in the development of these fibromuscular cells. As a result, it was speculated that the smooth muscle component in endometriosis lesions either results from the capacity of the totipotent coelomic serosal cells to differentiate not only into endometrial glands and stroma but also into smooth muscle, or from the fibromuscular differentiation of regurgitated endometrial stromal cells.

\section{Transforming growth factor-beta signaling and fibrosis}

Among the many factors that modulate the formation of fibrosis, transforming growth factor-beta (TGF- $\beta$ ), and especially the isoform TGF- $\beta 1$, is the cytokine most causatively associated with disorders characterized by fibrosis throughout the body (24). The TGF- $\beta$ isoforms TGF- $\beta 1$, TGF- $\beta 2$ and TGF- $\beta 3$ are pleiotropic cytokines that mediate a variety of effects on a range of cell types. After activation, the TGF- $\beta$ s bind with high affinity to TGF$\beta$ receptor (TKR) II which phosphorylates $T \beta R I$, leading to the recruitment and phosphorylation of the intracellular downstream effector proteins Smad2 and Smad3. Phosphorylated Smad2 and Smad3 subsequently bind to Smad4 and translocate to the nucleus to initiate target gene expression. TGF- $\beta 1$ exerts its fibrogenic effects by promoting expression of extracellular matrix (ECM) genes and suppressing the activity of enzymes that degrade ECM (such as matrix metalloproteinases). Furthermore, TGF- $\beta$ enhances fibroblast proliferation, and induces their differentiation into the myofibroblast phenotype.

TGF- $\beta 1$ has been implicated in both the physiologic growth and differentiation of the endometrium as well as in the pathogenesis of endometriosis. All TGF- $\beta$ s and their high affinity receptors are stage specifically expressed in both endometrial glands and stroma (25), suggesting that their expression is under hormonal control. Since mRNA and protein expression of all three TGF- $\beta$ s is increased around menstruation, it was suggested that TGF- $\beta$ s might be involved in initiation of menstruation. TGF- $\beta 3$ is thought to participate in the postmenstrual regeneration of endometrium, because of high expression levels in this phase of the menstrual cycle (26). Higher concentrations of TGF- $\beta 1$ have been measured in the peritoneal fluid of endometriosis patients compared to controls (26-28), suggesting that this cytokine may be crucial in the establishment and/or maintenance of endometriosis.

\section{Progesterone resistance}

\section{Evidence for progesterone resistance in endometriosis}

Endometriosis is an estrogen dependent disease, demonstrated by the fact that it occurs primarily in cycling women of reproductive age $(2,6)$ and regresses after menopause or 
after ovariectomy. Progesterone is the most potent antagonist of estrogen-induced proliferation in the endometrium and as such may play a pivotal role in the pathogenesis of endometriosis. Progesterone induces differentiation of both endometrial stromal and epithelial cells, exemplified at the histological level by pseudodecidual and secretory changes, and reduces mitotic figures and cell proliferation. Another striking effect of progesterone on the endometrium is to stimulate the expression of the enzyme $17 \beta$ hydroxysteroid dehydrogenase type 2 (17ß-HSD type 2 ) in epithelial cells. $17 \beta$-HSD type 2 catalyzes the conversion of the biologically active E2 into the biologically less active estrone (E1) (29). In women with endometriosis, this enzyme is expressed in eutopic endometrium in the luteal phase of the menstrual cycle, but not in ectopic endometriotic lesions simultaneously biopsied from the same patient (30). The lack of $17 \beta$-HSD type 2 in ectopic endometriotic tissue during the luteal phase, despite histologically recognizable secretory changes, is suggestive of selective resistance to progesterone action. Eutopic endometrium of endometriosis patients also exhibits signs of progesterone resistance since a number of progesterone target genes, such as glycodelin, was shown to be deregulated in eutopic endometrium of endometriosis patients during the window of implantation, at which time the endometrium is exposed to the highest levels of progesterone (31). Finally, failure of endometriosis to regress in response to treatment with progestins in a significant number of patients is another, clinical indicator of progesterone resistance $(32,33)$.

\section{Progesterone receptor}

The effects of progesterone are mediated through intracellular progesterone receptors that are expressed from a single gene as two protein isoforms, progesterone receptor $A$ (PR-A) and progesterone receptor $B$ (PR-B) (34). The PR-A and PR-B isoforms are liganddependent members of the nuclear receptor family that are structurally identical, except for an additional 164 amino acids at the amino terminal of PR-B (35). This region encodes a transactivation function that is specific to PR-B and is required to specify target genes that can be activated by PR-B but not PR-A (36). PR-B functions as a stronger transcriptional activator of progesterone target genes, whereas PR-A has been shown to act as a dominant repressor of PR-B $(37,38)$. Furthermore, the responses of ligandactivated PR-A and PR-B strongly depend on the cellular context. The physiologic importance of maintaining correct relative expression levels of $P R$ isoforms in tissues is underlined by the fact that loss of coordinate expression of $P R$ isoforms is an early event in breast carcinogenesis (39). Alteration of the PR-A/PR-B ratio in breast and endometrial carcinoma cells has been shown to favor cellular invasion and metastasis $(40,41)$. Moreover, high PR-B levels often are found in highly malignant endometrial cancers, and selective ablation of the $A$ isoform in knockout mice results in endometrial hyperproliferative and premalignant changes. Hence, the anti-proliferative effects of progesterone are thought to depend on a tight regulation of the PR-A/ PR-B isoform 
balance. Several studies have reported aberrant expression of progesterone receptor in eutopic and ectopic endometrium of endometriosis patients. For example, both PR-A and PR-B were present in eutopic endometrium of endometriosis patients, but PR-B was completely absent in ectopic endometriotic lesions (42). Wu and coworkers also demonstrated significantly reduced expression of PR-B in epithelial cells of endometriotic lesions, associated with hypermethylation of the PR-B promoter region (43). Furthermore, a lower PR-B/PR-A ratio in eutopic endometrium of endometriosis patients compared to disease-free controls was demonstrated by western blotting (44). Hence, the reported disruption of PR-A/PR-B ratio in endometriotic tissue might lead to an impaired stromal differentiation and a consequent relative resistance to $P$ action. Factors influencing the relative expression levels of PR-A to PR-B may therefore be of importance in the pathogenesis of endometriosis.

\section{Genetics}

\section{Genetic contributions to endometriosis}

Endometriosis is commonly regarded as a complex trait, caused by the interplay between genetic and environmental factors. Evidence for the contribution of genetic factors to the individual susceptibility for endometriosis has been provided by numerous studies (45-52), demonstrating familial clustering and increased prevalence among first degree relatives and in twins. A strong familial tendency has also been reported in non-human primates, further supporting a genetic predisposition to the disorder (53).

Higher rates of endometriosis are found among the relatives of endometriosis cases compared with those of both hospital $(50,54)$ and population-based $(51)$ controls. In an Australian sample of twins and their families, the relative recurrence risk to sibs has been estimated at 2.34 (52). However, estimates from imaging studies on the sisters of women with more severe disease suggest that the relative risk may be as high as 15 (55). Overall, the risk to first-degree relatives of patients for developing endometriosis has been reported to be $5-8 \%$.

Stefansson and coworkers estimated the contribution of genetic factors in endometriosis in the Icelandic population, which is known to have limited genetic variability because of its isolated geographical position (51). These authors demonstrated that 750 women with endometriosis were significantly more interrelated than matched control groups. The risk ratio for sisters was 5.20 and for cousins 1.56 . The average kinship coefficient for endometriosis patients was significantly higher than that calculated for 1000 sets of 750 matched controls, which is consistent with a complex genetic basis of this disease.

Another type of study design that is suitable for studying the impact of genetic factors is the twin study, which compares the concordance rate (the percentage of twin pairs who both have the disease) between monozygotic (MZ) and dizygotic (DZ) twins. Increased concordance in $\mathrm{MZ}$ compared with $\mathrm{DZ}$ twins suggests a role for genetic factors in disease 
causation, assuming that $\mathrm{MZ}$ twins do not share more environmental influences than $\mathrm{DZ}$ twins. In the case of endometriosis, higher concordance for $M Z$ than DZ twins has consistently been observed $(54,56,57)$. A large-scale study in 3096 twins on the Australian National Health and Medical Research Council Twin Register showed a 2.0\% concordance for monozygotic and $0.6 \%$ for dizygotic twins (58). Moreover, these authors concluded that $51 \%$ of the variation in endometriosis risk may be attributable to genetic factors.

\section{Mode of inheritance}

The $5-8 \%$ risk observed for first-degree relatives is more consistent with a polygenic/multifactorial mode of inheritance than with a single mutant gene (Mendelian or monogenic mode of inheritance). However, the risk of recurrence is slightly higher than expected for polygenic inheritance (generally 2-5\%), indicating that one or more Mendelian forms could coexist. Still, a polygenic mode of inheritance is more likely if endometriosis is assumed to be a single disease entity. The polygenic model postulates that a given disease is caused by cumulative individual effects of many different genes acting together in an additive fashion. If an individual carries a relatively large number of these genes, there is a threshold beyond which the disease is manifested.

According to the polygenic/multifactorial model, first-degree relatives will have more susceptibility genes and will be more frequently affected than the general population, which is indeed the case in endometriosis. Additional support for polygenic inheritance is the increased severity in familial cases. According to the polygenic model, the severity of a polygenic disorder increases with increasing underlying genetic liability. Hence, the higher the proportion of affected relatives, the greater the likelihood that the proband has severe endometriosis. The fact that there is an earlier age of onset for familial versus nonfamilial cases and a similar age of onset among affected relatives also supports a polygenic mode of inheritance (59).

\section{Strategies for identifying causative genes}

Finding genetic variants that contribute to complex diseases such as endometriosis is a difficult task because the contribution of individual genes is small, many genes contribute to an individual's risk of developing the disease and disease risk is often modified by other, environmental factors. However, common diseases present a much greater burden to public health than Mendelian diseases, that are generally much rarer. Therefore, considerable (international) efforts are made to define genetic contributions to these diseases. The most widely used general approaches so far in the search for genes causatively related to the pathogenesis of endometriosis are genome-wide quantitative linkage analysis (QTL), microarray technology, and the candidate gene approach based on biological plausibility. An overview of these techniques and a summary of their main advantages and disadvantages is presented in Table 1. 
In the past decades, many genes that were implicated in monogenic (Mendelian) diseases have been identified by QTL. Although this method has been successful in identifying high relative risk genes, it has not been successful in identifying genes that are involved in complex traits. This can be explained by several key features of complex disease. First, complex diseases typically vary in severity of symptoms and age of onset, which makes it difficult to define an appropriate phenotype and select the best population to study. Second, complex diseases may vary in their etiological mechanisms, which may involve various biological pathways. Third, and probably most important, complex diseases are more likely to be caused by several (and even numerous) genes, each with an overall small contribution and relative risk.

The candidate gene approach focuses on genes that are selected because of a priori hypotheses about their etiological role in disease, rather than rely on markers that are evenly spaced throughout the genome without regard to their function or context. In the case of endometriosis, endometriotic tissue may have an increased capability to adhere, proliferate, implant and survive in ectopic locations compared to normal endometrium. Genes that are known to be involved in the regulation of these processes are often selected as candidate genes for conducting genetic association studies. This is based on the premises that the susceptibility for endometriosis is caused by variations in DNA sequence (i.e. single nucleotide polymorphisms) in the selected candidate gene. In this respect, the preferred strategy is to search for SNPs with known functional consequences, meaning that they either change gene expression or the structure of the protein for which it codes, because these are most likely to affect the risk of a phenotype. Genes and their polymorphic variants that have been investigated so far with respect to the possible association with endometriosis mainly include genes involved in inflammation (cytokines, chemokines and their receptors, growth factors, Human Leukocyte Antigens, nitric oxide, adhesion molecules), steroid hormone regulation, metabolism and biosynthesis, detoxification, tissue remodeling, vascular function, and cell-cycle regulation.

As described earlier, both the formation of fibrosis and progesterone resistance are presumed etiological mechanisms in the pathogenesis of deep infiltrating endometriosis. TGF-beta 1 and progesterone receptor are pivotal genes involved in these respective processes, rendering both these genes plausible candidates for genetic association studies. Overproduction of TGF beta 1 is implicated in the pathogenesis of several fibrotic diseases at various sites throughout the body. Deep infiltrating endometriosis lesions are largely composed of fibromuscular tissue, and mechanisms increasing the fraction of biologically active TGF beta 1 , such as single nucleotide polymorphisms, may increase the susceptibility for developing this type of endometriosis. The $-509 \mathrm{C} / \mathrm{T}$ polymorphism is located in the promoter region of the TGF beta 1 gene and is associated with a significant increase in TGF-beta 1 plasma concentration, to the extent that $10 \%$ of the genetic variance in TGF beta 1 plasma concentration can be attributed to the presence of this polymorphism (60). 
Table 1 Strategies used for the identification of causative genes involved in endometriosis.

\begin{tabular}{|c|c|c|c|}
\hline Strategy & QTL & Microarray technology & Candidate gene approach \\
\hline \multirow[t]{2}{*}{ Principle } & $\begin{array}{l}\text { Requires no information } \\
\text { concerning candidate genes or } \\
\text { chromosomal loci (non- } \\
\text { hypothesis driven) }\end{array}$ & $\begin{array}{l}\text { Requires no information } \\
\text { concerning candidate genes or } \\
\text { chromosomal loci (non- } \\
\text { hypothesis driven) }\end{array}$ & $\begin{array}{l}\text { Selection of genes based on } \\
\text { biological plausibility, requires } \\
\text { knowledge of biological } \\
\text { pathways involved in disease } \\
\text { (hypothesis driven) }\end{array}$ \\
\hline & $\begin{array}{l}\text { Pivotal genes can be identified } \\
\text { if the same chromosomal } \\
\text { locus shows allele sharing in } \\
\text { different families of affected } \\
\text { individuals (Identity by } \\
\text { descent; IBD) }\end{array}$ & $\begin{array}{l}\text { Differentially expressed genes } \\
\text { may point to causative } \\
\text { association with the disease }\end{array}$ & $\begin{array}{l}\text { Susceptibility for } \\
\text { endometriosis is caused by a } \\
\text { variation in DNA sequence } \\
\text { that alters: } \\
\text {-gene expression or } \\
\text {-structure of protein for which } \\
\text { it codes }\end{array}$ \\
\hline Advantages & $\begin{array}{l}\text { Can be detected irrespective } \\
\text { of (incomplete) penetrance, } \\
\text { phenocopy, or genetic } \\
\text { heterogeneity }\end{array}$ & $\begin{array}{l}\text { Many potential relevant genes } \\
\text { can be tested simultaneously }\end{array}$ & $\begin{array}{l}\text { Genes do not have to be } \\
\text { expressed at the time that } \\
\text { tissue is obtained }\end{array}$ \\
\hline \multirow[t]{3}{*}{ Disadvantages } & $\begin{array}{l}\text { Need for multigenerational } \\
\text { families of affected and } \\
\text { unaffected individuals }\end{array}$ & $\begin{array}{l}\text { Need for an invasive } \\
\text { procedure (laparoscopy, } \\
\text { pipelle biopsy, hysteroscopy) } \\
\text { to obtain endometrial tissues }\end{array}$ & $\begin{array}{l}\text { Genetic associations often } \\
\text { inconsistent across ethnic } \\
\text { barriers }\end{array}$ \\
\hline & $\begin{array}{l}\text { Need for an invasive } \\
\text { procedure (laparoscopy) to } \\
\text { reliably confirm the absence of } \\
\text { endometriosis in presumably } \\
\text { unaffected individuals }\end{array}$ & $\begin{array}{l}\text { True causative gene may not } \\
\text { be expressed at the point in } \\
\text { time when the tissue was } \\
\text { studied }\end{array}$ & $\begin{array}{l}\text { Insufficient statistical power to } \\
\text { detect variants with expected } \\
\text { small effect size (small sample } \\
\text { sizes) }\end{array}$ \\
\hline & $\begin{array}{l}\text { Possible interaction between } \\
\text { different chromosomal loci }\end{array}$ & $\begin{array}{l}\text { Genes expressed may have } \\
\text { little to do with causality or } \\
\text { disease progression }\end{array}$ & $\begin{array}{l}\text { Publication bias: negative } \\
\text { associations less likely to be } \\
\text { published }\end{array}$ \\
\hline
\end{tabular}

As demonstrated in progesterone deficient mice, the physiological effects of progesterone depend completely on the presence of the human progesterone receptor (61). Within this context, structural changes in the PR and factors influencing the relative expression levels of PR-A to PR-B may be of importance in the pathogenesis of endometriosis. To date, several polymorphisms with (possible) functional consequences in the PR gene have been identified. The PROGINS polymorphism consists of a $320 \mathrm{bp} \mathrm{PV/HS-1} \mathrm{Alu} \mathrm{insertion} \mathrm{in} \mathrm{intron}$ $\mathrm{G}$, and two point mutations, a silent point mutation in exon $5(\mathrm{H} 77 \mathrm{OH})$ and a single amino acid change in exon 4 (V660L). The functional consequences of the PROGINS polymorphism are not yet fully understood, but there are indications that the PROGINS variant of $\mathrm{PR}$ is less responsive to progestin compared with the most common PR because of (1) reduced amounts of gene transcript and (2) decreased protein activity (62). The $+331 \mathrm{G} / \mathrm{A}$ polymorphism is located in the promoter region of the PR gene and gives rise to 
an increased synthesis of PR-B by generating an additional TATA box, thereby altering the PR-A-to-PR-B ratio (63). Given their functional consequences, it is conceivable that these genetic variants may influence the individual susceptibility for endometriosis.

\section{Epigenetics}

\section{Epigenetic regulatory mechanisms}

Classic genetics alone is not sufficient to explain the diversity of phenotypes within a population, nor does it explain how, despite the fact that their DNA sequences are identical, monozygotic twins (64) or cloned animals (65) can have different phenotypes and different susceptibilities to a disease. The concept of epigenetics may offer a logical explanation for these phenomena and could therefore be of importance in the pathogenesis of complex diseases such as endometriosis. Epigenetics refers to the study of heritable changes in gene expression capacity that occur without changes in the DNA sequence (66). Human cells have to manage the proper spatiotemporal expression of 23.000 genes in a broad range of cell types. Cells accomplish this feat by packaging DNA into chromatin, whose basic unit is the nucleosome, consisting of octamers of histone proteins with DNA wrapped around it. Epigenetic regulatory mechanisms modify this basic unit by the interplay of different protein complexes that interfere with chromatin configuration and subsequent accessibility of the chromatin for transcription factors, thus allowing the cell to modulate the transcriptional activity of given gene promoters. In this manner, a broad range of transcriptional activity is provided, varying from high-level expression to complete silencing. It is now widely accepted that epigenetic inheritance is an essential mechanism that allows a stable propagation of gene activity states over many cell generations. The two main epigenetic mechanisms that have emerged as critical layers of control participating in the regulation of transcription are 1) DNA methylation and 2) posttranscriptional modifications of histone proteins. In this thesis the role of DNA methylation in the pathogenesis of endometriosis has been interrogated, and will therefore be discussed in further detail below.

\section{DNA methylation}

The most studied epigenetic modification in humans is DNA methylation, which occurs at cytosines that precede a guanosine in the DNA sequence (termed CpG dinucleotides). Stretches of DNA that are rich in $\mathrm{CpG}$ dinucleotides are referred to as $\mathrm{CpG}$ islands, and are often located near the promoter region of approximately $70 \%$ genes of the human genome. In the bulk of the genome, most of the $\mathrm{CpG}$ dinucleotides that are not associated with CpG islands are predominantly methylated. This methylation in normal cells probably prevents chromosomal instability, translocations, and gene disruption caused by the 
reactivation of transposable DNA sequences (67-69). In contrast, the cytosines within CpG islands, especially those associated with promoter regions are normally unmethylated. This lack of methylation in promoter-associated CpG islands permits expression of the gene, if the appropriate transcription factors are present, and the chromatin structure allows access to them (70). A small but significant proportion of all $\mathrm{CpG}$ islands become methylated during development, and when this happens the associated promoter is stably silent. Developmentally programmed CpG-island methylation of this kind is involved in genomic imprinting (the phenomenon by which only one of the two inherited copies of a gene is expressed in a parent-of-origin dependent manner), in X-chromosome inactivation (a process by which one of the two copies of the X-chromosome present in females is randomly inactivated), and in the differentiation of pluripotent embryonic stem (ES) cells. Methylation of DNA is accompanied by post-translational modifications of histone residues that modulate DNA function, regulating chromatin structure and determining the transcriptional state of the DNA wrapped around it (71). Nowadays, it is widely recognized that DNA methylation is associated with condensed heterochromatin and silencing of gene expression. This has been extensively investigated in the context of cancer research, where certain tumor suppressor genes were shown to be inactivated by promoter hypermethylation.

The mammalian DNA methylation machinery is composed of two components. The patterns of DNA methylation are established and maintained by enzymes called DNA methyltransferases (DNMTs). The crosstalk between DNA methylation and histone modifications is established by a family of proteins that contain a methyl-CpG-binding domain commonly known as MBD proteins (MBDs). These proteins are able to recognize single methylated $\mathrm{CpG}$ dinucleotides and recruit chromatin remodeling factors. An overview of the different DNMTs and MBDs and the mechanism by which they regulate gene expression is presented in the next paragraphs.

\section{DNMTS}

The methylation of mammalian genomic DNA is catalyzed by enzymes called DNA methyltransferases (DNMTs). In mammals, three active DNA methyltransferases-called DNMT1, DNMT3A and DNMT3B-and one related protein lacking catalytic activity, called DNMT3L, are present. A fifth protein with structural homology to the mammalian methyltransferase family is DNMT2. However, it does not exhibit particular de novo or maintenance methyltransferase activity in ES cells or adult somatic tissue. Its function is not yet clear, but the structure of DNMT2 suggests that it may be involved in processes such as recognition of DNA damage, DNA recombination and mutation repair. DNMTs can be divided into maintenance and de novo methyltransferases. DNMT1 is the major enzyme responsible for maintaining existing DNA methylation patterns during replication. It is ubiquitously and highly expressed in proliferating cells, representing the major DNA MTase activity in somatic tissues throughout mammalian development and is present only 
at low levels in non-dividing cells (72). DNMT1 shows a preference for hemimethylated DNA over unmethylated DNA $(73,74)$, is located at the replication fork and methylates newly synthesized DNA strands directly after the replication round (75). Numerous gene targeting studies indicate a crucial role of DNMT1 in normal mammalian development, as well as in cell proliferation and survival. For example, depletion of DNMT1 has proven to be lethal, as mice deficient for DNMT1 die in mid-gestation, with significantly reduced levels of DNA methylation (76). These mice also exhibit bi-allelic expression of imprinted genes and ectopic $X$ chromosome activation (77), indicating the importance of methylation for these processes. In addition, DNMT1 loss of function is directly linked to tumorigenesis, as demonstrated by the finding that mice with depleted levels of DNMT1 are susceptible to tumors and display chromosomal instability $(78,79)$.

DNMT3A and DNMT3B are de novo methyltransferases that are involved in the postreplicative methylation of previously unmethylated DNA. DNMT3A and DNMT3B are expressed at high levels in embryonic stem cells (ESC) but in adult somatic tissues their activity is low. The expression of DNMT3A is ubiquitous, whereas DNMT3B is expressed at very low levels in most tissues except testis, thyroid, and bone marrow (80). DNMT3B expression is profoundly increased in various tumor cell lines, indicating that this enzyme may play an important part in tumorigenesis $(72,75)$. Similar to DNMT1, both DNMT3A and DNMT3B are indispensable for embryonic development in mice (81). Mouse DNMT3B knockout embryos die in utero and show multiple developmental defects, whereas the DNMT3A knockout animals develop to term, but become runts and die shortly after birth.

\section{MBDs and mechanism of gene silencing}

DNA methylation is linked with transcriptional silencing of associated genes, and much effort has been invested in studying the mechanisms that underlie this relationship. So far, two basic models have evolved. In the first, DNA methylation can directly repress transcription by blocking transcriptional coactivators from binding to cognate DNA sequences (82) (Figure 1, right side). In the second, gene expression is silenced by the interplay between 5-methyl-cytosines and methyl-CpG-binding domain proteins (MBDs) $(83,84)$. MBDs specifically recognize and bind to methylated $\mathrm{CpGs}$ and recruit histone deacetylase (HDAC), either directly or via a corepressor complex. The HDAC removes acetyl groups from the lysines on the $\mathrm{NH}_{2}$-terminal histone tails, resulting in chromatin condensation, inaccessibility of transcription factors, and transcriptional inactivation (Figure 1, left side). The process of gene silencing therefore requires the combined action of both DNMTs and MBDs.

To date, five proteins with homologous methylcytosine-binding domains have been cloned: MeCP2, MBD1, MBD2, MBD3, and MBD4. MBD proteins differ in their DNAbinding characteristics and the precise means by which they exert repressive effects, although a common theme is the recruitment of corepressors and histone deacetylase (HDAC), leading to the remodeling of chromatin. MeCP2, MBD1, and MBD2 have been 
shown to recruit HDAC and function as transcriptional repressors. MBD3 is a non-DNA binding component of the Mi-2/NuRD corepressor complex (85). MBD4 is not associated with transcriptional inactivation, but has uracil DNA glycosylase activity and has been implicated in DNA repair (86).

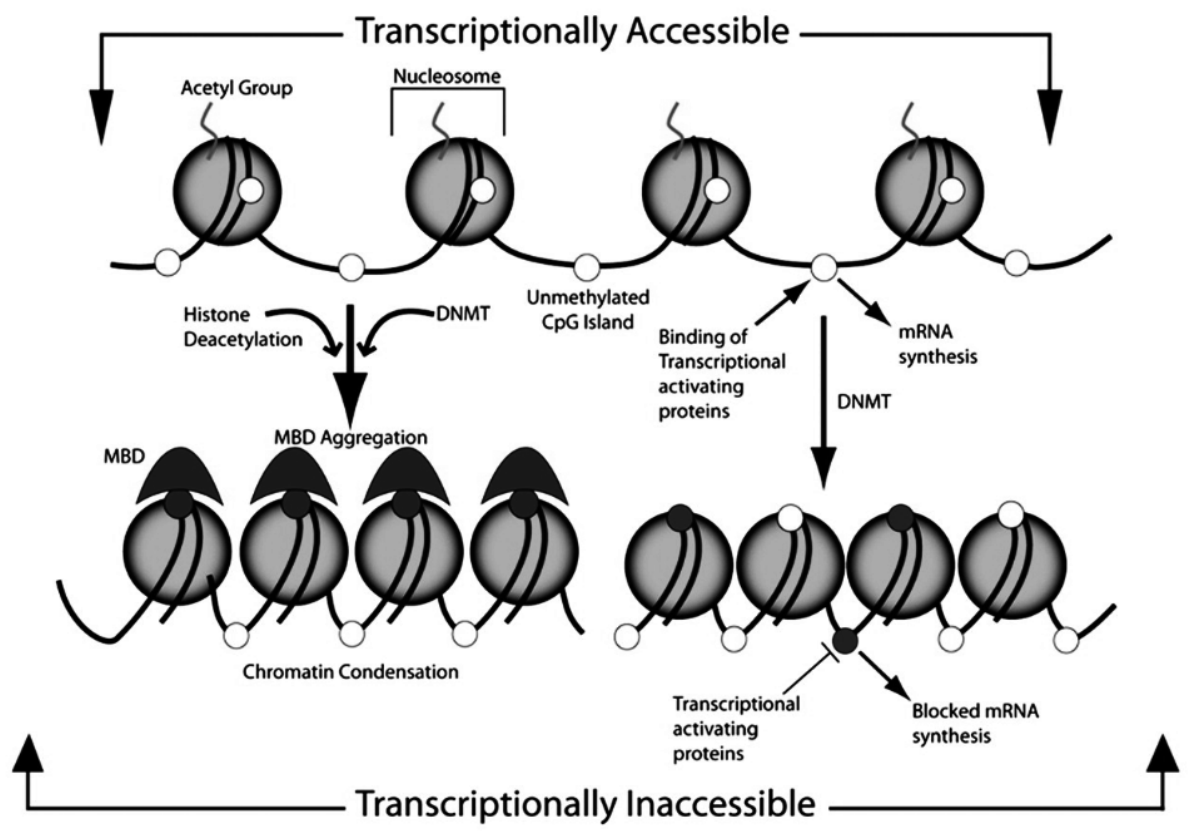

Figure 1 Schematic representation of the two different models of gene silencing by DNMTs and MBDs. Left: Unmethylated CpGs (open spheres) are converted to 5-methylcytosines (shaded spheres) by the action of DNMTs. These are recognized by MBDs which in turn attract histone deacetylases to the site. Histone tails are deacetylated and the chromatin becomes condensed and inaccessible for transcription. Right: DNMTs directly block transcriptional coactivators from binding to cognate DNA sequences.

\section{Endometriosis and epigenetics: the missing link?}

In the last decades, numerous gene expression profiling studies have demonstrated that many genes that may promote the initiation and progression of endometriosis are consistently deregulated in tissues from endometriosis patients, such as 17hydroxysteroid dehydrogenase type 2 (30), interleukin (IL)-1 receptor type I (87), HOXA10 (88), IL-6 (89) and aromatase (90). The fact that these aberrant expressions are seemingly quite stable in endometriosis indicates that cellular memory of some sort must be 
involved. Although aberrant DNA methylation has been primarily studied in the context of cancer $(70,91)$, epigenetic changes have also been implicated in several complex traits such as diabetes mellitus, obesity, cardiovascular diseases and neurological disorders (9294). Recent reports indicate a role for various epigenetic aberrations in the pathogenesis of endometriosis. The expression of certain genes that are presumably involved in the pathogenesis of endometriosis such as estrogen receptor-2 (95), steroidogenic factor-1 (96), aromatase (97) and E-cadherin (98) were shown to be regulated by promoter hyperor hypomethylation in ectopic lesions of women with endometriosis. Furthermore, the expression of HOXA10, a gene critical for endometrial decidualization and uterine receptivity during the window of implantation, is significantly reduced in eutopic endometrium of endometriosis patients. In 2005, Wu and coworkers demonstrated that the promoter region of HOXA10 is hypermethylated in eutopic endometrium of endometriosis patients compared to eutopic endometrium of controls (99). As promoter hypermethylation is generally associated with gene silencing, this provides a plausible explanation for the observation that the expression of HOXA10 is reduced in this tissue $(88,100)$. The simultaneous occurrence of promoter hypermethylation and reduced HOXA10 expression has also been demonstrated in experimental animal models of endometriosis $(101,102)$, suggesting that HOXA10 promoter methylation may indeed constitute the mechanism through which HOXA10 is downregulated in endometriosis. The same is true for progesterone receptor $B$, which has been demonstrated to be undetectable in ectopic endometriotic tissues, in contrast to PR-A $(42,103)$. Recently, it was reported that the promoter region of PR-B, but not PR-A is hypermethylated in association with reduced expression of PR-B in epithelial cells of ectopic endometriotic lesions, suggesting that downregulation of PR-B in endometriosis is caused by promoter hypermethylation (43). Finally, overexpression of DNA methyltransferases has been implicated in the establishment of aberrant methylation patterns (104), and expression levels of DNMT1, DNMT3A and DNMT3B have been shown to be higher in ectopic endometrium compared to eutopic endometrium of both endometriosis patients and controls (105), providing support for the notion that endometriosis is, in part, an epigenetic disease. 


\section{Aims and outline of the thesis}

Despite many years of hypothesis-driven research, the pathogenesis of endometriosis remains largely elusive. In addition to its description of being a hormonal disease, it is thought that environmental, genetic and epigenetic factors contribute to the initiation and progression of endometriosis. The general aim of this thesis is to gain more insight in the contribution of each of these factors to the pathogenesis of this enigmatic disease.

The first part of the thesis addresses the origin of smooth muscle like cells in deep infiltrating endometriosis and the underlying mechanism responsible for their presence. Deep infiltrating endometriosis is considered by some to be a distinct disease entity because of its distinct histological appearance resembling adenomyosis. Lesions are nodular in appearance and are largely composed of fibromuscular tissue containing smooth muscle-like cells and fibrosis, the origin of which may be the endometrium itself, or, alternatively, the local environment. In Chapter 2, the fibromuscular component of deep infiltrating endometriotic lesions will be characterized using immunohistochemical markers of smooth muscle differentiation. Furthermore, we will investigate the origin of the smooth muscle-like cells in endometriosis lesions in a nude mouse model. Finally, a possible causative role for TGF- $\beta 1$ in this process will be assessed by using immunohistochemical markers of active TGF- $\beta$ signaling.

The second part of this thesis addresses the question whether genetic aberrations such as single nucleotide polymorphisms (SNPs), with functional consequences at the gene or protein level, in two selected candidate genes influence the susceptibility for developing endometriosis. Given the fact that TGF $\beta-1$ has a prominent role in fibrogenesis and deep infiltrating endometriosis lesions largely consist of fibromuscular tissue, we will investigate the possible association between the presence of the $-509 \mathrm{C} / \mathrm{T}$ polymorphism of the TGF $\beta$ 1 gene and the risk of developing deep infiltrating endometriosis in Chapter 3. Because of the observed biochemical and clinical progesterone resistance in endometriosis, the prevalence of two polymorphisms of the progesterone receptor gene, PROGINS and $+331 \mathrm{G} / \mathrm{A}$, will be investigated in women with deep infiltrating endometriosis and adenomyosis of the uterine wall in Chapter 4. In addition to this, expression levels of PR-A and PR-B in endometriotic lesions will be correlated to the presence of either polymorphism by immunohistochemistry.

The third part of the thesis addresses the question whether epigenetic regulatory mechanisms such as DNA methylation are involved in the regulation of endometrial growth and differentiation and in differential expression of genes in endometriosis patients. In Chapter 5, we will assess expression levels of both components of the DNA methylation machinery, DNA methyltransferases (DNMTs) and methyl-CpG-binding domain proteins (MBDs), in [1] normal endometrium throughout the menstrual cycle and [2] eutopic and ectopic endometrium of women with endometriosis. Furthermore, hormone responsiveness of DNMT and MBD expression will be investigated in endometrial explant cultures. In Chapter 6, we will test the hypothesis that severe up- or 
downregulation of several genes in eutopic endometrium of endometriosis patients in a previously conducted microarray study is the result of promoter methylation.

Finally, in Chapter 7, we will discuss the implications of these findings and possible directions for future research will be given. 


\section{References}

1. Missmer SA, Hankinson SE, Spiegelman D, Barbieri RL, Malspeis S, Willett WC, Hunter DJ. Reproductive history and endometriosis among premenopausal women. Obstet Gynecol 2004;104:965-74.

2. Eskenazi B, Warner ML. Epidemiology of endometriosis. Obstet Gynecol Clin North Am 1997;24: 235-58.

3. Nnoaham KE, Hummelshoj L, Webster P, d'Hooghe T, de Cicco Nardone F, de Cicco Nardone C, Jenkinson C, Kennedy SH, Zondervan KT; World Endometriosis Research Foundation Global Study of Women's Health consortium. Impact of endometriosis on quality of life and work productivity: a multicenter study across ten countries. Fertil Steril 2011;96:366-73 e8.

4. Olive DL, Schwartz LB. Endometriosis. N Engl J Med 1993;328:1759-69.

5. Levander G, Normann P. The pathogenesis of endometriosis; an experimental study. Acta Obstetricia et Gynecologica Scandinavica 1955;34:366-98.

6. Sampson JA. Metastatic or Embolic Endometriosis, due to the Menstrual Dissemination of Endometrial Tissue into the Venous Circulation. Am J Pathol 1927;3:93-110 43.

7. Jenkins S, Olive DL, Haney AF. Endometriosis: pathogenetic implications of the anatomic distribution. Obstet Gynecol 1986;67:335-8.

8. Kruitwagen RF, Poels LG, Willemsen WN, de Ronde IJ, Jap PH, Rolland R. Endometrial epithelial cells in peritoneal fluid during the early follicular phase. Fertil Steril 1991;55:297-303.

9. Koks CA, Dunselman GA, de Goeij AF, Arends JW, Evers JL. Evaluation of a menstrual cup to collect shed endometrium for in vitro studies. Fertil Steril 1997;68:560-4.

10. van der Linden PJ. Theories on the pathogenesis of endometriosis. Hum Reprod 1996;11 Suppl 3: 53-65.

11. Spuijbroek MD, Dunselman GA, Menheere PP, Evers JL. Early endometriosis invades the extracellular matrix. Fertil Steril 1992;58:929-33.

12. Maas JW, Groothuis PG, Dunselman GA, de Goeij AF, Struijker-Boudier HA, Evers JL. Development of endometriosis-like lesions after transplantation of human endometrial fragments onto the chick embryo chorioallantoic membrane. Hum Reprod 2001;16:627-31.

13. Groothuis PG, Nap AW, Winterhager E, Grummer R. Vascular development in endometriosis. Angiogenesis 2005;8:147-56.

14. Halme J, Hammond MG, Hulka JF, Raj SG, Talbert LM. Retrograde menstruation in healthy women and in patients with endometriosis. Obstet Gynecol 1984;64:151-4.

15. Liu DT, Hitchcock A. Endometriosis: its association with retrograde menstruation, dysmenorrhoea and tubal pathology. Br J Obstet Gynaecol 1986;93:859-62.

16. Koninckx PR, Oosterlynck D, D'Hooghe T, Meuleman C. Deeply infiltrating endometriosis is a disease whereas mild endometriosis could be considered a non-disease. Ann N Y Acad Sci 1994;734:333-41.

17. Cornillie FJ, Oosterlynck D, Lauweryns JM, Koninckx PR. Deeply infiltrating pelvic endometriosis: histology and clinical significance. Fertil Steril 1990;53:978-83.

18. Koninckx PR, Meuleman C, Demeyere S, Lesaffre E, Cornillie FJ. Suggestive evidence that pelvic endometriosis is a progressive disease, whereas deeply infiltrating endometriosis is associated with pelvic pain. Fertil Steril 1991;55:759-65.

19. Fauconnier A, Chapron C, Dubuisson JB, Vieira M, Dousset B, Breart G. Relation between pain symptoms and the anatomic location of deep infiltrating endometriosis. Fertil Steril 2002;78:719-26.

20. Itoga T, Matsumoto T, Takeuchi H, Yamasaki S, Sasahara N, Hoshi T, Kinoshita K. Fibrosis and smooth muscle metaplasia in rectovaginal endometriosis. Pathol Int 2003;53:371-5.

21. Nisolle M, Donnez J. Peritoneal endometriosis, ovarian endometriosis, and adenomyotic nodules of the rectovaginal septum are three different entities. Fertil Steril 1997;68:585-96.

22. Vercellini P, Aimi G, Panazza S, Vicentini S, Pisacreta A, Crosignani PG. Deep endometriosis conundrum: evidence in favor of a peritoneal origin. Fertil Steril 2000;73:1043-6.

23. Anaf V, Simon P, Fayt I, Noel J. Smooth muscles are frequent components of endometriotic lesions. Hum Reprod 2000;15:767-71.

24. LeRoy EC, Trojanowska MI, Smith EA. Cytokines and human fibrosis. Eur Cytokine Netw 1990;1:215-9.

25. Gaide Chevronnay HP, Cornet PB, Delvaux D, Lemoine P, Courtoy PJ, Henriet P, Marbaix E. Opposite regulation of transforming growth factors-beta2 and -beta3 expression in the human endometrium. Endocrinology 2008;149:1015-25. 
26. Omwandho CO, Konrad L, Halis G, Oehmke F, Tinneberg HR. Role of TGF-betas in normal human endometrium and endometriosis. Hum Reprod;25:101-9.

27. Pizzo A, Salmeri FM, Ardita FV, Sofo V, Tripepi M, Marsico S. Behaviour of cytokine levels in serum and peritoneal fluid of women with endometriosis. Gynecol Obstet Invest 2002;54:82-7.

28. Kyama CM, Overbergh L, Debrock S, Valckx D, Vander Perre S, Meuleman C, Mihalyi A, Mwenda JM, Mathieu C, D'Hooghe TM. Increased peritoneal and endometrial gene expression of biologically relevant cytokines and growth factors during the menstrual phase in women with endometriosis. Fertil Steril 2006;85:1667-75.

29. Wu L, Einstein M, Geissler WM, Chan HK, Elliston KO, Andersson S. Expression cloning and characterization of human 17 beta-hydroxysteroid dehydrogenase type 2, a microsomal enzyme possessing 20 alphahydroxysteroid dehydrogenase activity. J Biol Chem 1993;268:12964-9.

30. Zeitoun K, Takayama K, Sasano H, Suzuki T, Moghrabi N, Andersson S, Johns A, Meng L, Putman M, Carr B, Bulun SE. Deficient 17beta-hydroxysteroid dehydrogenase type 2 expression in endometriosis: failure to metabolize 17beta-estradiol. J Clin Endocrinol Metab 1998;83:4474-80.

31. Kao LC, Germeyer A, Tulac S, Lobo S, Yang JP, Taylor RN, Osteen K, Lessey BA, Giudice LC. Expression profiling of endometrium from women with endometriosis reveals candidate genes for disease-based implantation failure and infertility. Endocrinology 2003;144:2870-81.

32. Vercellini P, Cortesi I, Crosignani PG. Progestins for symptomatic endometriosis: a critical analysis of the evidence. Fertil Steril 1997;68:393-401.

33. Surrey ES. The role of progestins in treating the pain of endometriosis. J Minim Invasive Gynecol 2006;13:528-34.

34. Kastner P, Krust A, Turcotte B, Stropp U, Tora L, Gronemeyer H, Chambon P. Two distinct estrogenregulated promoters generate transcripts encoding the two functionally different human progesterone receptor forms A and B. Embo J 1990;9:1603-14.

35. Horwitz KB, Alexander PS. In situ photolinked nuclear progesterone receptors of human breast cancer cells: subunit molecular weights after transformation and translocation. Endocrinology 1983;113:2195-201.

36. Li X, O'Malley BW. Unfolding the action of progesterone receptors. J Biol Chem 2003;278:39261-4.

37. Tung L, Mohamed MK, Hoeffler JP, Takimoto GS, Horwitz KB. Antagonist-occupied human progesterone Breceptors activate transcription without binding to progesterone response elements and are dominantly inhibited by A-receptors. Mol Endocrinol 1993;7:1256-65.

38. Vegeto E, Shahbaz MM, Wen DX, Goldman ME, O'Malley BW, McDonnell DP. Human progesterone receptor A form is a cell- and promoter-specific repressor of human progesterone receptor $B$ function. Mol Endocrinol 1993; 7:1244-55.

39. Mote PA, Bartow S, Tran N, Clarke CL. Loss of co-ordinate expression of progesterone receptors A and B is an early event in breast carcinogenesis. Breast Cancer Res Treat 2002;72:163-72.

40. De Vivo I, Hankinson SE, Colditz GA, Hunter DJ. A functional polymorphism in the progesterone receptor gene is associated with an increase in breast cancer risk. Cancer Res 2003;63:5236-8.

41. Ito K, Utsunomiya $\mathrm{H}$, Yaegashi N, Sasano $\mathrm{H}$. Biological roles of estrogen and progesterone in human endometrial carcinoma--new developments in potential endocrine therapy for endometrial cancer. Endocr J 2007;54:667-79.

42. Attia GR, Zeitoun K, Edwards D, Johns A, Carr BR, Bulun SE. Progesterone receptor isoform A but not B is expressed in endometriosis. J Clin Endocrinol Metab 2000;85: 2897-902.

43. Wu Y, Strawn E, Basir Z, Halverson G, Guo SW. Promoter hypermethylation of progesterone receptor isoform B (PR-B) in endometriosis. Epigenetics 2006;1:106-11.

44. Igarashi TM, Bruner-Tran KL, Yeaman GR, Lessey BA, Edwards DP, Eisenberg E, Osteen KG. Reduced expression of progesterone receptor- $B$ in the endometrium of women with endometriosis and in cocultures of endometrial cells exposed to 2,3,7,8-tetrachlorodibenzo-p-dioxin. Fertil Steril 2005;84:67-74.

45. Malinak LR, Buttram VC, Jr., Elias S, Simpson JL. Heritage aspects of endometriosis. II. Clinical characteristics of familial endometriosis. Am J Obstet Gynecol 1980;137:332-7.

46. Lamb K, Hoffmann RG, Nichols TR. Family trait analysis: a case-control study of 43 women with endometriosis and their best friends. Am J Obstet Gynecol 1986;154:596-601.

47. Moen MH, Magnus P. The familial risk of endometriosis. Acta Obstet Gynecol Scand 1993;72:560-4.

48. Kennedy S. The genetics of endometriosis. J Reprod Med 1998;43:263-8. 
49. Zondervan KT, Cardon LR, Kennedy SH. The genetic basis of endometriosis. Curr Opin Obstet Gynecol 2001;13:309-14.

50. Simpson JL, Bischoff FZ. Heritability and molecular genetic studies of endometriosis. Ann N Y Acad Sci 2002;955:239-51; discussion 93-5, 396-406.

51. Stefansson H, Geirsson RT, Steinthorsdottir V, Jonsson H, Manolescu A, Kong A, Ingadottir G, Gulcher J, Stefansson K. Genetic factors contribute to the risk of developing endometriosis. Hum Reprod 2002;17:555-9.

52. Treloar S, Hadfield R, Montgomery G, Lambert A, Wicks J, Barlow DH, O'Connor DT, Kennedy S; International Endogene Study Group. The International Endogene Study: a collection of families for genetic research in endometriosis. Fertil Steril 2002;78:679-85.

53. Zondervan KT, Weeks DE, Colman R, Cardon LR, Hadfield R, Schleffler J, Trainor AG, Coe CL, Kemnitz JW, Kennedy $\mathrm{SH}$. Familial aggregation of endometriosis in a large pedigree of rhesus macaques. Hum Reprod 2004;19:448-55.

54. Kennedy S, Mardon H, Barlow D. Familial endometriosis. J Assist Reprod Genet 1995;12:32-4.

55. Kennedy S, Hadfield R, Barlow D, Weeks DE, Laird E, Golding S. Use of MRI in genetic studies of endometriosis. Am J Med Genet 1997;71:371-2.

56. Moen MH. Endometriosis in monozygotic twins. Acta Obstet Gynecol Scand 1994;73:59-62.

57. Hadfield RM, Mardon HJ, Barlow DH, Kennedy SH. Endometriosis in monozygotic twins. Fertil Steril 1997;68:941-2.

58. Treloar SA, O'Connor DT, O'Connor VM, Martin NG. Genetic influences on endometriosis in an Australian twin sample.sueT@qimr.edu.au. Fertil Steril 1999;71:701-10.

59. Kennedy S, Hadfield R, Mardon H, Barlow D. Age of onset of pain symptoms in non-twin sisters concordant for endometriosis. Hum Reprod 1996;11:403-5.

60. Grainger DJ, Percival J, Chiano M, Spector TD. The role of serum TGF-beta isoforms as potential markers of osteoporosis. Osteoporos Int 1999;9:398-404.

61. Lydon JP, DeMayo FJ, Funk CR, Mani SK, Hughes AR, Montgomery CA, Jr. Shyamala G, Conneely OM, O'Malley BW.. Mice lacking progesterone receptor exhibit pleiotropic reproductive abnormalities. Genes Dev 1995;9:2266-78.

62. Romano A, Delvoux B, Fischer DC, Groothuis P. The PROGINS polymorphism of the human progesterone receptor diminishes the response to progesterone. J Mol Endocrinol 2007;38:331-50.

63. De Vivo I, Huggins GS, Hankinson SE, Lescault PJ, Boezen M, Colditz GA, Hunter DJ. A functional polymorphism in the promoter of the progesterone receptor gene associated with endometrial cancer risk. Proc Natl Acad Sci USA 2002;99:12263-8.

64. Fraga MF, Ballestar E, Paz MF, Ropero S, Setien F, Ballestar ML, Heine-Suñer D, Cigudosa JC, Urioste M, Benitez J, Boix-Chornet M, Sanchez-Aguilera A, Ling C, Carlsson E, Poulsen P, Vaag A, Stephan Z, Spector TD, Wu YZ, Plass C, Esteller M. Epigenetic differences arise during the lifetime of monozygotic twins. Proc Natl Acad Sci USA 2005;102:10604-9.

65. Humpherys D, Eggan K, Akutsu H, Hochedlinger K, Rideout WM, 3rd, Biniszkiewicz D, Yanagimachi R, Jaenisch R. Epigenetic instability in ES cells and cloned mice. Science 2001;293:95-7.

66. Bird A. DNA methylation patterns and epigenetic memory. Genes \& development 2002;16:6-21.

67. Esteller M, Herman JG. Cancer as an epigenetic disease: DNA methylation and chromatin alterations in human tumours. J Pathol 2002;196:1-7.

68. Herman JG, Baylin SB. Gene silencing in cancer in association with promoter hypermethylation. $N$ Engl J Med 2003;349:2042-54.

69. Bestor TH. Transposons reanimated in mice. Cell 2005;122:322-5.

70. Jones PA, Baylin SB. The fundamental role of epigenetic events in cancer. Nat Rev Genet 2002;3: 415-28.

71. Esteller M, Almouzni G. How epigenetics integrates nuclear functions. Workshop on epigenetics and chromatin: transcriptional regulation and beyond. EMBO Rep 2005;6:624-8.

72. Robertson KD, Uzvolgyi E, Liang G, Talmadge C, Sumegi J, Gonzales FA, Jones PA. The human DNA methyltransferases (DNMTs) 1, 3a and 3b: coordinate mRNA expression in normal tissues and overexpression in tumors. Nucleic Acids Res 1999;27:2291-8. 
73. Fatemi M, Hermann A, Pradhan S, Jeltsch A. The activity of the murine DNA methyltransferase Dnmt1 is controlled by interaction of the catalytic domain with the N-terminal part of the enzyme leading to an allosteric activation of the enzyme after binding to methylated DNA. J Mol Biol 2001;309:1189-99.

74. Goyal R, Reinhardt R, Jeltsch A. Accuracy of DNA methylation pattern preservation by the Dnmt1 methyltransferase. Nucleic Acids Res 2006;34:1182-8.

75. Hermann A, Goyal R, Jeltsch A. The Dnmt1 DNA-(cytosine-C5)-methyltransferase methylates DNA processively with high preference for hemimethylated target sites. J Biol Chem 2004;279:48350-9.

76. Li E, Bestor TH, Jaenisch R. Targeted mutation of the DNA methyltransferase gene results in embryonic lethality. Cell 1992;69:915-26.

77. Li E, Beard C, Jaenisch R. Role for DNA methylation in genomic imprinting. Nature 1993;366:362-5.

78. Eden A, Gaudet F, Waghmare A, Jaenisch R. Chromosomal instability and tumors promoted by DNA hypomethylation. Science 2003;300:455.

79. Gaudet F, Hodgson JG, Eden A, Jackson-Grusby L, Dausman J, Gray JW, Leonhardt H, Jaenisch R. Induction of tumors in mice by genomic hypomethylation. Science 2003;300:489-92.

80. Xie S, Wang Z, Okano M, Nogami M, Li Y, He WW, Okumura K, Li E. Cloning, expression and chromosome locations of the human DNMT3 gene family. Gene 1999;236:87-95.

81. Okano M, Bell DW, Haber DA, Li E. DNA methyltransferases Dnmt3a and Dnmt3b are essential for de novo methylation and mammalian development. Cell 1999;99:247-57.

82. Watt F, Molloy PL. Cytosine methylation prevents binding to DNA of a HeLa cell transcription factor required for optimal expression of the adenovirus major late promoter. Genes Dev 1988;2:1136-43.

83. Nan X, Campoy FJ, Bird A. MeCP2 is a transcriptional repressor with abundant binding sites in genomic chromatin. Cell 1997;88:471-81.

84. Nan X, Ng HH, Johnson CA, Laherty CD, Turner BM, Eisenman RN. Bird A. Transcriptional repression by the methyl-CpG-binding protein MeCP2 involves a histone deacetylase complex. Nature 1998;393: 386-9.

85. Saito M, Ishikawa F. The mCpG-binding domain of human MBD3 does not bind to mCpG but interacts with NuRD/Mi2 components HDAC1 and MTA2. J Biol Chem 2002;277: 35434-9.

86. Hendrich $\mathrm{B}$, Hardeland $\mathrm{U}, \mathrm{Ng} \mathrm{HH}$, Jiricny J, Bird A. The thymine glycosylase MBD4 can bind to the product of deamination at methylated CpG sites. Nature 1999;401:301-4.

87. Nishida M, Nasu K, Fukuda J, Kawano Y, Narahara H, Miyakawa I. Down-regulation of interleukin-1 receptor type 1 expression causes the dysregulated expression of CXC chemokines in endometriotic stromal cells: a possible mechanism for the altered immunological functions in endometriosis. J Clin Endocrinol Metab 2004;89:5094-100.

88. Taylor HS, Bagot C, Kardana A, Olive D, Arici A. HOX gene expression is altered in the endometrium of women with endometriosis. Hum Reprod 1999;14:1328-31.

89. Tseng JF, Ryan IP, Milam TD, Murai JT, Schriock ED, Landers DV, Taylor RN. Interleukin-6 secretion in vitro is up-regulated in ectopic and eutopic endometrial stromal cells from women with endometriosis. J Clin Endocrinol Metab 1996;81:1118-22.

90. Noble LS, Simpson ER, Johns A, Bulun SE. Aromatase expression in endometriosis. J Clin Endocrinol Metab 1996;81:174-9.

91. Esteller M. Aberrant DNA methylation as a cancer-inducing mechanism. Annu Rev Pharmacol Toxicol 2005;45:629-56.

92. Egger G, Liang G, Aparicio A, Jones PA. Epigenetics in human disease and prospects for epigenetic therapy. Nature 2004;429:457-63.

93. Jiang $\mathrm{YH}$, Bressler J, Beaudet AL. Epigenetics and human disease. Annu Rev Genomics Hum Genet 2004;5:479-510.

94. Urdinguio RG, Sanchez-Mut JV, Esteller M. Epigenetic mechanisms in neurological diseases: genes, syndromes, and therapies. Lancet Neurol 2009;8:1056-72.

95. Xue Q, Lin Z, Cheng YH, Huang CC, Marsh E, Yin P, Milad MP, Confino E, Reierstad S, Innes J, Bulun SE. Promoter methylation regulates estrogen receptor 2 in human endometrium and endometriosis. Biol Reprod 2007;77:681-7.

96. Xue Q, Lin Z, Yin P, Milad MP, Cheng YH, Confino E, Reierstad S, Bulun SE. Transcriptional activation of steroidogenic factor- 1 by hypomethylation of the $5^{\prime}$ CpG island in endometriosis. J Clin Endocrinol Metab 2007;92:3261-7. 
97. Izawa M, Harada T, Taniguchi F, Ohama Y, Takenaka Y, Terakawa N. An epigenetic disorder may cause aberrant expression of aromatase gene in endometriotic stromal cells. Fertil Steril 2008;89:1390-6.

98. Wu Y, Starzinski-Powitz A, Guo SW. Trichostatin A, a histone deacetylase inhibitor, attenuates invasiveness and reactivates E-cadherin expression in immortalized endometriotic cells. Reprod Sci 2007;14:374-82.

99. Wu Y, Halverson G, Basir Z, Strawn E, Yan P, Guo SW. Aberrant methylation at HOXA10 may be responsible for its aberrant expression in the endometrium of patients with endometriosis. Am J Obstet Gynecol 2005;193:371-80.

100. Gui Y, Zhang J, Yuan L, Lessey BA. Regulation of HOXA-10 and its expression in normal and abnormal endometrium. Mol Hum Reprod 1999;5:866-73.

101. Kim JJ, Taylor HS, Lu Z, Ladhani O, Hastings JM, Jackson KS, Wu Y, Guo SW, Fazleabas AT. Altered expression of HOXA10 in endometriosis: potential role in decidualization. Mol Hum Reprod 2007;13: 32332.

102. Lee B, Du H, Taylor HS. Experimental murine endometriosis induces DNA methylation and altered gene expression in eutopic endometrium. Biol Reprod 2009;80:79-85.

103. Bulun SE, Cheng YH, Yin P, Imir G, Utsunomiya H, Attar E, Innes J, Julie Kim J. Progesterone resistance in endometriosis: link to failure to metabolize estradiol. Mol Cell Endocrinol 2006;248:94-103.

104. Robertson KD. DNA methylation, methyltransferases, and cancer. Oncogene 2001;20:3139-55.

105. Wu Y, Strawn E, Basir Z, Halverson G, Guo SW. Aberrant expression of deoxyribonucleic acid methyltransferases DNMT1, DNMT3A, and DNMT3B in women with endometriosis. Fertil Steril 2007;87:2432. 


\section{Chapter 2}

Fibromuscular differentiation in deeply infiltrating endometriosis is a reaction of resident fibroblasts to the presence of ectopic endometrium

KJAF van Kaam, JP Schouten, AW Nap, GAJ Dunselman, PG Groothuis Human Reproduction 2008;23:2692-2700 


\section{Abstract}

\section{Background}

In this study, we characterized the fibromuscular (FM) tissue, typical of deeply infiltrating endometriosis, investigated which cells are responsible for the FM reaction, and evaluated whether transforming growth factor- $\beta$ (TGF- $\beta$ ) signaling is involved in this process.

\section{Methods}

FM differentiation and TGF- $\beta$ signaling were assessed in deeply infiltrating endometriosis lesions $(n=20)$ and a nude mouse model of endometriosis 1, 2, 3 and 4 weeks posttransplantation. The FM reaction was evaluated by immunohistochemistry using different markers of FM and smooth muscle cell differentiation (vimentin, desmin, alpha-smooth muscle actin, smooth muscle myosin heavy chain). TGF- $\beta$ signaling was assessed by immunostaining for its receptors and phosphorylated Smad.

\section{Results}

Deeply infiltrating endometriosis lesions contain myofibroblast-like cells that express multiple markers of FM differentiation. Expression of TGF- $\beta$ receptors and phospho-Smad was more pronounced in the endometrial component of the lesions than in the FM component. In the nude mouse model, alpha-smooth muscle actin expression was observed in murine fibroblasts surrounding the lesion, but not in human endometrial stroma.

\section{Conclusions}

FM differentiation in deeply infiltrating endometriosis is the result of a reaction of the local environment to the presence of ectopic endometrium. It shares characteristics with pathological wound healing, but cannot be explained by TGF- $\beta$ signaling alone. 


\section{Introduction}

Endometriosis is a common benign gynecological condition characterized by the presence of endometrial glands and stroma at ectopic locations outside the uterine cavity. Deeply infiltrating endometriosis is defined as the presence of endometriosis $>5 \mathrm{~mm}$ under the peritoneal surface and is often associated with symptoms such as dysmenorrhea, dyspareunia and pelvic pain (1). Deeply infiltrating lesions are nodular in appearance and are histologically characterized by dense tissue composed of smooth muscles and fibrosis with islands or strands of glands and stroma. In contrast to other lesion types, the major component of these nodular lesions is fibromuscular (FM) tissue rather than endometrial tissue (2). For this reason this type of lesion is often referred to as adenomyosis, and is considered by some to be a specific disease entity, distinct from peritoneal or ovarian endometriosis (3). However, it cannot be excluded that these lesions have developed from superficial peritoneal implants in the pouch of Douglas (4).

Smooth muscles are frequent components of peritoneal, ovarian, uterosacral and rectovaginal lesions but are absent in their respective unaffected sites and in eutopic endometrium of women with and without endometriosis (5). Nerve fibers trapped in these FM lesions are a significant contributor to the induction of pain symptoms in patients (6).

There is no unequivocal explanation for the presence of smooth muscle -like cells in endometriosis, and in particular deeply infiltrating endometriosis lesions. Several explanations can account for this phenomenon. First, the FM cells may result from smooth muscle metaplasia of endometrial stromal fibroblasts. It has been shown that endometrial stromal cells decidualized by progesterone in vitro express alpha-smooth muscle actin, a contractile microfilament that is expressed solely by smooth muscle cells, myofibroblasts and related cells (7). Smooth muscle metaplasia of endometrial stromal cells has also been described in ovarian endometriosis (8). Second, smooth muscle-like cells in deeply infiltrating endometriosis lesions originate from transdifferentiation of local tissue fibroblasts into a more contractile phenotype bearing features of smooth muscle, a phenomenon that has been extensively described within the context of tissue injury and wound healing (9). Third, the cells may have developed from remnants of the Müllerian duct system. The latter explanation is less likely, however, as smooth muscle differentiation was not restricted to deep infiltrating lesions but was observed in all lesion types (5).

All hypotheses involve differentiation of fibroblasts to myofibroblasts and, possibly, differentiated smooth muscle cells. Myofibroblasts are a unique group of smooth musclelike fibroblasts that have acquired the capacity to neoexpress alpha-smooth muscle actin, the actin isoform typical of vascular smooth muscle cells, and to synthesize important amounts of collagen and other extracellular matrix components $(10,11)$. The fibroblast/myofibroblast transition is accepted as the key event in the formation of granulation tissue during wound healing and fibrotic changes It has been shown that the 
cytokine transforming growth factor- $\beta 1$ (TGF- $\beta 1$ ) is responsible for inducing the synthesis of alpha-smooth muscle actin in fibroblastic cells and for stimulating the production of collagen type I (12). In this respect, TGF- $\beta 1$ is the key cytokine in the evolution of lesions characterized by myofibroblast formation. This is further supported by the clinical observation that overproduction of TGF- $\beta 1$ has been implicated in the pathogenesis of several fibrocontractive diseases at various sites throughout the body, such as pulmonary fibrosis, glomerulonephritis, cirrhosis of the liver, skin scarring and peritoneal adhesion formation (13-17).

From animal studies it has become clear that transient overexpression of active TGF- $\beta$ in the lung induces a chronic fibrotic response (18). Conversely, blocking TGF- $\beta$ inhibits experimentally induced fibrosis in the lung, skin and liver (19-21). Given the fact that smooth muscle metaplasia and more or less extensive fibrosis can be observed in and around deeply infiltrating endometriosis lesions, we hypothesize that active TGF- $\beta 1$ signaling may be a key feature in the development of this type of endometriosis.

In this study we aim (i) to characterize the fibromuscular component of deeply infiltrating endometriotic lesions using immunohistochemical markers of smooth muscle differentiation, (ii) to investigate the origin of smooth muscle-like cells in endometriosis lesions in a nude mouse model and (iii) to assess a possible causative role for TGF- $\beta 1$ in this process by using immunohistochemical markers of active TGF- $\beta$ signaling.

\section{Materials and Methods}

\section{Patients and tissue specimens}

Twenty patients with a surgical and histological diagnosis of deep infiltrating endometriosis who were operated between 1998 and 2004 in the University Hospital of Maastricht were included in the study. Deeply infiltrating endometriosis was defined as the presence of one or more deeply infiltrating lesions in the rectovaginal septum, bowel wall, vaginal wall and/or bladder wall. After evaluation of histology by a gynecopathologist, serial sections $(5 \mu \mathrm{m})$ were cut from paraffin embedded deeply infiltrating endometriosis lesions.

Normal endometrium for the nude mouse experiment was collected during laparoscopy in two women who had normal ovulatory cycles. Tissue was collected by transvaginal biopsy using a sampling device (Gynotec, Malden, The Netherlands) on cycle day 7 and 9 of the menstrual cycle. No gynecological pathology was found in the endometrium biopsies. The use of human endometrium was approved by the institutional ethical review committee of University Hospital Maastricht. All women gave written informed consent. 


\section{Nude mouse model}

Eight female mice (Swiss v/v, Charles River, Maastricht, The Netherlands) were individually housed in autoclaved cages and bedding, in laminar flow filtered hoods. The animal room was maintained at $26 \mathrm{C}$ with a 12-h light, 12-h dark cycle, and mice were fed ad libitum with autoclaved laboratory rodent chow and acidified water. All handling was performed in laminar flow filtered hoods. A mixture of ketamine / xylazine $(100 \mathrm{mg} / \mathrm{kg}$ ketamine and $10 \mathrm{mg} / \mathrm{kg}$ xylazine; Eurovet, Bladel, the Netherlands), subcutaneously (s.c.) injected in a volume of $0.1 \mathrm{ml} / 10 \mathrm{~g}$ bodyweight, was used to anesthetize mice before invasive procedures, using sterile instruments. The Maastricht University ethical review committee for animal experiments approved the use of mice for this study.

At the age of 5 weeks, sterile 60-d release capsules containing $18 \mathrm{mg} 17 \beta$-estradiol (Innovative Research of America, Sarasota, FL) were placed s.c. in the neck of each animal. According to the manufacturer's information, capsules provide continuous release of hormone at serum concentrations of $150-250$ pmol/liter in the range of physiological levels in mice during the estrous cycle (22). This stable physiological level of estrogen promotes the growth of transplanted human endometrium and eliminates intermouse differences related to various stages of the estrous cycle.

Four days after insertion of the estrogen pellet, an entrance was made to the peritoneal cavity in the midline of the lower abdomen with an 18-gauge needle, and with the help of a pipette, 10 fragments of fresh human endometrium in $200 \mu$ sterile PBS were inoculated intraperitoneally to mimic the situation after retrograde menstruation in women. Another entrance was made sc through the skin in the flank, and 10 fragments of fresh human endometrium were pipetted s.c. to enlarge the probability of recovery. Endometrium collected on cycle day 7 and 9 was pooled and was transplanted in all 8 mice. Two mice at a time were killed by cervical dislocation 1, 2, 3, and 4 weeks after implantation of the endometrium fragments to study the development of endometriosis lesions in time.

\section{Analysis of endometriosis lesions in nude mice}

To evaluate endometriosis lesions the abdominal skin was opened, and the abdominal s.c. region, the peritoneum and visceral organs were examined under a binocular microscope. Organs and areas suspect of endometriosis were removed, fixed in $10 \%$ buffered formalin and embedded in paraffin wax. Paraffin sections $(4 \mu \mathrm{m})$ were cut from the entire specimen (150-200 sections) and sections were stained with hematoxylin and eosin or used for immunohistochemistry. Histology of endometriosis lesions was evaluated by a gynecopathologist and a laboratory animal pathologist.

\section{Characterization of FM tissue and detection of TGF- $\beta$ signaling}

Myofibroblasts were distinguished by antibody reaction to vimentin and desmin (intermediate filaments), alpha-smooth muscle actin (cytoskeletal element) and smooth 
muscle myosin heavy chain (SM-MHC) (microfilament). A classification system of myofibroblasts is based on immunohistochemical staining of cytoskeletal filaments. Myofibroblasts that express vimentin are called $V$ type, those that express vimentin and alpha-smooth muscle actin are called VA type, those that express vimentin and desmin are called VD type, those that express vimentin, alpha smooth muscle actin and desmin are called VAD type, and those that express vimentin, alpha-smooth muscle actin and SMMHCs with and without desmin are called VA(D)M type. Active TGF- $\beta$ signaling was detected by using antibodies directed against phosphorylated Smad2. In addition we stained for TGF- $\beta$ receptors type I and II to identify the target cells in deep infiltrating endometriosis lesions and surrounding tissues.

\section{Immunohistochemistry}

A summary of the primary antibodies used and conditions applied is given in Table 1.

Sections of human and mouse endometriosis lesions were fixed on Starfrost adhesive slides (Klinipath, Duiven, the Netherlands). Sections were deparaffinized in xylene and rehydrated in alcohol series prior to blocking endogenous peroxidase activity by incubation with $3 \%$ hydrogen peroxide/methanol for $20 \mathrm{~min}$. After rinsing three times with phosphate-buffered saline (PBS, $\mathrm{pH}$ 7.2), antigen retrieval was performed (see Table 1). Sections were cooled down to room temperature and washed again three times in PBS followed by incubation with the primary antibody (room temperature, $2 \mathrm{~h}$ ). After three PBS rinses, sections were exposed to the secondary antibody (Envision rabbit anti-mouse, ChemMate $^{\mathrm{TM}}$ detection kit, DAKO, Copenhagen, Denmark) for $30 \mathrm{~min}$ at room temperature. Antibody binding was visualized using 3, 3' -diaminobenzidine. Sections were counterstained mildly with hematoxylin, dehydrated and mounted in Entellan for light microscopy. Negative control slides for the monoclonal antibodies were incubated with mouse immunoglobulin (Ig)Gs of the same class and same dilution as the primary antibodies. Negative control slides for the rabbit polyclonal antibodies (pAbs) were incubated with rabbit IgG at the same dilution as the pAbs.

\section{Evaluation of immunostaining in human endometriotic tissues}

The percentage of stained cells $(0,0-10,10-50,>50 \%)$ and the intensity of staining (absent, weak, moderate, strong) were determined $(0,1,2$ or 3 for each variable) for the entire lesion with respect to (i) visceral smooth muscle (if present), (ii) connective tissue not comprising part of fibromuscular reaction, (iii) fibromuscular tissue surrounding endometriosis lesions, (iv) endometrial stromal cells and (v) endometrial epithelial cells. 
Table 1 Primary antibodies and conditions used for immunohistochemistry of human and mouse endometriosis lesions

\begin{tabular}{|c|c|c|c|c|c|c|}
\hline Antibody & Species & $\begin{array}{l}\text { Catalog } \\
\text { number }\end{array}$ & IgG class & Dilution & Manufacturer & $\begin{array}{l}\text { Antigen } \\
\text { retrieval }\end{array}$ \\
\hline Vimentin & Mouse & M0725 & $\operatorname{lgG} 1 \mathrm{k}$ & $1: 100$ & $\begin{array}{l}\text { DAKO, Copenhagen, } \\
\text { Demark }\end{array}$ & $\begin{array}{l}\text { Citrate } \\
(\mathrm{pH} 6.0)\end{array}$ \\
\hline $\begin{array}{l}\alpha \text { - smooth } \\
\text { muscle actin }\end{array}$ & Mouse & M0851 & IgG2ак & $1: 500$ & $\begin{array}{l}\text { DAKO, Copenhagen, } \\
\text { Denmark }\end{array}$ & $\begin{array}{l}\text { Tris EDTA } \\
(\mathrm{pH} \mathrm{9.0)}\end{array}$ \\
\hline Desmin & Mouse & MUB0400 & $\lg G 2 b$ & $1: 700$ & $\begin{array}{l}\text { MUbio products BV, } \\
\text { Maastricht, the Netherlands }\end{array}$ & $\begin{array}{l}\text { Citrate } \\
(\mathrm{pH} 6.0)\end{array}$ \\
\hline $\begin{array}{l}\text { SM-Myosin } \\
\text { heavy chain }\end{array}$ & Mouse & $260850-1$ & $\operatorname{lgG} 1 \kappa$ & 1:3000 & $\begin{array}{l}\text { Northstar Bioproducts, } \\
\text { East Falmouth, MA, USA }\end{array}$ & $\begin{array}{l}\text { Tris EDTA } \\
(\mathrm{pH} 9.0)\end{array}$ \\
\hline $\begin{array}{l}\text { TGF- } \beta \text { receptor } \\
\text { type I }\end{array}$ & Rabbit & sc-398 & Not specified & 1:2000 & $\begin{array}{l}\text { Santa Cruz Biotechnology, } \\
\text { Santa Cruz, CA, USA }\end{array}$ & $\begin{array}{l}\text { Citrate } \\
(\mathrm{pH} 6.0)\end{array}$ \\
\hline $\begin{array}{l}\text { TGF- } \beta \text { receptor } \\
\text { type II }\end{array}$ & Rabbit & sc- 220 & Not specified & 1:3000 & $\begin{array}{l}\text { Santa Cruz Biotechnology, } \\
\text { Santa Cruz, CA, USA }\end{array}$ & $\begin{array}{l}\text { Citrate } \\
\text { (pH 6.0) }\end{array}$ \\
\hline $\begin{array}{l}\text { Phosphorylated } \\
\text { Smad2 }\end{array}$ & Rabbit & 3101 & Not specified & 1:1000 & $\begin{array}{l}\text { Cell Signaling, Danvers, } \\
\text { MA, USA }\end{array}$ & $\begin{array}{l}\text { Citrate } \\
(\mathrm{pH} 6.0)\end{array}$ \\
\hline
\end{tabular}

A staining index ( $\mathrm{SI}$, ranging from 0 to 9) was calculated by multiplying categorized parameters. Two different observers (P.G.G. and K.J.A.F.K) performed evaluation of immunostaining in a blinded fashion. Both observers scored the sections once. The mean of these two observations was used for analyses. The level of inter-observer agreement was determined by calculating kappa statistics for ordinal variables and showed that concordance between the two observers was adequate with respect to the percentage of stained cells ( $\kappa 0.73$ ), intensity of the staining ( $\kappa 0.86)$ and SI ( $\mathrm{k} 0.76)$.

\section{Results}

\section{Human deeply infiltrating endometriosis lesions}

All twenty paraffin embedded deeply infiltrating endometriosis tissue specimens contained connective tissue, endometriosis lesions consisting of endometrial epithelium and endometrial stroma and fibromuscular tissue surrounding endometriosis lesions (Figure 1). Seventeen out of 20 paraffin-embedded tissue samples contained visceral smooth muscle. Immunochemistry results from patient tissue did not differ between lesions obtained from rectovaginal septum, bowel wall, vaginal wall or bladder wall. To investigate the immunophenotype of the lesions and surrounding tissues, sections were stained for vimentin, alpha-smooth muscle actin, desmin and smooth muscle myosin (Figures 1 and 2). Representative photographs of the negative controls for the various immunohistochemical staining procedures are presented in Figure 3. 

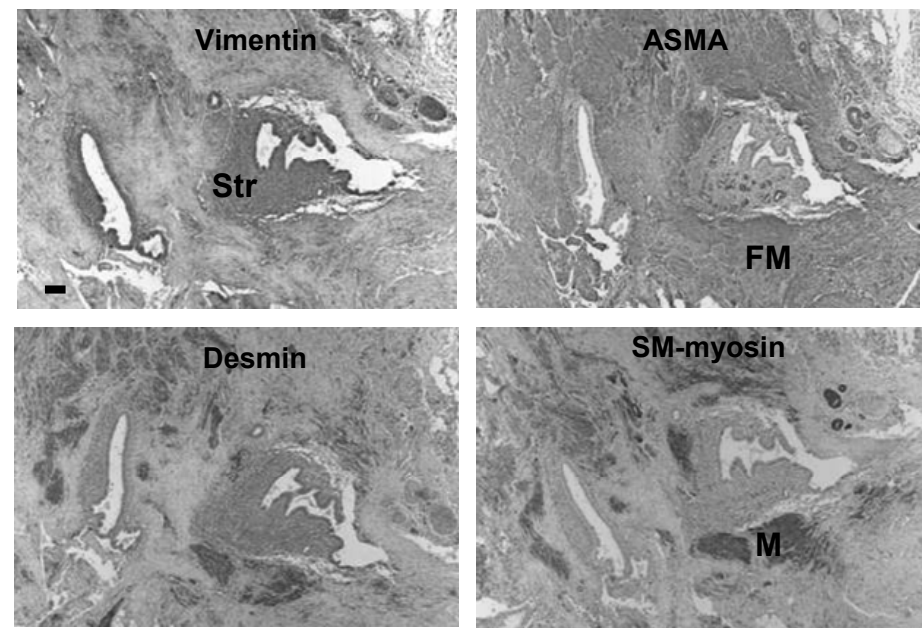

Figure 1 Representative photographs of deep-invasive endometriotic lesions stained with antibodies against vimentin, alpha-smooth muscle actin (ASMA), desmin and smooth muscle myosin heavy chain (SM- myosin). Vimentin staining is strong in the stroma (Str) of the ectopic endometrium, whereas the cells surrounding the lesion (FM) are positive for ASMA. Some areas (M) are also positive for desmin and SM-myosin; most likely resident smooth muscle cells. Scale bar $=100 \mu \mathrm{m}$. (For color figure see page 145)
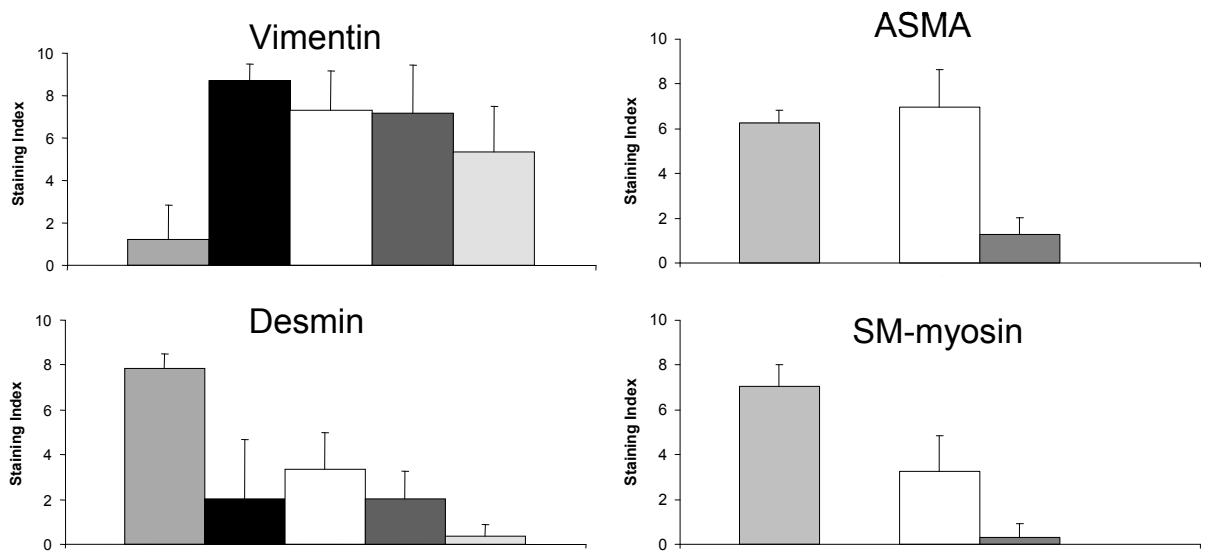

Figure 2 Staining indices for vimentin, ASMA, desmin and SM-myosin in the different tissue components of endometriotic lesions and host environment.

$\square$ visceral smooth muscle, $\square$ connective tissue, $\square$ fibromuscular tissue, $\square$ endometrial stroma, endometrial epithelium. 


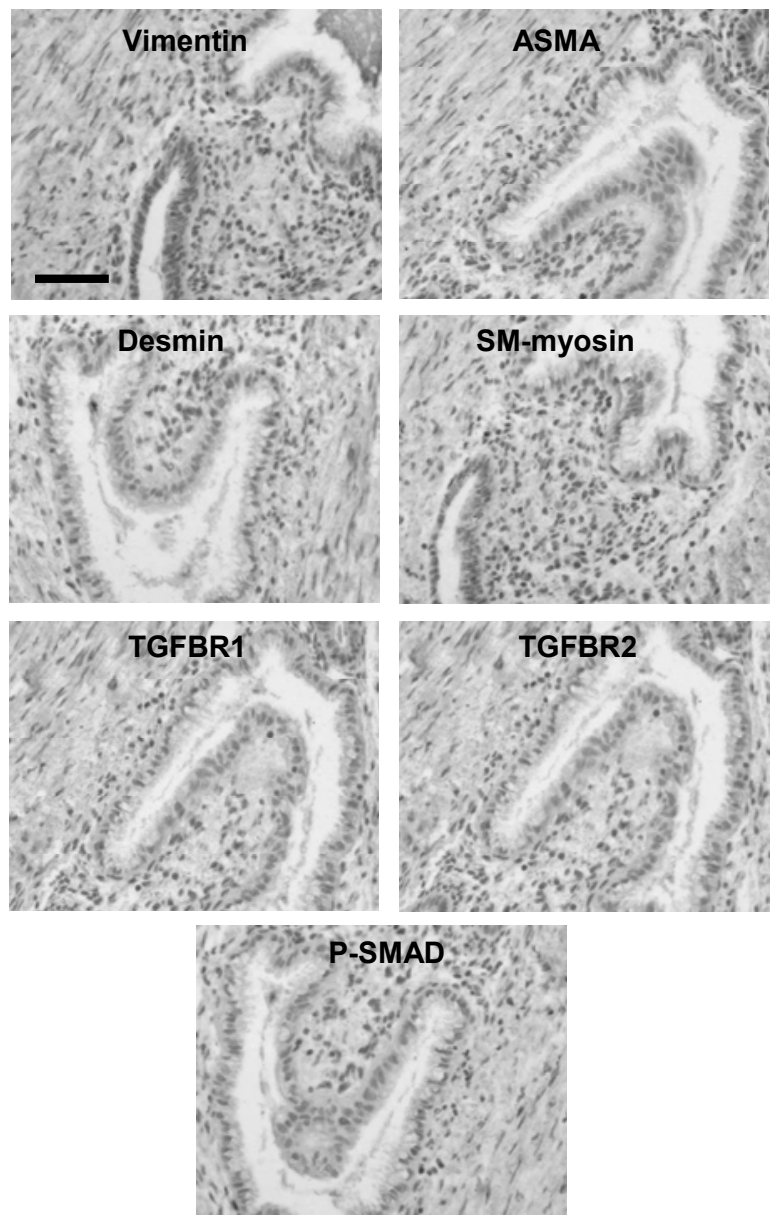

Figure 3 Representative photographs of the negative controls for the vimentin, ASMA, desmin, SM-myosin, TGF$\beta$ receptor 1 and 2 and phosphorylated Smad immunostainings. Scale bar $=100 \mu \mathrm{m}$. (For color figure see page 146)

\section{Connective tissue fibroblasts}

As a reference to assess the extent of fibromuscular differentiation close to the lesions, we evaluated the immunophenotype of connective tissue fibroblasts of the submucosal connective tissue of the large bowel in patients with deep infiltrating endometriosis lesions. An example is presented in Figure 4. The intermediate filament vimentin was strongly expressed in connective tissue fibroblasts (mean SI $8.7 \pm 0.8$, Figure 2). In some tissue samples, connective tissue fibroblasts showed weak desmin expression (mean SI 2.0 \pm 2.6 ), whereas expression of myosin heavy chain and alpha-smooth muscle actin was completely absent in connective tissue fibroblasts of all specimens. 

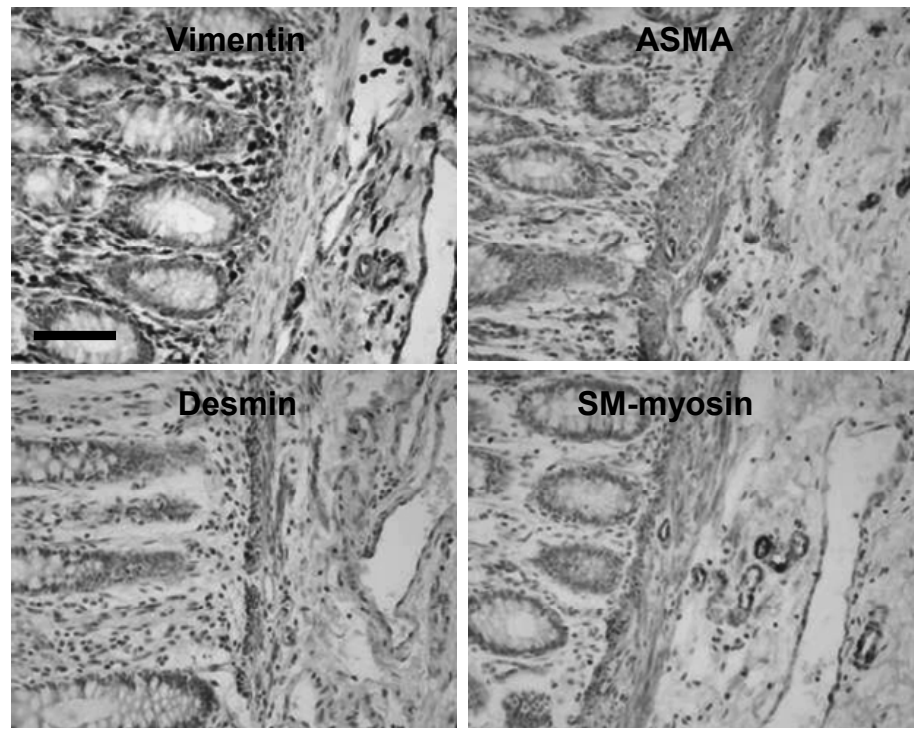

Figure 4 Immunostaining of vimentin, ASMA, desmin and SM-myosin in submucosal connective tissue of the large bowel. Scale bar $=100 \mu \mathrm{m}$. (For color figure see page 147)

\section{Endometrial stroma}

Endometrial stromal cells in deeply infiltrating endometriosis lesions strongly express vimentin (mean SI $7.2 \pm 2.3$ ). Weak expression of alpha-smooth muscle actin (mean SI 1.3 \pm 0.8 ) and desmin (mean SI $2.0 \pm 1.2$ ) could be observed, mostly localized in endothelial cells of blood vessels within the lesions (Figures 2 and 5). SM-MHC expression (mean SI 0.3 \pm 0.6 ) was very weak and could only be observed in a small minority of lesions (Figures 2 and 5).

\section{Fibromuscular tissue}

Cells comprising part of the fibromuscular reaction around endometriosis lesions also strongly express vimentin (mean SI $7.3 \pm 1.9$ ). As opposed to fibroblasts in connective tissue, these cells abundantly express alpha-smooth muscle actin (Figures 2 and 6; mean $\mathrm{SI}$ $7.0 \pm 1.7$ ), thereby demonstrating their myofibroblastic nature. Within the regions that stain positive for alpha-smooth muscle actin, focal areas showing moderate to strong expression of smooth muscle differentiation markers desmin and myosin heavy chain (mean SI $3.3 \pm 1.6$ and $3.4 \pm 1.6$, respectively) can be observed (Figure 6). 

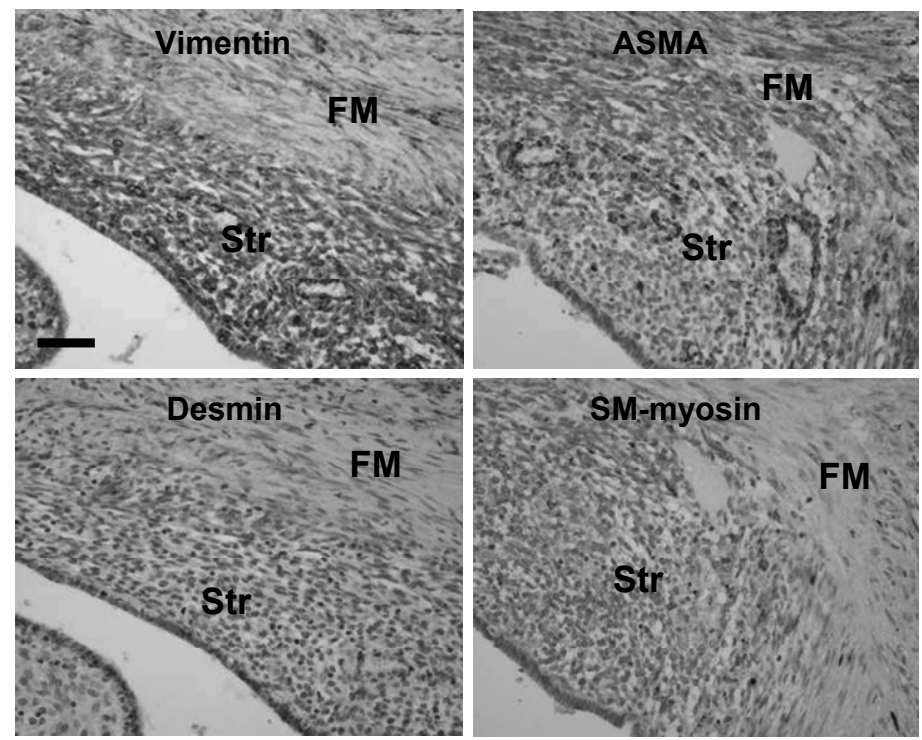

Figure 5 Higher magnification photographs of an endometriotic lesion in the sigmoid, with fibromuscular tissue, stained for vimentin, ASMA, desmin and SM-myosin. Str = stroma in ectopic lesion, FM = fibromuscular tissue. Scale bar $=100 \mu \mathrm{m}$. (For color figure see page 147)
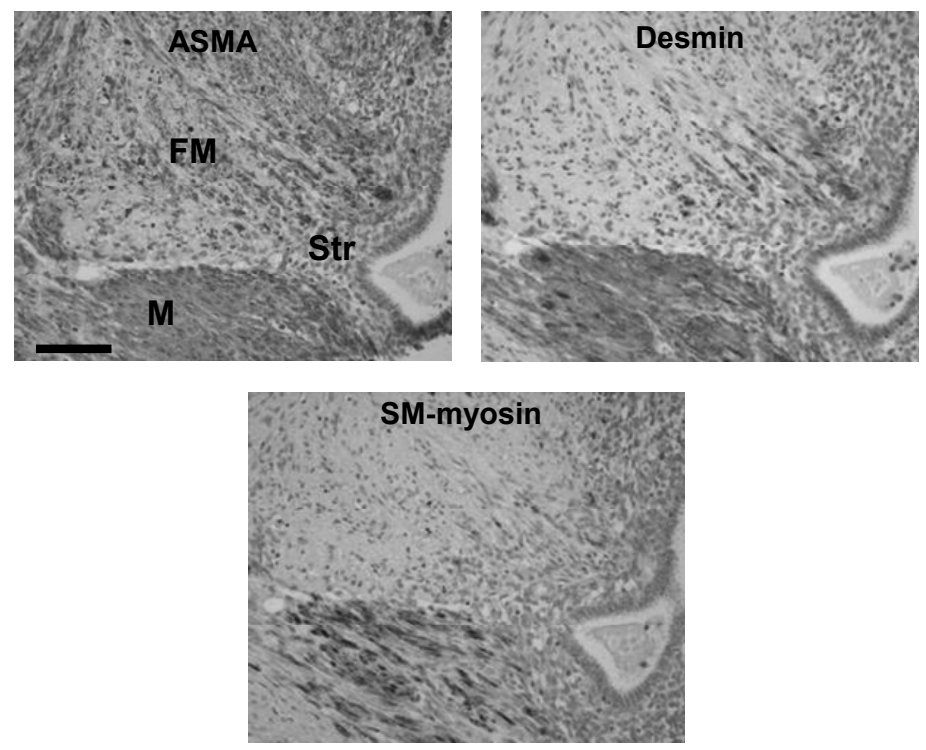

Figure 6 Difference in fibromuscular tissue and structures that are most likely resident smooth muscle cells. The sections were stained for ASMA, desmin and SM-myosin. Str = stroma in ectopic lesion, FM = fibromuscular tissue, $M=$ visceral muscle. Scale bar $=100 \mu \mathrm{m}$. (For color figure see page 148) 


\section{Visceral smooth muscle}

Visceral smooth muscle shows weak vimentin expression (mean SI $1.3 \pm 1.6$ ) and abundant generalized expression of desmin (mean SI $7.9 \pm 0.7$ ), myosin heavy chain (mean SI $7.1 \pm$ 1.0) and alpha-smooth muscle actin (mean SI $6.3 \pm 0.6$ ), all markers of smooth muscle differentiation (Figures 2 and 7). Sometimes endometriotic lesions are present in the visceral muscle layer (Figure 7).

\section{TGF- $\beta$ signaling}

Smad 2 phosphorylation was closely associated with the presence of TGF- $\beta$ receptors type I and II. Expression of TGF- $\beta$ receptor I, TGF- $\beta$ receptor II and phosphorylated Smad 2 was most pronounced in endometrial epithelium (mean SI $6.5 \pm 1.2$ / $6.8 \pm 1.6$ / $7.9 \pm 1.3$, respectively) followed by endometrial stroma (mean SI $4.0 \pm 1.0$ / $3.7 \pm 1.0$ / $6.8 \pm 1.4$, respectively), visceral smooth muscle (mean SI $4.5 \pm 1.2$ / $3.4 \pm 0.9$ / $6.0 \pm 2.1$, respectively) and connective tissue (mean SI $3.8 \pm 1.1 / 2.3 \pm 1.6 / 5.0 \pm 2.0$, respectively) and was least pronounced in cells comprising part of the fibromuscular reaction (mean $\mathrm{SI}$ $1.9 \pm 0.7$ / $1.5 \pm 0.8$ / $4.6 \pm 2.2$ respectively) (Figures 8 and 9).
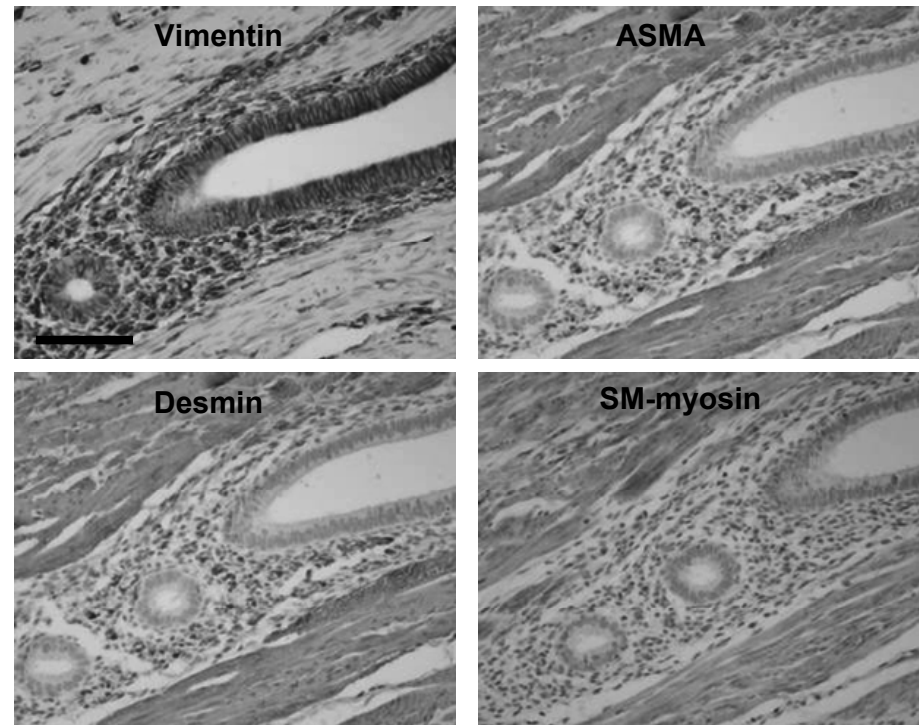

Figure 7 A lesion in the visceral muscle of the colon wall. The stroma is positive for vimentin and ASMA, whereas the muscle cells are positive for ASMA, desmin and SM-myosin. Scale bar $=100 \mu \mathrm{m}$. (For color figure see page 148) 

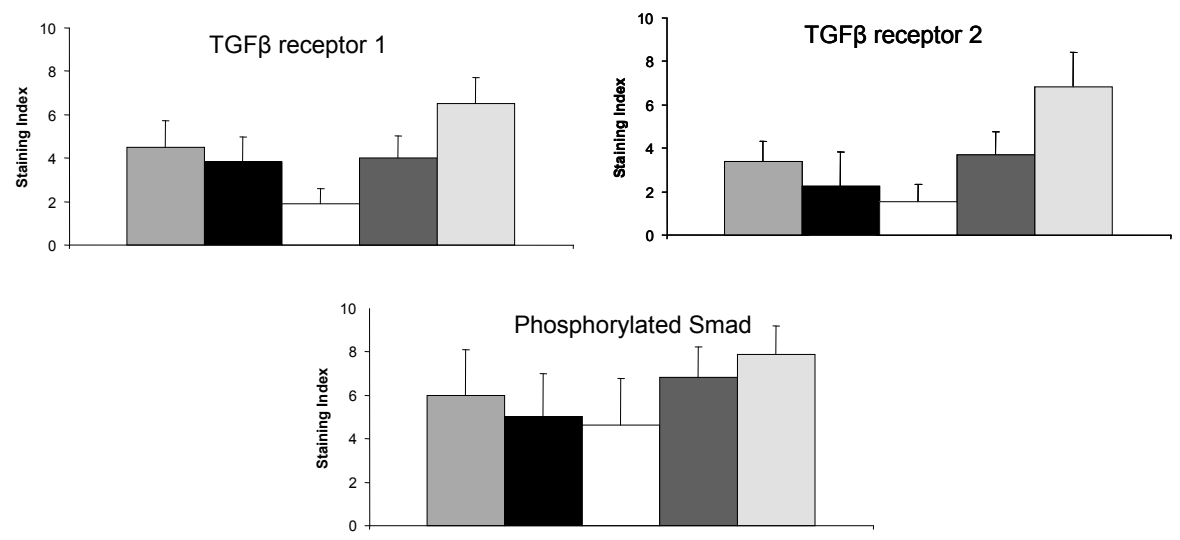

Figure 8 Staining indices for TGF- $\beta$ receptor 1 and 2 and phosphorylated Smad in the different tissue components of endometriotic lesions and host environment.

$\square$ visceral smooth muscle, $\square$ connective tissue, $\square$ fibromuscular tissue, $\square$ endometrial stroma,

endometrial epithelium.

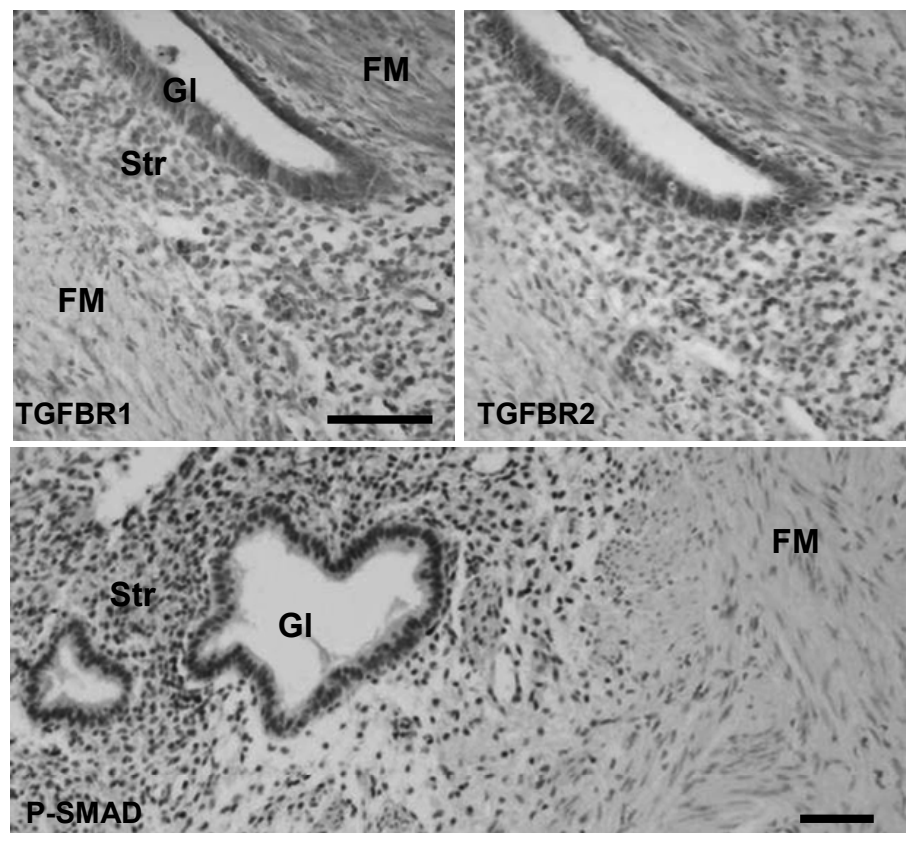

Figure 9 Representative photographs of immunostaining for TGF- $\beta$ receptor 1 and 2 and phosphorylated Smad in deeply infiltrating endometriosis. Str = stroma in ectopic lesion, FM = fibromuscular tissue, $\mathrm{Gl}=$ gland in ectopic lesion. Scale bar $=100 \mu \mathrm{m}$. (For color figure see page 149) 


\section{Mouse endometriosis lesions}

Endometriosis lesions were identified in all mice, except for one mouse that was sacrificed after 2 weeks. Most lesions were found at the s.c. injection sites, some lesions were present on the peritoneum near the umbilical region. All lesions consisted of endometrial glands and stroma. For immunohistochemical analysis the subcutaneous lesions were used. Cells of human origin could be distinguished from mouse cells by positive staining for the human-specific vimentin antibody (Figure 10).

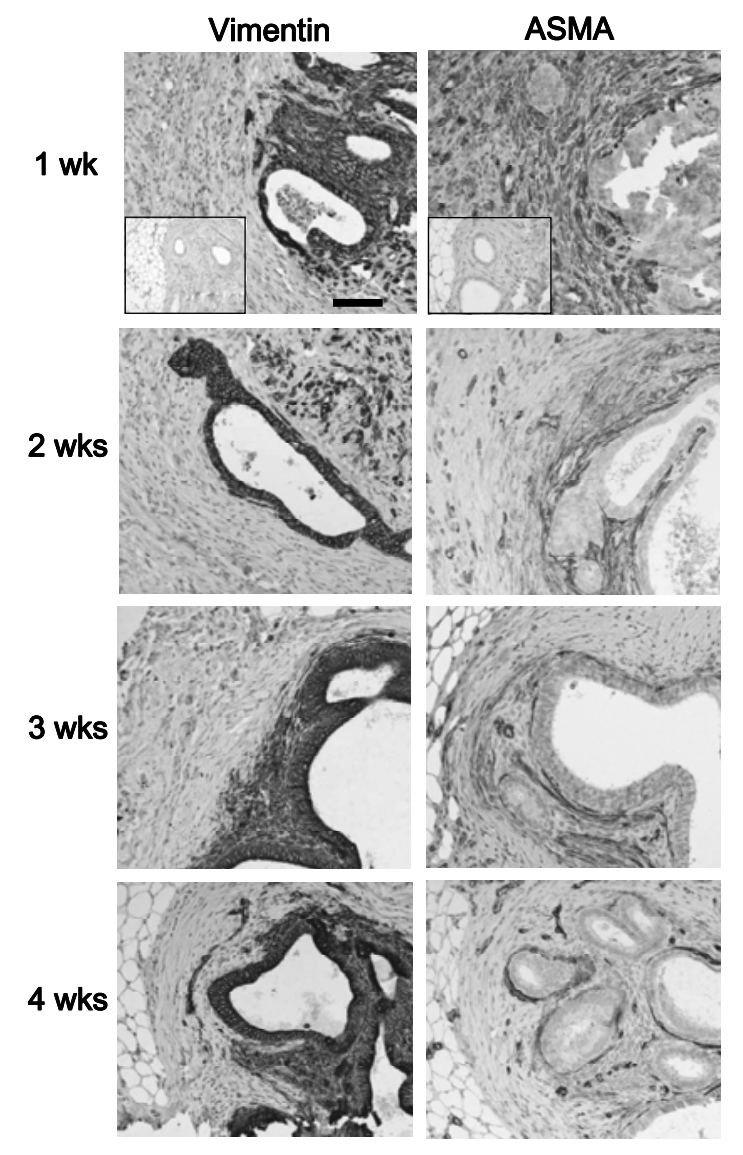

Figure 10 Vimentin and ASMA expression in endometriotic lesions generated through the subcutaneous transplantation of human endometrium in nude mice. Lesions were collected weekly for four weeks. The vimentin antibody is human-specific, which demonstrates that the ASMA expression is strongly enhanced in the host cells. Negative controls for the vimentin and ASMA stainings are shown in the inserts. Scale bar $=100 \mu \mathrm{m}$. (For color figure see page 150) 
One week after tissue inoculation, alpha-smooth muscle actin was highly expressed in the mouse cells directly surrounding the lesion (Figure 10) but not in the human endometrial cells or in connective tissue fibroblasts remote from the lesion. Two weeks after inoculation, alpha-smooth muscle actin expression in mouse cells slightly decreased. After three and four weeks alpha-smooth muscle actin expression progressively declined but remained visible as a thin sheath directly adjacent to and surrounding the endometrial glandular epithelium. The number of endometrial stromal cells appeared to decrease at the same time collagen deposition became apparent in a circular pattern surrounding the lesion after three weeks.

\section{Discussion}

Deeply infiltrating endometriosis is characterized by the existence of nodular lesions largely composed of FM tissue. In this study we show that FM tissue surrounding endometriosis lesions contains myofibroblastic cells that, in addition to alpha-smooth muscle actin, express multiple markers of smooth muscle differentiation such as desmin and SM-MHC.

Our findings support the contention that the formation of deeply infiltrating endometriosis lesions shares characteristics with pathological wound healing. During the initial phase of normal wound healing, alpha-smooth muscle actin is highly expressed by myofibroblasts in granulation tissue, thereby effectuating the necessary wound contraction. The contractile activity of myofibroblasts is terminated when the tissue is repaired: alpha-smooth muscle actin expression decreases and myofibroblasts disappear through massive apoptosis (23). In pathological fibrotic phenomena however, this wave of apoptosis is lacking and alpha-smooth muscle actin expression persists in the tissue myofibroblasts in addition to the expression of other markers of smooth muscle differentiation such as desmin and SM-MHC (24).

The presence of smooth muscles in endometriosis lesions is not a new finding: Anaf et al. demonstrated alpha-smooth muscle actin positivity in areas surrounding peritoneal, ovarian, uterosacral and rectovaginal endometriosis lesions (5). Smooth muscles were absent in the unaffected peritoneum and in the eutopic endometrium of women with and without pelvic endometriosis. In line with the induction theory (25), these authors speculated that the smooth muscle component of endometriosis might result from the capacity of the secondary Müllerian system to differentiate into both smooth muscle cells and endometrial glands and stroma. Alternatively, endometrial cells arriving through retrograde transplantation at ectopic sites could undergo smooth muscle metaplasia, or induce the surrounding tissue to undergo smooth muscle metaplasia. With the aid of a nude mouse model we were able to demonstrate that as soon as one week after inoculation with human endometrium, alpha-smooth muscle actin expression is induced in the surrounding murine fibroblasts, whereas no expression was observed in the human 
cells. These findings strongly suggest that the presence of smooth muscle-like tissue in deeply infiltrating endometriosis lesions is accounted for by a reaction of the local environment to the presence of ectopic endometrium rather than smooth muscle metaplasia of the ectopic endometrium itself.

This phenomenon mimics what is frequently observed in malignancies. Many epithelial tumors are also characterized by the presence of an "activated" stroma consisting of fibroblastic and myofibroblastic cells that produce collagen and extracellular matrix components, a phenomenon that is referred to as the stroma reaction or "desmoplastic reaction" (26). Desmoplasia is considered a response of the resident stromal fibroblasts of the host environment to inductive stimuli exerted by tumor cells, such as diffusible factors, extracellular matrix and/or direct cell-to-cell contacts. The reciprocal interactions between the tumor cells and resident fibroblasts potentiate tumor growth, stimulate angiogenesis and induce fibroblasts to undergo differentiation into myofibroblasts. Although endometriosis cannot be regarded as a bona fide neoplasm, it displays certain important characteristics of malignant tumor growth such as invasion of the extracellular matrix (27) and the acquisition of its own blood supply (28). Therefore, it is conceivable that a similar process may take place in the evolution of smooth muscle-containing endometriotic lesions. However, a limitation of the present study is constituted by the fact that the endometrial tissue used for the animal study was sampled from only two women and the experiment was carried out only once in a relatively small number of animals. The possibility that these results occurred by chance can therefore not be ruled out completely.

We hypothesized that prolonged TGF- $\beta$ signaling is involved in the development of fibromuscular tissue in deep infiltrating endometriotic lesions. It has been shown that the cytokine TGF- $\beta 1$ is responsible for inducing the synthesis of alpha-smooth muscle actin in fibroblastic cells and for stimulating the production of collagen type I (12), and overproduction of TGF- $\beta 1$ has been implicated in the pathogenesis of disorders characterized by fibrosis (13-17). In this respect, TGF- $\beta 1$ is a key cytokine in the evolution of lesions characterized by myofibroblast formation. TGF- $\beta 1$ is expressed in the human endometrium throughout the menstrual cycle, it is regulated by ovarian steroids $(29,30)$, and could be responsible for the induction of the FM reaction in the fibroblasts of the host environment. Surprisingly however, the expression of the marker of active TGF- $\beta$ signaling, phosphorylated Smad 2, was consistently lower in myofibroblasts of the FM tissue compared with surrounding tissues. Consistent with these findings, we found that the expression of the receptors for TGF- $\beta$ was most pronounced in the endometrial tissue of the lesion, and not in the surrounding fibromuscular tissue. Most TGF- $\beta$ signaling apparently occurs in the endometrial tissue and not in the local host cells.

An important factor which may contribute to the differentiation and maintenance of the myofibroblast phenotype could be mechanical strain (31). Deeply infiltrating endometriosis lesions are often found in areas subjected to continuous or intermittent mechanical tension: the bowel wall and rectovaginal septum repeatedly stretch and relax 
as a result of peristalsis and the passage of feces. Frequent mechanical stress could constitute an important determinant in the development of deep infiltrating endometriosis lesions. In rat models for wound healing in the skin, Hinz et al. showed that mechanically inflicted tension induced alpha-smooth muscle actin expression in fibroblasts in the wound; relief of the mechanical pressure resulted in disappearance of the actin filaments which preceded a decrease in TGF- $\beta 1$ levels (32). These results indicate that TGF- $\beta 1$ alone may not be sufficient to maintain myofibroblast differentiation, and that a mechanical stimulus is equally important. Shi et al. showed in injured porcine arteries that after fourteen days of coexpression, TGF-ß1 expression disappeared, whereas alpha-smooth muscle actin expression in the neointima of injured porcine arteries remained high up to 90 days (33). As arteries are also subject to mechanical strain due to the high intravascular pressure, it is plausible that this is responsible for the continued alpha-smooth muscle actin expression.

Alternatively, the excessive fibromuscular reaction could be explained by the fact that ectopic endometrium arriving through repeated retrograde menstruation induces a chronic inflammatory response in the peritoneal cavity. It has been shown that the peritoneal fluid of women with endometriosis is marked by increased inflammation, including increased concentration of white blood cells and macrophages, and increased activation status of these macrophages $(34,35)$. In association with the activated state of these macrophages, an increase in the release of macrophage-derived cytokines such as TGF- $\beta 1$ has been demonstrated in the peritoneal fluid of women with endometriosis (3638). Overproduction of TGF- $\beta 1$ by activated macrophages in peritoneal fluid may therefore contribute to a microenvironment that favors the formation of fibromuscular tissue surrounding endometriosis lesions.

In conclusion, in this study we show that the FM cells surrounding deep infiltrating endometriosis lesions express multiple markers of FM differentiation, resembling the situation in pathologic wound healing and fibrocontractive diseases. In a nude mouse model we showed that alpha-smooth muscle actin expression is induced in the host tissue after implantation of human endometrial fragments, suggesting that the presence of smooth muscle-like tissue in endometriosis lesions is the result of a reaction of the local environment to the presence of ectopic endometrium rather than smooth muscle metaplasia of the ectopic endometrium itself. Based on our observations it is not likely that TGF- $\beta 1$ signaling alone is sufficient to account for the excessive FM tissue in deep infiltrating endometriosis lesions. In this respect, the presence of mechanical tension and increased inflammatory activity in peritoneal fluid of women with endometriosis may be important contributing factors in the establishment of myofibroblast-containing deep infiltrating endometriosis lesions. 


\section{References}

1. Cornillie FJ, Oosterlynck D, Lauweryns JM, Koninckx PR. Deeply infiltrating pelvic endometriosis: histology and clinical significance. Fertil Steril 1990;53:978-83.

2. Itoga T, Matsumoto T, Takeuchi H, Yamasaki S, Sasahara N, Hoshi T, Kinoshita K. Fibrosis and smooth muscle metaplasia in rectovaginal endometriosis. Pathol Int 2003;53:371-5.

3. Nisolle M, Donnez J. Peritoneal endometriosis, ovarian endometriosis, and adenomyotic nodules of the rectovaginal septum are three different entities. Fertil Steril 1997;68:585-96.

4. Vercellini P, Aimi G, Panazza S, Vicentini S, Pisacreta A, Crosignani PG. Deep endometriosis conundrum: evidence in favor of a peritoneal origin. Fertil Steril 2000;73:1043-6.

5. Anaf V, Simon P, Fayt I, Noel J. Smooth muscles are frequent components of endometriotic lesions. Hum Reprod 2000;15:767-71.

6. Anaf V, Simon P, El Nakadi I, Fayt I, Buxant F, Simonart T, Peny MO, Noel JC. Relationship between endometriotic foci and nerves in rectovaginal endometriotic nodules. Hum Reprod 2000;15:1744-50.

7. Kim MR, Park DW, Lee JH, Choi DS, Hwang KJ, Ryu HS, Min CK. Progesterone-dependent release of transforming growth factor-beta1 from epithelial cells enhances the endometrial decidualization by turning on the Smad signalling in stromal cells. Mol Hum Reprod 2005;11:801-8.

8. Fukunaga M. Smooth muscle metaplasia in ovarian endometriosis. Histopathology 2000;36:348-52.

9. Gabbiani G. The myofibroblast in wound healing and fibrocontractive diseases. J Pathol 2003;200:500-3.

10. Darby I, Skalli O, Gabbiani G. Alpha-smooth muscle actin is transiently expressed by myofibroblasts during experimental wound healing. Lab Invest 1990;63:21-9.

11. Schurch W ST, Hinz B, Gabbiani G. The myofibroblast. In: SE M, ed. Histology for pathologists: LippincottWilliams \& Wilkins, Philadelphia, USA, 2006.

12. Desmouliere A, Geinoz A, Gabbiani F, Gabbiani G. Transforming growth factor-beta 1 induces alphasmooth muscle actin expression in granulation tissue myofibroblasts and in quiescent and growing cultured fibroblasts. J Cell Biol 1993;122:103-11.

13. Okuda S, Languino LR, Ruoslahti E, Border WA. Elevated expression of transforming growth factor-beta and proteoglycan production in experimental glomerulonephritis. Possible role in expansion of the mesangial extracellular matrix. J Clin Invest 1990;86:453-62.

14. Broekelmann TJ, Limper AH, Colby TV, McDonald JA. Transforming growth factor beta 1 is present at sites of extracellular matrix gene expression in human pulmonary fibrosis. Proc Natl Acad Sci USA 1991;88: 6642-6.

15. Border WA, Noble NA. Transforming growth factor beta in tissue fibrosis. New Engl J Med 1994;331: 1286-92.

16. Roberts AB. Transforming growth factor-beta: activity and efficacy in animal models of wound healing. Wound Repair Regen 1995;3:408-18.

17. Chegini N. The role of growth factors in peritoneal healing: transforming growth factor beta (TGF-beta). Eur J Surg Supp/ 1997:17-23.

18. Sime PJ, Xing Z, Graham FL, Csaky KG, Gauldie J. Adenovector-mediated gene transfer of active transforming growth factor-beta1 induces prolonged severe fibrosis in rat lung. J Clin Invest 1997;100: 768-76.

19. Giri SN, Hyde DM, Hollinger MA. Effect of antibody to transforming growth factor beta on bleomycin induced accumulation of lung collagen in mice. Thorax 1993;48:959-66.

20. Nakamura T, Sakata R, Ueno T, Sata M, Ueno H. Inhibition of transforming growth factor beta prevents progression of liver fibrosis and enhances hepatocyte regeneration in dimethylnitrosamine-treated rats. Hepatology 2000;32:247-55.

21. McCormick LL, Zhang Y, Tootell E, Gilliam AC. Anti-TGF-beta treatment prevents skin and lung fibrosis in murine sclerodermatous graft-versus-host disease: a model for human scleroderma. J Immunol 1999;163:5693-9.

22. Bronson FH, Desjardins C. Circulating concentrations of FSH, LH, estradiol, and progesterone associated with acute, male-induced puberty in female mice. Endocrinology 1974;94:1658-68.

23. Desmouliere A, Chaponnier C, Gabbiani G. Tissue repair, contraction, and the myofibroblast. Wound Repair Regen 2005;13:7-12. 
24. Skalli O, Schurch W, Seemayer T, Lagace R, Montandon D, Pittet B, Gabbiani G. Myofibroblasts from diverse pathologic settings are heterogeneous in their content of actin isoforms and intermediate filament proteins. Lab Invest 1989;60:275-85.

25. Levander G, Normann P. The pathogenesis of endometriosis; an experimental study. Acta Obstet Gynecol Scand 1955;34:366-98.

26. Desmouliere A, Guyot C, Gabbiani G. The stroma reaction myofibroblast: a key player in the control of tumor cell behavior. Int J Dev Biol 2004;48:509-17.

27. Spuijbroek MD, Dunselman GA, Menheere PP, Evers JL. Early endometriosis invades the extracellular matrix. Fertil Steril 1992;58:929-33.

28. Groothuis PG, Nap AW, Winterhager E, Grummer R. Vascular development in endometriosis. Angiogenesis 2005;8:147-56.

29. Bruner KL, Eisenberg E, Gorstein F, Osteen KG. Progesterone and transforming growth factor-beta coordinately regulate suppression of endometrial matrix metalloproteinases in a model of experimental endometriosis. Steroids 1999;64:648-53.

30. Luo $\mathrm{X}, \mathrm{Xu} \mathrm{J}$, Chegini $\mathrm{N}$. The expression of Smads in human endometrium and regulation and induction in endometrial epithelial and stromal cells by transforming growth factor-beta. J Clin Endocrinol Metab 2003;88:4967-76.

31. Serini G, Bochaton-Piallat ML, Ropraz P, Geinoz A, Borsi L, Zardi L, Gabbiani G. The fibronectin domain ED-A is crucial for myofibroblastic phenotype induction by transforming growth factor-beta1. J Cell Biol 1998;142:873-81.

32. Hinz B, Mastrangelo D, Iselin CE, Chaponnier C, Gabbiani G. Mechanical tension controls granulation tissue contractile activity and myofibroblast differentiation. Am J Pathol 2001;159:1009-20.

33. Shi Y, O'Brien JE, Jr., Fard A, Zalewski A. Transforming growth factor-beta 1 expression and myofibroblast formation during arterial repair. Arterioscler Thromb Vasc Biol 1996;16:1298-305.

34. Oral E, Olive DL, Arici A. The peritoneal environment in endometriosis. Human Reprod Update 1996;2: 385-98.

35. Dunselman GA, Hendrix MG, Bouckaert PX, Evers JL. Functional aspects of peritoneal macrophages in endometriosis of women. J Reprod Fertil 1988;82:707-10.

36. Oosterlynck DJ, Meuleman C, Waer M, Koninckx PR. Transforming growth factor-beta activity is increased in peritoneal fluid from women with endometriosis. Obstet Gynecol 1994;83:287-92.

37. Pizzo A, Salmeri FM, Ardita FV, Sofo V, Tripepi M, Marsico S. Behaviour of cytokine levels in serum and peritoneal fluid of women with endometriosis. Gynecol Obstet Invest 2002;54:82-7.

38. Kyama CM, Overbergh L, Debrock S, Valckx D, Vander Perre S, Meuleman C, Mihalyi A, Mwenda JM, Mathieu C, D'Hooghe TM. Increased peritoneal and endometrial gene expression of biologically relevant cytokines and growth factors during the menstrual phase in women with endometriosis. Fertil Steril 2006;85:1667-75. 


\section{Chapter 3}

Transforming growth factor $\beta 1$ gene polymorphism

$-509 \mathrm{C} / \mathrm{T}$ in deep infiltrating endometriosis

KJAF van Kaam, A Romano, GAJ Dunselman, PG Groothuis

Reproductive Sciences 2007;14:367-73 


\section{Abstract}

Deep infiltrating endometriosis is characterized by the presence of nodular lesions largely composed of fibromuscular tissue. Transforming growth factor beta 1 (TGF- $\beta 1$ ) is the cytokine most causatively associated with disorders characterized by fibrosis throughout the body. Therefore, the hypothesis was tested that mechanisms increasing the fraction of biologically active TGF- $\beta 1$, such as TGF- $\beta 1$ gene polymorphisms, lead to an increased risk of developing deep infiltrating endometriosis. The frequency of the $-509 \mathrm{C} / \mathrm{T}$ polymorphism of the TGF- $\beta 1$ gene was tested in women with deep infiltrating endometriosis $(n=72)$, gynecological patients without symptoms of endometriosis $(n=95)$ and healthy females $(n=93)$. Detection of the $-509 \mathrm{C} / \mathrm{T}$ polymorphisms was performed using PCR-restriction fragment length polymorphism analysis. We did not observe statistically significant differences in the frequency of the $-509 \mathrm{C} / \mathrm{T}$ polymorphism between the groups. Our study does not support an association between the $-509 \mathrm{C} / \mathrm{T}$ polymorphism of the TGF- $\beta 1$ gene and an increased risk of deep infiltrating endometriosis. 


\section{Introduction}

Endometriosis is a commonly occurring, complex disease characterized by the presence of endometrial glands and stroma at ectopic locations outside the uterine cavity. The disease can manifest itself as superficial peritoneal lesions, ovarian endometriotic cysts and as deep infiltrating lesions, most often in the rectovaginal space. Many women with patent tubes harbor spots of peritoneal endometriosis without having any symptoms. In these women, superficial peritoneal lesions are often referred to as the phenomenon endometriosis. On the other hand, deep infiltrating lesions are considered to be the disease endometriosis, since they often lead to symptoms such as severe dysmenorrhea, dyspareunia, and pelvic pain. However, the pathogenesis of deep infiltrating endometriosis is still poorly understood and surrounded by controversy. Theories that have been developed on this subject either favor the argument that deep endometriosis develops from superficial peritoneal implants that infiltrate into the pouch of Douglas and the rectovaginal septum (1), whereas others suggest that deep infiltrating lesions arise as a result of metaplasia of Müllerian remnants, implying that deep infiltrating endometriosis is a specific disease entity, distinct from other types of endometriosis $(2,3)$.

Deep infiltrating endometriosis is defined as the presence of endometriosis more than $5 \mathrm{~mm}$ under the peritoneal surface (4), and often takes the form of a nodular lesion. A key feature of these deep infiltrating lesions is that, in contrast to superficial peritoneal implants, their major component is fibromuscular tissue rather than endometrial tissue. More or less extensive fibrosis has been demonstrated in nearly $100 \%$ of rectovaginal deep infiltrating endometriotic lesions (5). Endometriosis is generally considered to be a complex, polygenic disease with a multifactorial etiology. Based on biological plausibility, numerous candidate genes and their allelic variations were analyzed for their possible involvement in the pathogenesis of endometriosis (6-10). So far, this has yielded inconsistent results. A gene that may be of particular importance with respect to the pathogenesis of deep infiltrating endometriosis, is the transforming growth factor $\beta 1$ (TGF- $\beta 1$ ) gene. TGF- $\beta 1$ is the cytokine most causatively associated with disorders characterized by fibrosis (11). In the embryo, its fibrogenic effects are critical during both organogenesis and morphogenesis, whereas in the adult, they are central in wound healing and tissue repair. TGF- $\beta 1$ exerts its fibrogenic effects by inducing matrix deposition in mesenchymal cells in culture by promoting expression of extracellular matrix (ECM) genes, suppressing the activity of enzymes that degrade ECM (such as matrix metalloproteinases), enhancing fibroblast proliferation and inducing the myofibroblast phenotype.

Although TGF- $\beta 1$ is essential for wound healing, overproduction of TGF- $\beta 1$ has been implicated in the pathogenesis of several fibrotic diseases at various sites throughout the body, such as pulmonary fibrosis, glomerulonephritis, cirrhosis of the liver, skin scarring and peritoneal adhesion formation (12-15). Treatment of fetal wounds with TGF- $\beta 1$ promotes wound closure and scarring, supporting the notion that TGF- $\beta 1$ promotes 
fibrosis in vivo (16). Conversely, the cutaneous or intraperitoneal application of neutralizing antibodies against TGF- $\beta 1$ in rats decreased scar formation at the site of dermal injury, as well as intra-abdominal adhesions $(17,18)$.

High levels of TGF- $\beta 1$ have also been linked to the pathogenesis of endometriosis. It has been demonstrated that peritoneal fluid levels of TGF- $\beta 1$ are elevated in women with endometriosis and women with pelvic adhesions compared to women with a normal pelvis (19-21). However, despite the positive association between TGF- $\beta 1$ concentrations in peritoneal fluid and endometriosis, a direct causal relationship remains to be demonstrated.

Given the pivotal role of TGF- $\beta 1$ in various fibrotic disorders and the amount of fibromuscular tissue present in deep infiltrating endometriotic lesions, we hypothesized that mechanisms increasing the fraction of biologically active TGF- $\beta 1$, such as TGF- $\beta 1$ gene polymorphisms, lead to an increased risk of developing deep infiltrating endometriosis. Past research has shown that the $-509 \mathrm{C} / \mathrm{T}$ polymorphism of the TGF- $\beta 1$ gene is associated with a significant increase of mean TGF- $\beta 1$ plasma concentration, to the extent that almost $10 \%$ of the genetic variance in total TGF- $\beta 1$ plasma concentration could be attributed to the $-509 \mathrm{C} / \mathrm{T}$ polymorphism (22). One study has demonstrated a strong association between the presence of the $-509 \mathrm{~T}$ polymorphic allele and endometriosis (23). However, in their study there was no specific assessment of patients with deep infiltrating lesions although this study included patients with moderate/severe endometriosis according to the revised American Fertility Society classification.

The aim of the current study was to investigate the possible association between the presence of the $-509 \mathrm{C} / \mathrm{T}$ polymorphism and the risk of developing deep infiltrating endometriosis. Two groups of women without symptomatic endometriosis served as controls.

\section{Materials and Methods}

\section{Patients and tissue specimens}

Patients with a surgical and histological diagnosis of deep infiltrating endometriosis who were operated between 1998 and 2004 in the University Hospital of Maastricht $(n=72)$ were included in the study. Deep infiltrating endometriosis was defined as the histologically proven presence of one or more deep infiltrating lesions in the bowel wall, vaginal wall, bladder wall and/or rectovaginal septum. The first control group consisted of gynecological patients without symptoms of endometriosis who underwent a hysterectomy for benign indications such as prolapse, pelvic pain or menstrual cycle disorders (gynecological controls, $n=95$ ). Patients with uterine fibroids and postmenopausal women were excluded from this group. A second group of controls was taken from a DNA-control panel derived from female subjects who had been referred to 
the Clinical Genetics department for molecular testing of various disease genes. Only subjects that were tested negative for these diseases were included in the control panel, as they can be regarded as healthy, random controls (population controls, $n=93$ ). Both patients and controls originated from the same geographic region of the Netherlands.

\section{DNA isolation}

In patients with deep infiltrating endometriosis and the gynaecological control group the analyses were performed on DNA isolated from paraffin-embedded archival tissue. After reviewing all paraffin-embedded tissue specimens for the presence of endometriotic lesions, five consecutive sections of $20 \mu \mathrm{m}$ were cut from each tissue sample. Genomic DNA isolation was performed using proteinase $\mathrm{K}$ (Qiagen, Hilde, Germany) digestion in combination with the Puregene DNA Isolation Kit (Gentra Systems, Minneapolis, MN, USA), following the recommendations of the manufacturer.

The analyses of the population control group were performed on DNA isolated from blood. Genomic DNA was isolated from $8 \mathrm{ml}$ whole blood (EDTA tubes) using the Wizard Genomic DNA Purification Kit (Promega, Leiden, the Netherlands) following the manufacturer's protocol.

\section{$-509 \mathrm{C} / \mathrm{T}$ detection}

Detection of the $-509 \mathrm{C} / \mathrm{T}$ polymorphism (NCBI SNPs database number: rs1800469) was performed using restriction fragment length polymorphism (RFLP) analysis. From the patients with deep infiltrating endometriosis and the gynaecological controls only paraffin-embedded archival tissue was at our disposal, which is known to yield lower amounts of DNA of inferior quality compared to DNA isolated from blood or fresh tissue. Therefore, a nested PCR approach was used to obtain a higher sensitivity. We were able to successfully genotype 68/72 patients with deep infiltrating endometriosis and 91/95 gynecological controls. In the population control group DNA isolated from blood was used for analyses, and we were able to successfully genotype all 93 individuals in this group.

All PCR's were performed in a final volume of $20 \mu \mathrm{l}$, containing $100 \mathrm{ng}$ of genomic DNA, $50 \mathrm{nM}$ of each primer, $0.1 \mathrm{mM}$ of dNTP, 1 unit of Taq DNA polymerase and $1 \mathrm{x}$ buffer with $1.5 \mathrm{mM} \mathrm{MgCl}_{2}$. A summary of specific primers and cycling conditions is listed in Table 1. Upon digestion with Ddel (Promega) the $117 \mathrm{bp}$ fragment generated with the nested PCR contained one restriction site (generating two fragments of 72 and $45 \mathrm{bp}$ ) if derived from the most common allele $-509 \mathrm{C}$, and no restriction site (generating one fragment of $117 \mathrm{bp}$ ) if derived from the polymorphic allele -509T. Electrophoresis was performed with the use of a $3 \%$ agarose gel stained with Gelstar (Cambrex, ME, USA) for visualisation of the PCR products (Figure 1). 
Table 1 Primer sequences and conditions for determination of transforming growth factor $\beta 1$ gene polymorphism $-509 \mathrm{C} / \mathrm{T}$

\begin{tabular}{llccc}
\hline -509 C/T Forward & Reverse & $\begin{array}{c}\text { Annealing } \\
\text { temperature } \\
\left({ }^{\circ} \mathrm{C}\right)\end{array}$ & $\begin{array}{c}\text { No of } \\
\text { cycles }\end{array}$ & $\begin{array}{c}\text { Size of } \\
\text { amplicon } \\
(\mathrm{bp})\end{array}$ \\
\hline $\begin{array}{l}\text { Flank } \\
\text { primers }\end{array}$ & 5'GAGTGACAGGAGGCTGCTTAGC & $5{ }^{\prime}$ 'GTGTGGGTCACCAGAGAAAGAG & 55 & 188 \\
$\begin{array}{l}\text { Nested } \\
\text { primers }\end{array}$ & 5 'GGAGAGCAATTCTTACAGGTGTCT 5'CGAAAGGAGGGTCTGTCAACA & 55 & 35 & 117 \\
\hline
\end{tabular}

In all three groups only women of reproductive age were included (range: 20-50 years old). All samples were analyzed in duplo for both polymorphisms. In case of a discrepancy between the first and second result, the analysis was repeated. If the result remained inconclusive, the sample was omitted from the analysis.

\section{Statistical analysis}

Hardy-Weinberg equilibrium for the $-509 \mathrm{C} / \mathrm{T}$ polymorphism was assessed in each group by comparing the Pearson's goodness of fit with a chi square distribution with one degree of freedom (Institute of Human Genetics, Munich, Germany: http://www.ihg.gsf.de/). Allele and genotype frequencies were compared between groups using Fisher's exact test. The odds ratio (OR) was used to measure the strength of the association between the frequencies of allele and genotype and deep infiltrating endometriosis. Calculations were done using SPSS software (version 11.5). All P values were two-tailed and 95\% Cl's were calculated. A $P$ value $<0.05$ was considered to be statistically significant.

\section{Results}

The summarized TGF- $\beta 1$ genotyping data are presented in Table 2 . The genotype distribution for the $-509 \mathrm{C} / \mathrm{T}$ polymorphism did not differ from Hardy-Weinberg equilibrium in both patient and referent groups. Proportions of $-509 \mathrm{C} / \mathrm{C}$ homozygote, $509 \mathrm{C} / \mathrm{T}$ heterozygote and $-509 \mathrm{~T} / \mathrm{T}$ homozygote genotypes were $50.0 \%, 36.8 \%$ and $13.2 \%$ in the group of women with deep infiltrating endometriosis, $53.8 \%, 34.1 \%$ and $12.1 \%$ in gynecological controls and $44.1 \%, 47.3 \%$ and $8.6 \%$ in population controls. Frequencies for the most common allele $-509 \mathrm{C}$ and the polymorphic allele $-509 \mathrm{~T}$ were $68.4 \%$ and $31.6 \%$ in women with deep infiltrating endometriosis, $70.9 \%$ and $29.1 \%$ in gynecological controls and $67.7 \%$ and $32.3 \%$ in population controls. No statistically significant differences in allele or genotype frequencies were found between patients with deep infiltrating endometriosis and either control group. 


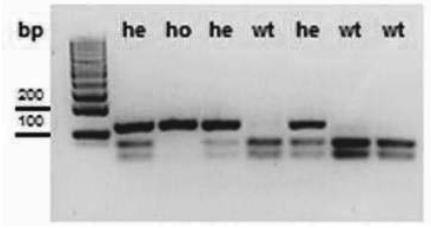

Figure 1 Restriction fragment length polymorphism analysis of the transforming growth factor beta1 gene polymorphism $-509 \mathrm{C} / \mathrm{T}$. wt: patient not carrying the $-509 \mathrm{~T}$ polymorphic allele $(-509 \mathrm{C} / \mathrm{C}$ individual); he: heterozygous -509T carrier (-509C/T individual) ; ho: homozygous -509T carrier (-509T/T individual)

\section{Discussion}

Deep infiltrating endometriosis is characterized by the existence of nodular lesions that are largely composed of fibromuscular tissue. In analogy to pathologic processes such as liver, kidney, and cardiac fibrosis, the establishment of deep infiltrating endometriotic lesions may also be regarded as a fibrotic phenomenon. Since the cytokine TGF- $\beta 1$ has long been recognized to be a central mediator in tissue fibrosis, it was hypothesized that the development of this type of lesions is associated with an increased fraction of biologically active TGF- $\beta 1$.

However, despite the fact that the $-509 \mathrm{C} / \mathrm{T}$ polymorphism of the TGF- $\beta 1$ gene is associated with a significant increase in TGF- $\beta 1$ serum concentration, in the present study we show that this polymorphism was not associated with an increased risk of deep infiltrating endometriosis. Our results contradict the ones of Hsieh et al. (23), who found an association between the presence of the -509T polymorphic allele and moderate/severe forms of endometriosis. It is known that in case of genetic association studies, one of the major problems causing false-negative results derives from an inadequate sample size, which leads to insufficient statistical power.

Table 2 Genotype and allele frequencies of the transforming growth factor $\beta 1$ gene polymorphism $-509 \mathrm{C} / \mathrm{T}$ in women with deep infiltrating endometriosis and controls

\begin{tabular}{|c|c|c|c|}
\hline$-509 \mathrm{C} / \mathrm{T}$ & $\begin{array}{c}\text { Deep infiltrating } \\
\text { endometriosis } \\
(n=68), n(\%)\end{array}$ & $\begin{array}{c}\text { Gynecological } \\
\text { controls } \\
(n=91), n(\%) \\
\end{array}$ & $\begin{array}{c}\text { Population controls } \\
(n=93), n(\%)\end{array}$ \\
\hline \multicolumn{4}{|l|}{ Genotypes } \\
\hline$-509 \mathrm{C} / \mathrm{C}$ & $34(50.0)$ & $49(53.8)$ & $41(44.1)$ \\
\hline$-509 \mathrm{C} / \mathrm{T}$ & $25(36.8)$ & 31 (34.1) & $44(47.3)$ \\
\hline$-509 \mathrm{~T} / \mathrm{T}$ & $9(13.2)$ & $11(12.1)$ & $8(8.6)$ \\
\hline$-509 \mathrm{C} / \mathrm{T}+\mathrm{TT}$ & $34(50.0)$ & $42(46.2)$ & $52(55.9)$ \\
\hline \multicolumn{4}{|l|}{ Alleles } \\
\hline$-509 C$ & $93(68.4)$ & $129(70.9)$ & $126(67.7)$ \\
\hline$-509 \mathrm{~T}$ & $43(31.6)$ & $53(29.1)$ & $60(32.3)$ \\
\hline
\end{tabular}

$\mathrm{n}=$ number of patients that could be genotyped successfully 
However, a power calculation reveals that the sample size used in the present study is sufficient to detect a potential increase in risk (Odds Ratio, OR) for polymorphic allelecarriers to develop the disease (in this case deep infiltrating endometriosis) of at least 2.8 with a statistical power of $80 \%$ and an $\alpha$ of 0.05 .Furthermore, when performing a power calculation based on the increase in risk found by Hsieh et al. (OR 3.6), statistical power rose to $95 \%$ at the $5 \%$ confidence level with the present sample size. It is therefore unlikely that the discrepancy between our results and the results obtained by the group of Hsieh is based on the sample size of the present study being too small. On the other hand, the study by Hsieh presents several major limitations, which lead us to suggest that their conclusions should be handled with caution. These authors found proportions of $\mathrm{C} / \mathrm{C}$ homozygote, $\mathrm{C} / \mathrm{T}$ heterozygote and $\mathrm{T} / \mathrm{T}$ homozygote genotypes of $49.3 \%, 61.3 \%$ and $29.4 \%$ in endometriosis patients and $1.3 \%, 58.5 \%$ and $0 \%$ in controls. These proportions deviate significantly from the Hardy-Weinberg equilibrium (HWE) in the control group. HWE includes a series of assumptions regarding the population tested, such as the largesize (i.e. no genetic drift should occur), the absence of new mutations, migration or natural selection, and the occurrence of random mating. Deviations from the HWE are due either to violation of these assumptions, indicating that the tested group is not representative of the general population, or may point to genotyping errors. Violation of the HWE in controls therefore lead to false genetic associations with a particular disease or pathological condition (24).

Another pitfall of this study is the selection of the control group. As stated by Zondervan and coworkers (25), appropriate selection of cases, and in particular of controls, is extremely important because this may have a profound effect on the results of candidate gene studies. In the study by Hsieh and coworkers, the authors reportedly confirmed the non-endometriosis status of their control group during either caesarean section or diagnostic laparoscopy. However, in this way one is very likely to miss deep infiltrating endometriotic lesions, as they are often not visible above the peritoneal surface. This is especially likely during caesarean section, when overview of the pelvis is impaired because of the enlarged uterus and sometimes large quantities of blood. Moreover, the progestagen-rich milieu provided by gestation may cause lesions that were present before pregnancy to substantially decrease in size, possibly to the extent that they are no longer visible at the time of (operative) delivery. It is therefore conceivable that the control group in this study was biased with respect to the occurrence of non-recognized endometriosis.

In order to minimize this type of bias, we included two control groups in the present study. The first one consisted of a well-defined group of gynecological patients without symptoms of endometriosis who underwent a hysterectomy for benign indications such as pelvic pain or heavy or irregular menstrual bleeding. Moreover, as recommended by Zondervan and coworkers (25), a second, general population-based control group consisting of healthy women of reproductive age was included in the study, as this group of women is the most representative of the source population from which cases were derived. In our opinion, the fact that we found no differences in the prevalence of the - 
509C/T polymorphism between patients with deep infiltrating endometriosis and either of the two control groups makes our results even more robust.

Finally, the study by Hsieh and coworkers (23) focused on patients with moderate/severe endometriosis according to the revised American Fertility Society criteria. However, this classification system is not particularly suitable for the purpose of defining the severity of endometriotic disease, since these criteria were principally developed to categorize women according to the probability of conceiving and do not correlate well with the presence of symptoms such as pelvic pain. Recently, Holt and Weiss have proposed a standard definition of definite (i.e. severe) and possible (i.e. less severe) endometriotic disease in order to render study results comparable between each other (26). In the present study, symptomatic women with histologically proven deep infiltrating endometriosis were included, which is in accordance with the criteria for definite disease as proposed by Holt and Weiss.

Although we did not find a significant association between the presence of the $-509 \mathrm{C} / \mathrm{T}$ polymorphism and deep infiltrating endometriosis, a possible role of TGF- $\beta 1$ and its overproduction in the pathogenesis of this disease entity cannot be excluded. A possible explanation could be that there is excess production of TGF- $\beta 1$ in these patients, but this takes place in the local peritoneal environment rather than in serum. TGF- $\beta 1$ is a major secretory product of macrophages and is detectable in peritoneal fluid. It has been shown that peritoneal fluid of women with endometriosis contains an increased number and activation of macrophages $(27,28)$. Endometriosis produces a localized inflammatory response. As a result, macrophages are attracted through chemotaxis and extravasate through small pores in the vessel wall into the peritoneal cavity where they perform their phagocytic and secretory functions. The higher number and activation of macrophages in the peritoneal cavity of women with endometriosis is likely to be accompanied by an increase in macrophage-derived cytokines such as TGF- $\beta 1$.

This contention is supported by the fact that three studies conducted on this subject consistently reported a significant increase of peritoneal fluid levels of TGF- $\beta 1$ in women with endometriosis compared to controls (19-21). However, it must be emphasized that the increased presence of macrophages and cytokines such as TGF- $\beta 1$ does not prove their involvement in the development and maintenance of endometriotic implants. These factors were investigated in women who had already developed endometriosis and may be therefore have been a consequence rather than a cause of the disease.

With respect to TGF- $\beta 1$ levels in serum of women with endometriosis, results are less equivocal. One study reported a significant increase of TGF- $\beta 1$ levels in women with endometriosis $(n=26)$ compared with controls $(n=5)(20)$. However, although the difference is statistically significant, these results should be handled with caution because of the disproportionally low number of controls compared to cases. Another study compared serum and peritoneal fluid levels of TGF- $\beta 1$ between women with deep infiltrating endometriosis and women with superficial endometriosis (29). The results did not show significant differences between the groups with respect to TGF- $\beta 1$ levels in 
blood or in peritoneal fluid. However, with a sample size too small to detect small but significant differences, this study was significantly underpowered. The question whether serum levels of TGF- $\beta 1$ are indeed elevated in women with endometriosis therefore cannot be answered conclusively.

In conclusion, we have shown that the presence of the TGF- $\beta 1$ gene polymorphism $-509 \mathrm{C} / \mathrm{T}$ is not associated with an increased risk of developing deep infiltrating endometriosis or adenomyosis in the uterine wall. Future research should be aimed at providing a more definite answer to the question if elevated levels of TGF- $\beta 1$ in serum or peritoneal fluid are in fact causally related to the presence of endometriosis, or if they represent a mere consequence of the disease. 


\section{References}

1. Vercellini P, Aimi G, Panazza S, Vicentini S, Pisacreta A, Crosignani PG. Deep endometriosis conundrum: evidence in favor of a peritoneal origin. Fertil Steril 2000;73:1043-6.

2. Koninckx PR, Martin DC. Deep endometriosis: a consequence of infiltration or retraction or possibly adenomyosis externa? Fertil Steril 1992;58:924-8.

3. Nisolle M, Donnez J. Peritoneal endometriosis, ovarian endometriosis, and adenomyotic nodules of the rectovaginal septum are three different entities. Fertil Steril 1997;68:585-96.

4. Cornillie FJ, Oosterlynck D, Lauweryns JM, Koninckx PR. Deeply infiltrating pelvic endometriosis: histology and clinical significance. Fertil Steril 1990;53:978-83.

5. Itoga T, Matsumoto T, Takeuchi H, Yamasaki S, Sasahara N, Hoshi T et al. Fibrosis and smooth muscle metaplasia in rectovaginal endometriosis. Pathol Int 2003;53:371-5.

6. Cramer DW, Hornstein MD, Ng WG, Barbieri RL. Endometriosis associated with the N314D mutation of galactose-1-phosphate uridyl transferase (GALT). Mol Hum Reprod 1996;2:149-52.

7. Georgiou I, Syrrou M, Bouba I, Dalkalitsis N, Paschopoulos M, Navrozoglou I et al. Association of estrogen receptor gene polymorphisms with endometriosis. Fertil Steril 1999;72:164-6.

8. Hadfield RM, Manek S, Weeks DE, Mardon HJ, Barlow DH, Kennedy SH. Linkage and association studies of the relationship between endometriosis and genes encoding the detoxification enzymes GSTM1, GSTT1 and CYP1A1. Mol Hum Reprod 2001;7:1073-8.

9. Nakago S, Hadfield RM, Zondervan KT, Mardon H, Manek S, Weeks DE et al. Association between endometriosis and $\mathrm{N}$-acetyl transferase 2 polymorphisms in a UK population. Mol Hum Reprod 2001;7:1079-83.

10. Vigano $P$, Infantino $M$, Lattuada D, Lauletta R, Ponti E, Somigliana E et al. Intercellular adhesion molecule-1 (ICAM-1) gene polymorphisms in endometriosis. Mol Hum Reprod 2003;9:47-52.

11. LeRoy EC, Trojanowska MI, Smith EA. Cytokines and human fibrosis. Eur Cytokine Network 1990;1:215-9.

12. Roberts $A B$. Transforming growth factor-beta: activity and efficacy in animal models of wound healing. Wound Repair Regen 1995;3:408-18.

13. Border WA, Noble NA. Transforming growth factor beta in tissue fibrosis. N Engl J Med 1994;331: 1286-92.

14. Broekelmann TJ, Limper AH, Colby TV, McDonald JA. Transforming growth factor beta 1 is present at sites of extracellular matrix gene expression in human pulmonary fibrosis. Proc Natl Acad Sci USA 1991;88: 6642-6.

15. Chegini N. The role of growth factors in peritoneal healing: transforming growth factor beta (TGF-beta). Eur J Surg Suppl 1997:17-23.

16. Lin RY, Sullivan KM, Argenta PA, Meuli M, Lorenz HP, Adzick NS. Exogenous transforming growth factorbeta amplifies its own expression and induces scar formation in a model of human fetal skin repair. Ann Surg 1995;222:146-54.

17. Shah M, Foreman DM, Ferguson MW. Neutralisation of TGF-beta 1 and TGF-beta 2 or exogenous addition of TGF-beta 3 to cutaneous rat wounds reduces scarring. J Cell Sci 1995;108:985-1002.

18. Lucas PA, Warejcka DJ, Young HE, Lee BY. Formation of abdominal adhesions is inhibited by antibodies to transforming growth factor-beta1. J Surg Res 1996;65:135-8.

19. Oosterlynck DJ, Meuleman C, Waer M, Koninckx PR. Transforming growth factor-beta activity is increased in peritoneal fluid from women with endometriosis. Obstet Gynecol 1994;83:287-92.

20. Pizzo A, Salmeri FM, Ardita FV, Sofo V, Tripepi M, Marsico S. Behaviour of cytokine levels in serum and peritoneal fluid of women with endometriosis. Gynecol Obstet Invest 2002;54:82-7.

21. Kyama CM, Overbergh L, Debrock S, Valckx D, Vander Perre S, Meuleman C et al. Increased peritoneal and endometrial gene expression of biologically relevant cytokines and growth factors during the menstrual phase in women with endometriosis. Fertil Steril 2006;85:1667-75.

22. Grainger DJ, Heathcote K, Chiano M, Snieder H, Kemp PR, Metcalfe JC et al. Genetic control of the circulating concentration of transforming growth factor type beta1. Hum Mol Genet 1999;8:93-7.

23. Hsieh YY, Chang CC, Tsai FJ, Peng CT, Yeh LS, Lin CC. Polymorphism for transforming growth factor beta 1509 (TGF-B1-509): association with endometriosis. Biochem Genet 2005;43:203-10.

24. Trikalinos TA, Salanti G, Khoury MJ, Ioannidis JP. Impact of violations and deviations in Hardy-Weinberg equilibrium on postulated gene-disease associations. Am J Epidemiol 2006;163:300-9. 
25. Zondervan KT, Cardon LR, Kennedy SH. What makes a good case-control study? Design issues for complex traits such as endometriosis. Hum Reprod 2002;17:1415-23.

26. Holt VL, Weiss NS. Recommendations for the design of epidemiologic studies of endometriosis. Epidemiology 2000;11:654-9.

27. Dunselman GA, Hendrix MG, Bouckaert PX, Evers JL. Functional aspects of peritoneal macrophages in endometriosis of women. J Reprod Fertil 1988;82:707-10.

28. Oral E, Olive DL, Arici A. The peritoneal environment in endometriosis. Hum Reprod Update 1996;2:385-98.

29. D'Hooghe TM, Xiao L, Hill JA. Cytokine profiles in autologous peritoneal fluid and peripheral blood of women with deep and superficial endometriosis. Arch Gynecol Obstet 2001;265:40-4. 


\section{Chapter 4}

Progesterone receptor polymorphism +331G/A is associated with a decreased risk of deep infiltrating endometriosis

KJAF van Kaam, A Romano, JP Schouten, GAJ Dunselman, PG Groothuis Human Reproduction 2007;22:129-35 


\section{Abstract}

\section{Background}

Alterations in the progesterone receptor (PR) are considered a risk factor for the development of endometriosis. In this study the frequencies of the PROGINS and +331G/A polymorphisms of the PR gene were determined in deep infiltrating endometriosis, and correlated with the expression of the PR protein.

\section{Methods and results}

The frequencies of the PR polymorphisms were determined in women with deep infiltrating endometriosis $(n=72)$, women with adenomyosis in the uterine wall $(n=40)$, gynecological patients without symptomatic endometriosis $(n=102)$ and healthy females $(n=93)$. Detection of $+331 \mathrm{G} / \mathrm{A}$ and PROGINS polymorphisms was performed using PCRrestriction fragment length polymorphism (RFLP) analysis. Expression of PR-A and PR-B protein was assessed with immunohistochemistry. The allelic frequency of the polymorphic allele $+331 \mathrm{~A}$ was lower in women with endometriosis $(p<0.01)$ and adenomyosis $(p<0.02)$ compared with healthy females. The frequency of the PROGINS polymorphism did not differ between the groups. The mean staining index (SI) for PR-B in endometriotic epithelium was higher in the presence of the $+331 \mathrm{~A}$ polymorphic allele $(n=2)(p<0.001)$ compared to $+331 G / G$ individuals. The PROGINS polymorphism did not affect the SI for PR-A and PR-B.

\section{Conclusions}

The presence of the PR gene polymorphic allele $+331 \mathrm{~A}$ is associated with a reduced risk of deep infiltrating endometriosis and adenomyosis. The PROGINS polymorphism does not seem to modify the risk of deep infiltrating endometriosis. 


\section{Introduction}

Endometriosis is one of the most commonly encountered benign problems in gynecology. Women with symptomatic endometriosis suffer from dysmenorrhea, dyspareunia, chronic pelvic pain and/or subfertility. Past research indicates that a combination of immunologic, genetic, anatomic and hormonal factors contribute to a woman's susceptibility to the development of endometriosis. Regarding the pathogenesis of this disease Sampson's retrograde transplantation theory is the most widely accepted, which implies that there is reflux of viable endometrial fragments through the fallopian tubes during menstruation, with subsequent adhesion, implantation and growth on and into the peritoneum (1). It has been argued that all women with patent tubes develop asymptomatic peritoneal endometriosis to a certain extent during their lifetime (2). However, Sampson's theory does not explain why only in a minority of women retrograde menstruation results in the development of symptomatic endometriosis. Endometriosis has long been recognized as having heritable tendencies and is considered a polygenic disease with a multifactorial etiology (3-6). Genetic association studies have been performed for a number of candidate genes potentially involved in the pathogenesis of endometriosis (7-11). However, so far results have been inconsistent.

A gene of specific interest within this context is the progesterone receptor (PR) gene. Progesterone is a potent antagonist of estrogen-induced proliferation in the endometrium and as such may play a pivotal role in the pathogenesis of endometriosis. The actions of progesterone are mediated by two functionally distinct receptor isoforms, PR-A and PR-B, which are expressed from a single gene as a result of transcription from two alternative promoters (12). The PR-A and PR-B isoforms are ligand-dependent members of the nuclear receptor family that are structurally identical, except for an additional 164 amino acids at the amino terminal of PR-B $(13,14)$. This region encodes a transactivation function that is specific to PR-B and is required to specify target genes that can be activated by PR$B$ but not PR-A (15). The ability of either PR-A or PR-B to activate transcription of progesterone target genes may be important in the pathogenesis of endometriosis. PR-B functions as a stronger transcriptional activator of progesterone target genes, whereas PR$A$ is a transcriptionally inactive dominant repressor of steroid hormone transcription activity that is thought to decrease the response to estrogen (16). Furthermore, the responses of ligand-activated PR-A and PR-B strongly depend on the cellular context. Hence, the anti-proliferative effects of progesterone depend on a tight regulation of the PR-A and PR-B isoform balance. Therefore, the hypothesis was made that DNA polymorphisms altering the activity of the protein or altering the PR-A to PR-B ratio may lead to unopposed estrogen action and therefore to an increased risk of developing endometriosis.

The PROGINS polymorphism of the progesterone receptor gene has been shown to be associated with endometriosis in previous studies $(17,18)$. This polymorphism consists of a $320 \mathrm{bp} \mathrm{PV/HS} \mathrm{-1} \mathrm{Alu} \mathrm{insertion} \mathrm{in} \mathrm{intron} \mathrm{G,} \mathrm{a} \mathrm{silent} \mathrm{point} \mathrm{mutation} \mathrm{in} \mathrm{exon} 5(\mathrm{H} 770 \mathrm{H})$, and 
a single amino acid change in exon 4 (V660L) (19). The functional consequences of the PROGINS polymorphism are not yet fully understood and are still a subject of investigation.

The $+331 \mathrm{G} / \mathrm{A}$ polymorphism is located in the promoter region of the PR-gene and gives rise to an increased synthesis of PR-B by generating an additional TATA-box, thereby altering the PR-A to PR-B ratio (20). This polymorphism has not been investigated before with respect to the risk of developing endometriosis.

Deep infiltrating endometriosis, for example in the rectovaginal space, histologically closely resembles adenomyosis in the uterine wall. This might imply that the pathogenesis of these two entities is similar. In order to ascertain if the presence of the PROGINS polymorphism or the $+331 \mathrm{G} / \mathrm{A}$ polymorphism contributes to the risk of developing these subtypes of endometriosis, we investigated the prevalence of these polymorphisms in women with deep infiltrating endometriosis and women with adenomyosis in the uterine wall. The prevalence of these polymorphisms in two groups of women without symptomatic endometriosis served as control. In addition to this, we determined the expression levels of PR-A and PR-B in endometriotic lesions by immunohistochemistry in relation to the presence of either polymorphism.

\section{Materials and Methods}

\section{Patients and tissue specimens}

Patients with a surgical and histological diagnosis of deep infiltrating endometriosis who were operated between 1998 and 2004 in the University Hospital of Maastricht $(n=72)$ were included in the study. Deep infiltrating endometriosis was defined as the presence of one or more deep infiltrating lesions in the bowel wall, vaginal wall, bladder wall and/or rectovaginal septum. Patients with adenomyosis in the uterine wall $(n=40)$ were selected from the Dutch National Pathology Database (PALGA). The first control group consisted of gynecological patients without symptoms of endometriosis who underwent a hysterectomy for benign indications such as prolapse, pelvic pain or menstrual cycle disorders (gynecological controls, $n=102$ ). Patients with uterine fibroids and postmenopausal women were excluded from this group. A second group of controls was taken from a DNA-control panel derived from female subjects who had been referred to the Clinical Genetics department for molecular testing of various disease genes. Only subjects that were tested negative for these diseases were included in the control panel, as they can be regarded as healthy, random controls (population controls, $n=93$ ). Both patients and controls originated from the same geographic region of the Netherlands. 


\section{DNA isolation}

In patients with deep infiltrating endometriosis, adenomyosis in the uterine wall and the gynecological control group the analyses were performed on DNA isolated from paraffinembedded archival tissue. After reviewing all paraffin-embedded tissue specimens for the presence of endometriotic and/or adenomyotic lesions, five consecutive sections of $20 \mu \mathrm{m}$ were cut from each tissue sample. Genomic DNA isolation was performed using proteinase K (Qiagen, Hilde, Germany) digestion in combination with the Puregene DNA Isolation Kit (Gentra Systems, Minneapolis, MN, USA), following the recommendations of the manufacturer.

The analyses of the population control group were performed on DNA isolated from blood. Genomic DNA was isolated from $8 \mathrm{ml}$ whole blood (EDTA tubes) using the Wizard Genomic DNA Purification Kit (Promega, Leiden, the Netherlands) following the manufacturer's protocol.

\section{PROGINS and +331G/A detection}

Detection of both polymorphisms was performed using restriction fragment length polymorphism (RFLP) analysis. From the patients with deep infiltrating endometriosis, adenomyosis and the gynecological controls only paraffin-embedded archival tissue was at our disposal, which is known to yield lower amounts of DNA of inferior quality compared to DNA isolated from blood or fresh tissue. Therefore, a nested PCR approach, previously described and validated by Pijnenborg and coworkers, was used to obtain a higher sensitivity (21). We were able to successfully genotype 65/72 patients with deep infiltrating endometriosis, 38/40 patients with adenomyosis and 101/102 gynecological controls for the PROGINS polymorphism. For the $+331 \mathrm{G} / \mathrm{A}$ polymorphism, 65/72 patients with deep infiltrating endometriosis, 39/40 patients with adenomyosis and 91/102 of gynecological controls were genotyped successfully. In the population control group DNA isolated from blood was used for analyses, and we were able to successfully genotype all 93 individuals in this group for both polymorphisms.

For detection of the PROGINS polymorphism, samples were analyzed for the V660L mutation in exon 4. Upon digestion with Brsl (isoschizomer BrsSI, Promega) the $138 \mathrm{bp}$ PCR fragment was cut in three bands $(95,23$ and $20 \mathrm{bp})$ in case of the V660 allele (indicated as T1 allele), or only two bands (115 and $23 \mathrm{bp}$ ) in case of the PROGINS allele (indicated as T2 allele). Electrophoresis was performed with the use of a $3 \%$ agarose gel stained with Gelstar (Cambrex, ME, USA) prior to casting for visualisation of the PCR products (Figure 1). A similar approach was used for detection of the $+331 \mathrm{G} / \mathrm{A}$ polymorphism. The $206 \mathrm{bp}$ fragment amplified by PCR was digested by NlaIV (isoschizomer BspLI, Fermentas) generating two bands (149 and $57 \mathrm{bp}$ ) in case of the most common allele $(+331 \mathrm{G})$ or one band $(206 \mathrm{bp})$ in case of the polymorphic allele $(+331 \mathrm{~A})$. The obtained digestion products were loaded on a $2 \%$ agarose gel stained with Gelstar (Cambrex, ME, USA) for electrophoresis (Figure 2). All PCRs were performed in a volume of 
$20 \mu \mathrm{l}$ containing $100 \mathrm{ng}$ of genomic DNA, $50 \mathrm{nM}$ of each primer, $0.1 \mathrm{mM}$ of each dNTP, 1 unit of Taq DNA polymerase (Qiagen, Hilden, Germany), and $1 \mathrm{x}$ buffer with $2.5 \mathrm{mM} \mathrm{MgCl}$. In all four groups only women of reproductive age were included (range: 20-50 years old). All samples were analyzed in duplo for both polymorphisms. In case of a discrepancy between the first and second result, the analysis was repeated. If the result remained inconclusive, the sample was omitted from the analysis.

\section{Immunohistochemistry}

The PgR636 mouse monoclonal antibody (DAKO, Copenhagen, Denmark) was used to detect PR-A and PR-B, the B30 mouse monoclonal antibody (Santa Cruz Biotechnology, California, USA) was used for specific detection of PR-B. Paraffin embedded lesions of patients with deep infiltrating endometriosis or adenomyosis in the uterine wall were sectioned $(5 \mu \mathrm{m})$ and fixed on Starfrost adhesive slides (Klinipath, Duiven, the Netherlands). Sections were deparaffinized in xylene and rehydrated in alcohol series prior to blocking endogenous peroxidase activity by incubation with $3 \%$ hydrogen peroxide/methanol for $20 \mathrm{~min}$. After rinsing three times with phosphate-buffered saline (PBS, pH 7.2), antigen retrieval was performed (Tris-EDTA, pH 9.0; microwave treatment: $20 \mathrm{~min}$ at $650 \mathrm{~W})$. Sections were cooled down to room temperature and washed again three times in PBS followed by incubation with the primary antibody (room temperature, $2 \mathrm{~h}$ ). After three PBS rinses, sections were exposed to the secondary antibody (Envision rabbit anti-mouse, ChemMate ${ }^{\mathrm{TM}}$ detection kit, DAKO, Copenhagen, Denmark) for $30 \mathrm{~min}$ at room temperature. Antibody binding was visualized using 3, 3' -diaminobenzidine. Sections were counterstained mildly with hematoxylin, dehydrated and mounted in Entellan for light microscopy.

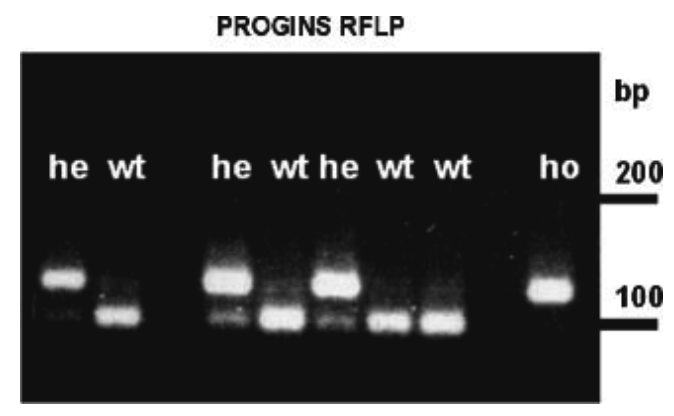

Figure 1 Restriction fragment length polymorphism analysis of the V660L mutation in exon 4 of the PROGINS complex of aberrations. wt: patient not carrying the PROGINS polymorphic allele (T1/T1 individual); he: heterozygous PROGINS carrier (T1/T2 individual) ; ho: homozygous PROGINS carrier (T2/T2 individual). 
331 GIA polymorphism-NIalV

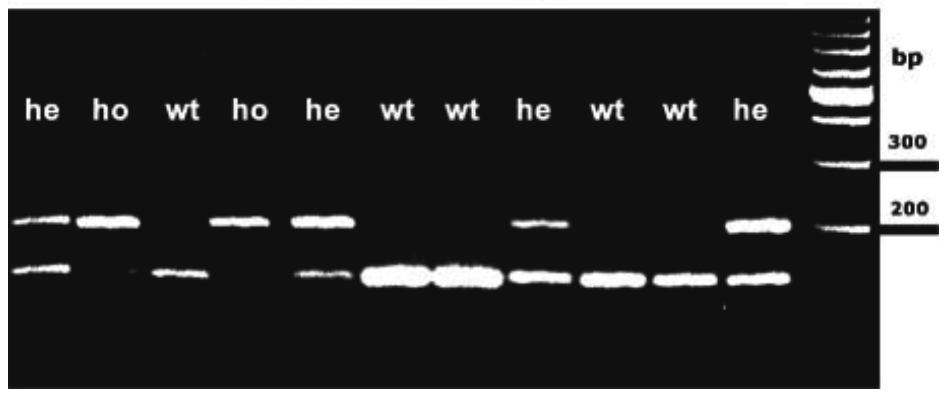

Figure 2 Restriction fragment length polymorphism analysis of the $+331 \mathrm{G} / \mathrm{A}$ polymorphism. wt: patient not carrying the $+331 \mathrm{~A}$ polymorphic allele (+331G/G individual). he: heterozygous $+331 \mathrm{~A}$ carrier $(+331 \mathrm{G} / \mathrm{A}$ individual); ho: homozygous $+331 \mathrm{~A}$ carrier (+331A/A individual)

\section{Evaluation of immunostaining in endometriotic tissues}

The percentage of stained endometrial stromal and epithelial cells $(0,0-10,10-50,>50 \%)$ and the intensity of staining (absent, weak, moderate, strong) were determined $(0,1,2$ or 3 for each variable) for the entire lesion. A staining index (SI, ranging from 0 to 9) was calculated for both the epithelial and stromal fraction of endometriotic lesions by multiplying categorized parameters. Two different observers (P.G.G. and K.v.K.) performed evaluation of immunostaining in a blinded fashion and independently. Both observers scored the sections once. The mean of these two observations was used for analyses.

\section{Statistical analysis}

Hardy-Weinberg equilibrium for the two polymorphisms was assessed in each group by comparing the Pearson's goodness of fit with a chi square distribution with one degree of freedom (Institute of Human Genetics, Munich, Germany: http://www.ing.gsf.de/). Allele and genotype frequencies were compared between groups using Fisher's exact test. The odds ratio (OR) was used to measure the strength of the association between the frequencies of allele and genotype and deep infiltrating endometriosis.

The difference in PR-A and PR-B expression between patients with the +331G/A or PROGINS polymorphism and women without either polymorphism was determined by using a two-sample t-test with separate variance estimates. Calculations were done using SPSS software (version 11.5). All $P$ values were two-tailed and $95 \% \mathrm{Cl}$ 's were calculated. $P<0.05$ was considered to be statistically significant. 


\section{Results}

\section{PROGINS}

Results are summarized in Table 1 and 2 . The allele T1 homozygote (T1/T1) was the dominating genotype in the group of women with deep infiltrating endometriosis $(66.2 \%)$ (Table 1 ), in the group of women with adenomyosis in the uterine wall $(71.1 \%)$, the gynecological control group (73.3\%) and the population control group (71.0\%). The overall frequency of the PROGINS complex of genomic alterations (T1/T2, heterozygote $+T 2 / T 2$, homozygote) was $33.8 \%$ in the group of women with deep infiltrating endometriosis, $28.9 \%$ in women with adenomyosis in the uterine wall, $26.7 \%$ in the gynecological control group and $29.0 \%$ in the population control group. The T2/T2 homozygous PROGINS genotype was found in $4.2 \%$ of women with severe endometriosis, $5.3 \%$ of women with adenomyosis, $1 \%$ of women in the gynecological control group and $3.2 \%$ of women in the population control group. None of the observed differences were statistically significant.

Table 1 Genotype and allele frequencies of the PROGINS polymorphism in women with deep infiltrating endometriosis, women with adenomyosis and controls

\begin{tabular}{lcccc}
\hline PROGINS & $\begin{array}{c}\text { Deep infiltrating } \\
\text { endometriosis }(n=65)\end{array}$ & $\begin{array}{c}\text { Adenomyosis } \\
(n=38)\end{array}$ & $\begin{array}{c}\text { Gynecological } \\
\text { controls } \\
(n=101)\end{array}$ & $\begin{array}{c}\text { Population } \\
\text { controls } \\
(n=93)\end{array}$ \\
\hline Genotypes & $46(66.2 \%)$ & $27(71.1 \%)$ & $74(73.3 \%)$ & $66(71.0 \%)$ \\
T1/T1 & $21(29.6 \%)$ & $9(23.7 \%)$ & $26(25.7 \%)$ & $24(25.8 \%)$ \\
T1/T2 & $3(4.2 \%)$ & $2(5.3 \%)$ & $1(1.0 \%)$ & $3(3.2 \%)$ \\
T2/T2 & $24(33.8 \%)$ & $11(28.9 \%)$ & $27(26.7 \%)$ & $27(29.0 \%)$ \\
T1/T2 + T2/T2 & & & & $156(83.9 \%)$ \\
Alleles & $113(81.0 \%)$ & $63(82.9 \%)$ & $174(86.1 \%)$ & $30(16.1 \%)$ \\
T1 & $27(19.0 \%)$ & $13(17.1 \%)$ & $28(13.9 \%)$ & \\
T2 & & & & \\
\hline
\end{tabular}

$\mathrm{n}=$ number of patients that could be genotyped successfully

Table 2 Presence of polymorphic allele PROGINS and risk of deep infiltrating endometriosis and adenomyosis

\begin{tabular}{lccc}
\hline & OR & $95 \% \mathrm{Cl}$ & $P$-value \\
\hline Deep infiltrating endometriosis versus population controls & 1.24 & $0.70-2.21$ & 0.47 \\
Deep infiltrating endometriosis versus gynecological controls & 1.49 & $0.83-2.65$ & 0.18 \\
Adenomyosis versus population controls & 1.07 & $0.53-2.19$ & 0.86 \\
Adenomyosis versus gynecological controls & 1.28 & $0.63-2.63$ & 0.57 \\
\hline
\end{tabular}

OR: odds ratio; $95 \% \mathrm{Cl}$ : $95 \%$ confidence interval 


\section{$+331 \mathrm{G} / \mathrm{A}$}

Results are summarized in Tables 3 and 4 . The percentage of women carrying the $+331 \mathrm{~A}$ polymorphic allele was lower in patients with deep infiltrating endometriosis $(3.0 \%)$ and adenomyosis $(2.6 \%)$ than in the gynecological control group $(8.8 \%)$ and the population control group (18.3\%). The presence of the polymorphic allele $+331 \mathrm{~A}$ was associated with a significant reduction of the risk of having the disease phenotype in women with deep infiltrating endometriosis (OR $0.22 ; 95 \% \mathrm{Cl} 0.06-0.77, P<0.01$ ) and adenomyosis (OR 0.12 , $95 \% \mathrm{Cl}$ 0.02-0.95, $P<0.02)$ compared with women from the population control group. Compared with gynecological controls, statistical significance was not reached. There was no significant difference in the distribution of the $+331 \mathrm{G} / \mathrm{A}$ polymorphism between women with adenomyosis and women with deep infiltrating endometriosis. There was one homozygous +331G/A carrier in the group of women with deep infiltrating endometriosis and one in the population control group. In the other two groups no homozygous $+331 \mathrm{G} / \mathrm{A}$ carriers could be observed.

Table 3 Genotype and allele frequencies of the $+331 \mathrm{G} / \mathrm{A}$ polymorphism in women with deep infiltrating endometriosis, women with adenomyosis and controls

\begin{tabular}{ccccc}
\hline$+331 \mathrm{G} / \mathrm{A}$ & $\begin{array}{c}\text { Deep infiltrating } \\
\text { endometriosis }(\mathrm{n}=65)\end{array}$ & $\begin{array}{c}\text { Adenomyosis } \\
(\mathrm{n}=38)\end{array}$ & $\begin{array}{c}\text { Gynecological } \\
\text { controls } \\
(\mathrm{n}=91)\end{array}$ & $\begin{array}{c}\text { Population } \\
\text { controls } \\
(\mathrm{n}=93)\end{array}$ \\
\hline $\begin{array}{c}\text { Genotypes } \\
\text { +331G/G }\end{array}$ & $63(96.9 \%)$ & $37(94.6 \%)$ & $83(91.2 \%)$ & $76(81.7 \%)$ \\
+331G/A & $1(1.5 \%)^{3}$ & $1(2.6 \%)^{1}$ & $8(8.8 \%)$ & $16(17.2 \%)$ \\
+331A/A & $1(1.5 \%)$ & $0(0.0 \%)$ & $0(0.0 \%)$ & $1(1.1 \%)$ \\
+331G/A + A/A & $2(3.0 \%)$ & $1(2.6 \%)$ & $8(8.8 \%)$ & $17(18.3 \%)$ \\
Alleles & & & & $168(90.3 \%)$ \\
+331G & $127(97.7 \%)$ & $75(98.7 \%)$ & $174(95.6 \%)$ & $18(9.7 \%)$ \\
+331A & $3(2.3 \%)^{2}$ & $1(1.3 \%)^{1}$ & $8(4.4 \%)$ & \\
\hline
\end{tabular}

$\mathrm{n}=$ number of patients that could be genotyped successfully. $1=P<0.05$ compared to population controls $2=P<0.01$ compared to population controls; $3=P<0.001$ compared to population controls

Table 4 Presence of polymorphic allele $+331 \mathrm{~A}$ and risk of deep infiltrating endometriosis and adenomyosis

\begin{tabular}{lccc}
\hline & OR & $95 \% \mathrm{Cl}$ & $P$-value \\
\hline Deep infiltrating endometriosis versus population controls & 0.22 & $0.06-0.77$ & 0.01 \\
Deep infiltrating endometriosis versus gynecological controls & 0.51 & $0.13-1.98$ & 0.37 \\
Adenomyosis versus population controls & 0.12 & $0.02-0.95$ & 0.02 \\
Adenomyosis versus gynecological controls & 0.29 & $0.04-2.36$ & 0.29 \\
\hline
\end{tabular}

OR: odds ratio; $95 \% \mathrm{Cl}$ : $95 \%$ confidence interval 


\section{Immunohistochemistry}

Immunohistochemical staining could be performed on 61/69 lesions from women without either polymorphism, 31/35 lesions of women with the PROGINS polymorphism and 2/3 lesions from women with the $+331 \mathrm{~A}$ polymorphic allele. Photographs of representative PR-A/B and PR-B staining are shown in Figures $3 A-C$. The overall level of PR-B expression was low in all three groups. In most endometriotic lesions, no staining was observed. Strong staining with the PgR636 antibody is therefore related to the presence of PR-A.

\section{PR-A/B}

Results are summarized in Figure 4A. The presence of the PROGINS polymorphic allele (T2) did not affect the SI for PR-A/B in endometrial epithelium $(5.6 \pm 2.7$ in PROGINS carriers versus $5.5 \pm 3.1$ in T1/T1 individuals) or stroma $(5.4 \pm 2.2$ in PROGINS carriers versus $5.3 \pm$ 2.5 in T1/T1 individuals). The expression of PR-A/B in the stromal fraction of endometriotic lesions in patients carrying the $+331 \mathrm{~A}$ polymorphic allele $(\mathrm{SI}=6.4 \pm 3.0)$ did not differ significantly from that in $+331 \mathrm{G} / \mathrm{G}$ patients $(\mathrm{SI}=5.3 \pm 2.5$ ). There also was no significant difference in the expression of PR-A/B in the epithelium of endometriotic lesions between patients carrying the $+331 \mathrm{~A}$ allele $(\mathrm{SI}=3.8 \pm 3.8)$ and $+331 \mathrm{G} / \mathrm{G}$ patients $(\mathrm{SI}=5.5 \pm 3.1)$.

\section{Non-carriers}

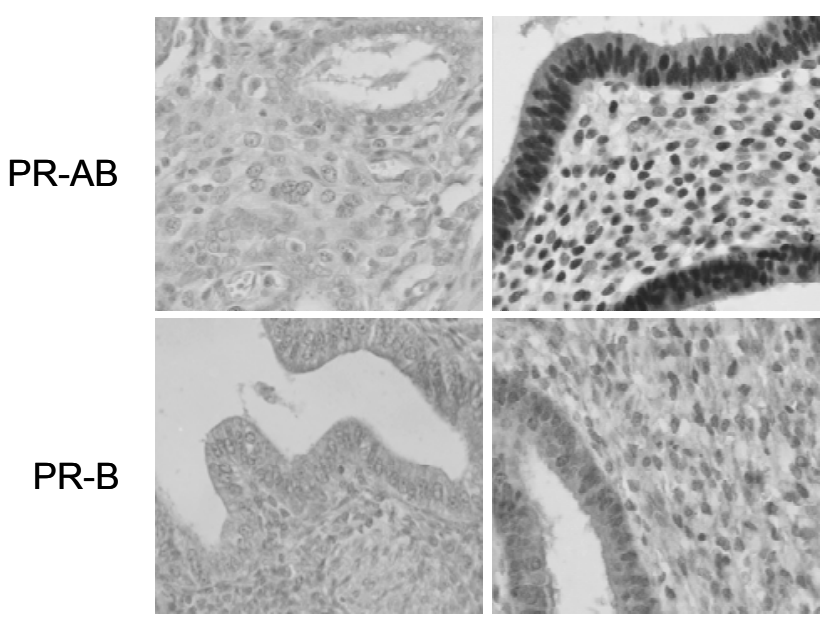

Figure 3A Representative examples of heterogeneous expression of PR-A/B and PR-B protein in endometriotic lesions in non-carriers (patients carrying neither the $+331 \mathrm{~A}$ nor the PROGINS polymorphic allele). (For color figure see page 151) 


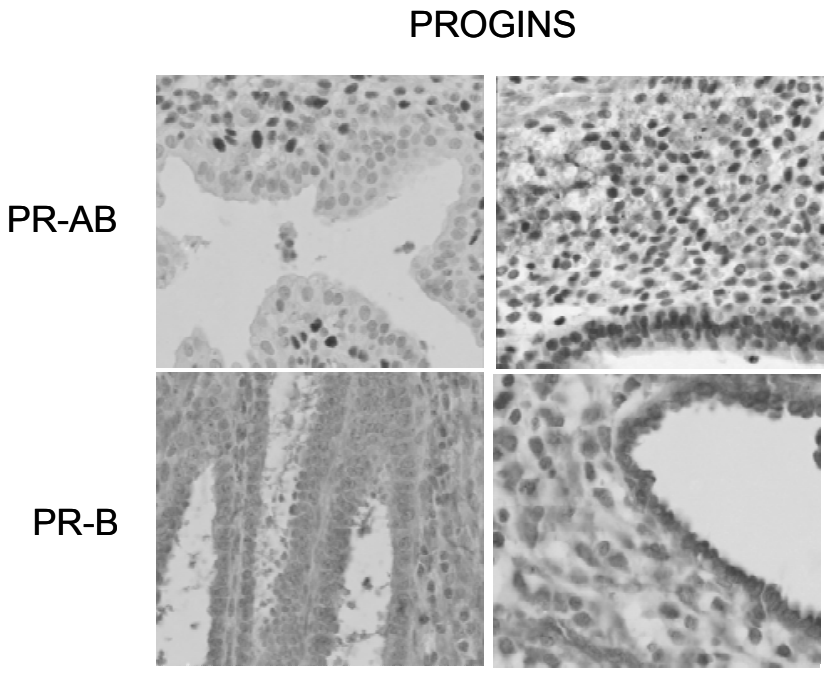

Figure 3B Representative examples of heterogeneous expression of PR-A/B and PR-B protein in endometriotic lesions in patients carrying the PROGINS polymorphic allele. The left panel shows weak expression of PR-A/B and PR-B, whereas the right panel shows strong expression. (For color figure see page 151)

$+331 \mathrm{GA}$

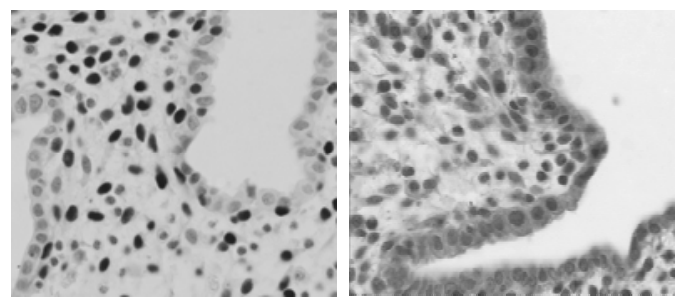

PR-AB

PR-B

Figure $3 C$ Representative examples of strong staining for PR-A/B and PR-B in endometriotic lesions of patients carrying the $+331 \mathrm{~A}$ polymorphic allele. (For color figure see page 152)

\section{PR-B}

Results are summarized in Figure 4B. There was no difference in mean SI for PR-B in endometriotic epithelium ( $\mathrm{Sl}=0.2 \pm 0.4$ versus $0.2 \pm 0.5$ ) or stroma $(\mathrm{SI}=0.4 \pm 0.6$ versus 0.3 $\pm 0.5)$ between PROGINS-carriers ( $\mathrm{T} 1 / \mathrm{T} 2+\mathrm{T} 2 / \mathrm{T} 2)$ and $\mathrm{T} 1 / \mathrm{T} 1$ individuals. The mean $\mathrm{SI}$ for $\mathrm{PR}-\mathrm{B}$ in endometriotic epithelium was significantly higher in the presence of the $+331 \mathrm{~A}$ polymorphic allele $(\mathrm{Sl}=2.0 \pm 0$ in $+331 \mathrm{~A}$ carriers versus $0.3 \pm 0.5$ in $+331 \mathrm{G} / \mathrm{G}$ patients, $P<0.001)$. There was no significant difference in mean staining index for PR-B in 
endometriotic stroma between $+331 \mathrm{~A}$ carriers and $+331 \mathrm{G} / \mathrm{G}$ individuals $(\mathrm{SI}=1.5 \pm 0.7$ vs. $0.3 \pm 0.5)$.

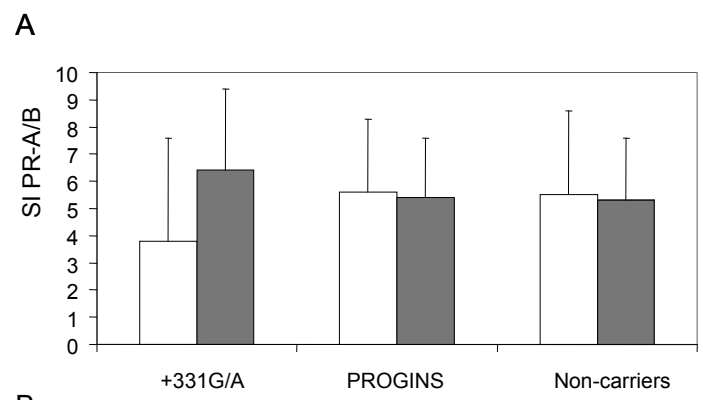

B

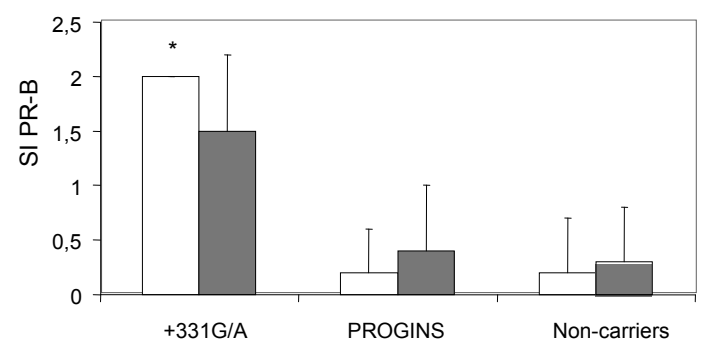

Figure 4 Staining indices (SI) for (A) PR-A/B and (B) PR-B protein expression in endometriotic lesions.

$+331 \mathrm{G} / \mathrm{A}$ : patients carrying the $+331 \mathrm{~A}$ polymorphic allele $(+331 \mathrm{G} / \mathrm{A}$, heterozygous and $+331 \mathrm{~A} / \mathrm{A}$, homozygous). PROGINS: patients carrying the PROGINS polymorphic allele (T1/T2, heterozygous and T2/T2, homozygous). Noncarriers: patients carrying neither the $+331 \mathrm{~A}$ nor the PROGINS polymorphic allele (+331G/G and T1/T1 individuals). Results are shown for glandular epithelium (white bars) and stroma (striped bars) separately, and are presented as mean \pm SD. $* p<0.001$ compared with non-carriers.

\section{Discussion}

Endometriosis is an estrogen-dependent disease and an adequate response to progesterone in the endometrium is required to antagonize estrogen-dependent proliferation. Structurally and functionally intact PRs are essential to mediate the antiproliferative effects of progesterone on the growth of endometriotic tissue (22).

Aberrations in the PR gene, such as DNA polymorphisms, may cause a diminished response to physiological levels of progesterone and may therefore lead to an increased risk of developing endometriosis. However, in the present study we show that the PROGINS polymorphism was not associated with an increased risk of deep infiltrating endometriosis or adenomyosis in the uterine wall. Interestingly, the presence of the $+331 \mathrm{~A}$ polymorphic allele was shown to be associated with a statistically significant 
decrease in risk of deep infiltrating disease and adenomyosis in the uterine wall, which is suggestive of a protective effect. Furthermore, the frequencies of both polymorphisms in women with adenomyosis in the uterine wall did not differ significantly from the frequencies observed in women with deep infiltrating endometriosis. This supports the contention that, based on histological criteria, endometriotic nodules of the rectovaginal septum and adenomyosis of the uterine wall are similar entities (23).

To this date, three studies have been carried out on the relationship between the presence of PROGINS and the risk of developing endometriosis. In two studies a statistically significant association between PROGINS and endometriosis was found (17, 18). However, findings in the third study agreed with our results and failed to provide support for an association between the PROGINS allele and endometriosis (24). Even though we detected a higher frequency of the PROGINS T2 allele in women with deep infiltrating endometriosis compared to gynecological and population controls, statistical significance was not reached. It is not surprising that conflicting results are published in genetic association studies. loannidis and coworkers have shown that only $16 \%$ of genetic associations identified were subsequently replicated with formal statistical significance (25). He also showed that in a large number of genetic associations a differential magnitude of effect was noted in large versus small studies. Moreover, results from first studies frequently differed significantly from the results of subsequent research, to the extent that large studies and subsequent research suggested weak associations or no association at all, compared with strong associations proposed by smaller studies and first research.

The relative expression of PR-A and PR-B is considered to be of great importance for an adequate response to progesterone and, as a result, for normal reproductive tissue functioning. Eutopic endometrium was shown to express both PR-A and PR-B isoforms, whereas in simultaneously biopsied peritoneal endometriotic tissue from the same patient PR-A, but not PR-B was detectable (26). The absence of PR-B conceivably leads to a perturbation of the PR-A to PR-B ratio in endometriotic implants, rendering this tissue less responsive to the anti-proliferative effects of progesterone.

In previous research, the PROGINS polymorphism was shown to increase transcriptional activity of the progesterone receptor, due to increased stability and increased half-life of both PR-A and PR-B isoforms (27). Whether this has any functional consequences for the progesterone receptor remains unclear. Expression levels of PR-A and PR-B are probably not affected, as we did not see a consistent increase in the expression of PR-A and PR-B in endometriotic tissues from women bearing the PROGINS allele.

Past research has shown that the $+331 \mathrm{~A}$ polymorphic allele creates a unique transcription start site by generating an additional TATA-box. As a consequence, transcription of the progesterone receptor gene is increased, favoring the production of PR-B (20). We were able to show that the presence of the $+331 \mathrm{G} / \mathrm{A}$ heterozygous genotype is associated with a significant decrease in the risk of developing deep infiltrating endometriosis. Like PROGINS, the $+331 \mathrm{G} / \mathrm{A}$ polymorphism of the progesterone receptor gene has also been 
studied with respect to the risk of developing several gynecological malignancies. In one study, the presence of the $+331 \mathrm{~A}$ polymorphic allele was associated with a reduced risk of endometrioid and clear cell ovarian cancers (28). There was also preliminary evidence of a protective effect of this polymorphism against endometriosis in controls. However, in contrast to the current study, the diagnosis of endometriosis in the former study was selfreported and was not supported by medical records or surgical and/or histological evidence of the disease.

One could hypothesize that overproduction of PR-B may correct the imbalance between PR-A and PR-B in endometriotic tissue. In this manner, the development and growth of endometriotic implants may be prevented to the extent that they become symptomatic. This point of view is supported by the fact that we find higher expression levels of PR-B in endometriotic epithelium of $+331 \mathrm{~A}$ carriers. However, we need to emphasize the fact that, although this result is statistically significant, the group of $+331 \mathrm{~A}$ carriers in this study that could be analyzed immunohistochemically in this study consists of only two patients. It may therefore not be possible to draw any definitive conclusions on the effect of the presence of the $+331 \mathrm{G} / \mathrm{A}$ polymorphic allele on the expression levels of PR-A and PR-B. Another limitation to our findings is the fact that it was not possible to satisfyingly evaluate the results for deep infiltrating endometriosis and adenomyosis separately, as in both groups only one $+331 \mathrm{~A}$ carrier could be observed. The association we found needs to be confirmed in a larger number of patients. Future research should be aimed at gaining more insight in the mechanism through which the $+331 \mathrm{G} / \mathrm{A}$ polymorphism exerts its protective effect against the development of endometriosis.

Strikingly, the decrease in risk of developing deep invasive endometriosis as a result of carriership of the $+331 \mathrm{G} / \mathrm{A}$ polymorphism only reached statistical significance when women with deep infiltrating endometriosis were compared with population controls. When compared with gynecological controls, this was not the case. A possible explanation for this finding is the fact that a control group consisting of gynecological patients is probably biased with respect to the prevalence of (undiagnosed) endometriosis. Although the women in our gynecological control group had not reported symptoms of endometriosis, a hysterectomy was performed as a result of gynecological complaints such as pelvic pain or irregular or heavy menstrual bleeding. Given the fact that endometriosis can cause similar complaints but may not always be recognized as such, it may explain why the prevalence of underreported and undiagnosed endometriosis is higher in this group compared with the general population.

In conclusion, we have shown that the presence of the PR gene polymorphic allele $+331 \mathrm{~A}$ reduces the risk of deep infiltrating endometriosis and adenomyosis in the uterine wall compared to the $+331 \mathrm{G} / \mathrm{G}$ genotype. In contrast, the PROGINS polymorphism does not seem to modify the risk of developing deep infiltrating endometriosis or adenomyosis. Moreover, our findings indicate that a general population-based control group is more suitable for this field of research than a probably biased control group consisting of gynecological patients. 


\section{References}

1. Sampson JA. The development of the implantation theory for the origin of peritoneal endometriosis. Am J Obstet Gynecol 1940;40:549-57.

2. Koninckx PR. Is mild endometriosis a condition occurring intermittently in all women? Hum Reprod 1994;9:2202-5.

3. Bischoff FZ, Simpson JL. Heritability and molecular genetic studies of endometriosis. Hum Reprod Update 2000;6:37-44.

4. Simpson JL, Bischoff FZ. Heritability and molecular genetic studies of endometriosis. Ann N Y Acad Sci. 2002;955:239-51; discussion 93-5, 396-406.

5. Simpson JL, Bischoff FZ, Kamat A, Buster JE, Carson SA. Genetics of endometriosis. Obstet Gynecol Clin North Am. 2003;30:21-40, vii.

6. Simpson JL ES. Genetics in Obstetrics and Gynecology. 3rd ed. Philadelphia, PA, USA: WB Saunders, 2003.

7. Cramer DW, Hornstein MD, Ng WG, Barbieri RL. Endometriosis associated with the N314D mutation of galactose-1-phosphate uridyl transferase (GALT). Mol Hum Reprod 1996;2:149-52.

8. Georgiou I, Syrrou M, Bouba I, Dalkalitsis N, Paschopoulos M, Navrozoglou I, Lolis D. Association of estrogen receptor gene polymorphisms with endometriosis. Fertil Steril 1999;72:164-6.

9. Nakago S, Hadfield RM, Zondervan KT, Mardon H, Manek S, Weeks DE, Barlow D, Kennedy S. Association between endometriosis and $\mathrm{N}$-acetyl transferase 2 polymorphisms in a UK population. Mol Hum Reprod 2001;7:1079-83.

10. Hadfield RM, Manek S, Weeks DE, Mardon HJ, Barlow DH, Kennedy SH. Linkage and association studies of the relationship between endometriosis and genes encoding the detoxification enzymes GSTM1, GSTT1 and CYP1A1. Mol Hum Reprod 2001;7:1073-8.

11. Vigano $P$, Infantino M, Lattuada D, Lauletta R, Ponti E, Somigliana E, Vignali M, DiBlasio AM. Intercellular adhesion molecule-1 (ICAM-1) gene polymorphisms in endometriosis. Mol Hum Reprod 2003;9:47-52.

12. Punyadeera $C$, Verbost $P$, Groothuis $P$. Oestrogen and progestin responses in human endometrium. $J$ Steroid Biochem Mol Biol. 2003;84:393-410.

13. Horwitz KB, Alexander PS. In situ photolinked nuclear progesterone receptors of human breast cancer cells: subunit molecular weights after transformation and translocation. Endocrinology 1983;113:2195-201.

14. Lessey BA, Alexander PS, Horwitz KB. The subunit structure of human breast cancer progesterone receptors: characterization by chromatography and photoaffinity labeling. Endocrinology 1983;112: 1267-74.

15. Li X, O'Malley BW. Unfolding the action of progesterone receptors. J Biol Chem 2003;278:39261-4.

16. Giangrande PH, Kimbrel EA, Edwards DP, McDonnell DP. The opposing transcriptional activities of the two isoforms of the human progesterone receptor are due to differential cofactor binding. Mol Cell Biol 2000;20:3102-15.

17. Wieser F, Schneeberger C, Tong D, Tempfer C, Huber JC, Wenzl R. PROGINS receptor gene polymorphism is associated with endometriosis. Fertil Steril 2002;77:309-12.

18. Lattuada D, Somigliana E, Vigano P, Candiani M, Pardi G, Di Blasio AM. Genetics of endometriosis: a role for the progesterone receptor gene polymorphism PROGINS? Clin Endocrinol 2004;61:190-4.

19. Rowe SM, Coughlan SJ, McKenna NJ, Garrett E, Kieback DG, Carney DN, Headon DR. Ovarian carcinomaassociated Taql restriction fragment length polymorphism in intron $\mathrm{G}$ of the progesterone receptor gene is due to an Alu sequence insertion. Cancer Res 1995;55:2743-5.

20. De Vivo I, Huggins GS, Hankinson SE, Lescault PJ, Boezen M, Colditz GA, Hunter DJ. A functional polymorphism in the promoter of the progesterone receptor gene associated with endometrial cancer risk. Proc Natl Acad Sci USA 2002;99:12263-8.

21. Pijnenborg JM, Romano A, Dam-de Veen GC, Dunselman GA, Fischer DC, Groothuis PG, Kieback DG. Aberrations in the progesterone receptor gene and the risk of recurrent endometrial carcinoma. J Pathol 2005;205:597-605.

22. Fang Z, Yang S, Lydon JP, DeMayo F, Tamura M, Gurates B, Bulun SE. Intact progesterone receptors are essential to counteract the proliferative effect of estradiol in a genetically engineered mouse model of endometriosis. Fertil Steril 2004;82:673-8. 
23. Nisolle M, Donnez J. Peritoneal endometriosis, ovarian endometriosis, and adenomyotic nodules of the rectovaginal septum are three different entities. Fertil Steril 1997;68:585-96.

24. Treloar SA, Zhao ZZ, Armitage T, Duffy DL, Wicks J, O'Connor DT, Martin NG, Montgomery GW. Association between polymorphisms in the progesterone receptor gene and endometriosis. Mol Hum Reprod 2005;11:641-7.

25. Ioannidis JP, Trikalinos TA, Ntzani EE, Contopoulos-loannidis DG. Genetic associations in large versus small studies: an empirical assessment. Lancet 2003;361:567-71.

26. Attia GR, Zeitoun K, Edwards D, Johns A, Carr BR, Bulun SE. Progesterone receptor isoform A but not B is expressed in endometriosis. J Clin Endocrino Metab 2000;85:2897-902.

27. Agoulnik IU, Tong XW, Fischer DC, Korner K, Atkinson NE, Edwards DP, Headon DR, Weigel NL, Kieback DG. A germline variation in the progesterone receptor gene increases transcriptional activity and may modify ovarian cancer risk. J Clin Endocrinol Metab 2004;89:6340-7.

28. Berchuck A, Schildkraut JM, Wenham RM, Calingaert B, Ali S, Henriott A, Halabi S, Rodriguez GC, Gertig D, Purdie DM, Kelemen L, Spurdle AB, Marks J, Chenevix-Trench G. Progesterone receptor promoter $+331 \mathrm{~A}$ polymorphism is associated with a reduced risk of endometrioid and clear cell ovarian cancers. Cancer Epidemiol Biomarkers Prev. 2004;13:2141-7. 


\section{Chapter 5}

\section{DNA methyltransferases and methyl-CpG binding domain proteins in human endometrium and endometriosis}

KJAF van Kaam, B Delvoux, A Romano, T D'Hooghe, GAJ Dunselman, PG Groothuis Adapted from: Fertility and Sterility 2011;95:1421-7 


\section{Abstract}

\section{Objective}

To determine (1) expression levels of both DNA methyltransferases (DNMTs) and methylCpG binding domain proteins (MBDs) in human endometrium throughout the menstrual cycle and in eutopic and ectopic endometrium of endometriosis patients and (2) hormone responsiveness of DNMT and MBD expression in explant cultures of proliferative phase endometrium

\section{Design}

In vitro study

\section{Setting}

Academic Medical Center

\section{Patients}

Premenopausal women with and without endometriosis

Interventions: Explant cultures of proliferative phase endometrium were treated with vehicle, $17 \beta$-estradiol (E2), or a combination of E2 and progesterone (E2+P) for 24 hours

\section{Main outcome measures}

Expression levels of DNMT1, DNMT2, DNMT3B and MBD1, MBD2 and MeCP2 using realtime quantitative PCR

\section{Results}

Expression levels of DNMT1 and MBD2 were significantly higher in secretory phase endometrium compared to proliferative endometrium and menstrual endometrium. In explant cultures, treatment with $\mathrm{E} 2+\mathrm{P}$ resulted in significant upregulation of DNMT1 and MBD2. Expression levels of several DNMTs and MBDs were significantly lower in endometriotic lesions compared to eutopic endometrium of women with endometriosis and disease-free controls.

\section{Conclusions}

These findings suggests a role for DNMTs and MBDs in the growth and differentiation of the human endometrium and support the notion that endometriosis may be an epigenetic disease. 


\section{Introduction}

Endometriosis is a benign gynecological disorder that is characterized by the presence of endometrial glands and stroma at ectopic sites outside the uterine cavity. Its exact pathogenesis remains enigmatic. Recent reports support a role for epigenetic processes such as DNA methylation in the pathogenesis of endometriosis (1-4). Epigenetics refers to the study of heritable changes in gene expression that occur without changes in the underlying DNA sequence (5). Several types of epigenetic regulatory mechanisms exist, including DNA methylation, histone modifications and posttranscriptional gene regulation by micro-RNAs (miRNAs) $(6,7)$. The most studied epigenetic alteration is DNA methylation, which refers to the addition of a methyl group to the 5 ' position of cytosines that precede a guanine in the DNA sequence, the CpG dinucleotide. Unmethylated CpGs are clustered in CpG islands, and are often associated with transcriptional start sites in promoter regions. DNA methylation is accompanied by post-translational histone modifications that modulate DNA function, regulating chromatin structure and determining the transcriptional state of the associated DNA. Nowadays it is widely recognized that promoter hypermethylation is associated with condensed chromatin and silencing of gene expression. The importance of this phenomenon has been extensively demonstrated in the context of cancer research, where certain tumor-suppressor genes were shown to be inactivated by promoter hypermethylation.

The mammalian DNA methylation machinery is composed of two components. DNA methyltransferases (DNMTs) are enzymes that catalyze the addition of methyl groups to CpG dinucleotides. DNMT1 is regarded as the major enzyme responsible for maintaining existing DNA methylation patterns during replication. It is located at the replication fork and methylates newly synthesized DNA strands directly after each replication round. DNMT3A and DNMT3B are thought of as de novo methyltransferases, which are involved in the post-replicative methylation of previously unmethylated DNA. Finally, DNMT2 is an enzyme with strong sequence similarities with 5-methylcytosine methyltransferases of both prokaryotes and eukaryotes but was shown not to methylate DNA (8).

The crosstalk between DNA methylation and histone modifications is established by a family of proteins that contain a methyl-CpG binding domain, commonly known as MBD proteins (MBDs). On the basis of several studies $(9,10)$, a model has been proposed for DNA methylation-mediated transcriptional silencing. According to this model, MBDs specifically recognize and subsequently bind to methylated CpGs and recruit histone deacetylases (HDACs), either directly or via a corepressor complex. The HDAC removes acetyl groups from the lysines on the $\mathrm{NH}_{2}$-terminal histone tails, resulting in chromatin condensation, inaccessibility of transcription factors, and transcriptional inactivation. The process of gene silencing therefore requires the combined action of both DNMTs and MBDs. 
To date, five MBDs have been cloned: MeCP2, MBD1, MBD2, MBD3, and MBD4. Of these, MeCP2, MBD1, and MBD2 have been shown to recruit HDAC and function as transcriptional repressors (11).

A significant correlation was demonstrated between DNA methylation and the expression of $\mathrm{PR}$ in normal endometrium, suggesting that DNA methylation may be involved in steroid hormone dependent endometrial growth and differentiation during the menstrual cycle (12). In addition, overexpression of steroidogenic factor-1 (2) and estrogen receptor 2 (1) was shown to be the result of demethylation of the gene promoters.

To date, two studies addressing DNMT expression in endometrium (13) and endometriosis (14) have been performed. However, these studies have focused on DNMT expression solely, and, so far, no studies reporting MBD expression in these tissues are known. Therefore, the aim of this study is to investigate the expression levels of both DNMTs and MBDs in (i) normal endometrium throughout the menstrual cycle and (ii) eutopic and ectopic endometrium of women with endometriosis. A second aim is to investigate hormone responsiveness of DNMTs and MBD expression. The presence of DNMT and MBD proteins in these tissues was assessed by immunohistochemistry.

\section{Materials and Methods}

\section{Tissues}

As described in more detail below, tissues were collected in two different clinics, the Maastricht University Medical Center (MUMC) in Maastricht, the Netherlands and the Leuven Fertility Clinic (LFC) in Leuven, Belgium.

\section{Tissues collected in the MUMC}

Endometrial tissue was collected from all phases of the menstrual cycle from 23 women with regular menstrual cycles. These women underwent surgery for benign indications other than endometriosis in the University Hospital of Maastricht. The tissue was collected from hysterectomy specimens or by pipelle biopsies during laparoscopy (Pipelle catheter, Unimar Inc., Prodimed, Neuilly-Enthelle, France). All women signed an informed consent, as required by the protocol approved by the Medical Ethical Committee of the University Hospital Maastricht. Of the twenty-three biopsies collected, 3 were collected in the menstrual phase, 8 were collected in the proliferative phase and another 12 were collected in the secretory phase of the menstrual cycle. Each biopsy was divided in three parts: the first part was immediately frozen in liquid nitrogen and stored at $-80^{\circ} \mathrm{C}$ until used for research in this study, the second part was fixed in $10 \%$ buffered formalin for histology. Of the proliferative phase tissue samples, a third part was kept apart and directly used for endometrial explant cultures (see below). The endometrium was dated 
according to clinical information with respect to the start of the last menstrual period, which was reconfirmed by histological examination of the tissue (15).

\section{Explant cultures}

Part of the proliferative phase endometrium from 8 biopsies collected in the proliferative phase of the menstrual cycle was used for endometrial explant cultures as described earlier (16). The tissue was cultured for 24 hours in the presence of vehicle $(0.1 \%$ ethanol) or steroid hormones (estradiol, E2, 1 nM; progesterone, P4, 1 nM; E2 plus P4, 1 nM each). At the end of the experiment, the explants were collected in lysis buffer (SV Total RNA Isolation Kit, Promega, Madison, WI, USA) and stored at $-80^{\circ} \mathrm{C}$ until RNA isolation. The steroid hormones were gifts from Organon pharmaceuticals (Oss, The Netherlands).

\section{Tissues collected in the LFC}

Patient material used for the present investigation has been described before (17). In short, tissue was obtained during the proliferative phase of the menstrual cycle from 34 women, including 20 women with laparoscopically confirmed absence of endometriosis 14 women with both laparoscopically and histologically confirmed stage III-IV endometriosis [American Society for Reproductive Medicine classification (18)]. Both eutopic and ectopic tissue was harvested. All patients had a regular menstrual cycle and were documented not to be on any steroid medication within six months before surgery.

\section{RNA isolation and cDNA synthesis}

Total cellular RNA from the cultured explants and uncultured endometrium was extracted using the SV total RNA isolation kit (Promega) according to the manufacturer's protocol. RNA from the tissue samples collected in the Leuven Fertility Clinic was isolated using the TRIzol reagent method (Invitrogen, Carlsbad, CA, USA) according to the manufacturer's protocol. RNA quantity and quality was assessed with a spectrophotometer at 260 and $280 \mathrm{~nm}$ wavelengths. For the production of the complementary DNA (cDNA) the iScript cDNA Synthesis Kit (Bio-Rad, Hercules, CA, USA) was used.

\section{Real-time PCR}

The TaqMan Gene Expression Assays for DNMT1 (Hs00154749_m1), DNMT2 (Hs00189402_m1), DNMT3B (Hs00171876_m1), MBD1 (Hs00242770_m1), MBD2 (Hs00187506_m1), and MeCP2 (Hs00172845_m1), $\beta$-actin (Hs99999903_m1), and cyclophilin A (Hs99999904_m1) were purchased from Applied Biosystems (Foster City, CA, USA). Human cyclophilin A was used as housekeeping gene to normalize the differences in the amount of CDNA added to each PCR reaction. To check for the amount of endometrial tissue present in eutopic and ectopic endometrial biopsies, the expression level of $17 ß$ - 
hydroxysteroid dehydrogenase 4 (17ßHSD4), a gene previously shown to be expressed at equal levels in the eutopic endometrium and endometriotic tissue, was measured (17).

\section{Immunohistochemistry}

A summary of the primary and secondary antibodies, antigen retrieval steps and incubation conditions used is given in Table 1. Antibody binding was visualized using the Envision rabbit anti-mouse (for mouse monoclonal antibodies), or anti-goat (for goat polyclonal antibodies) ChemMate ${ }^{\mathrm{TM}}$ detection kits (DAKO, Copenhagen, Denmark) followed by incubation with 3, 3'-diaminobenzidine. Negative control slides for the monoclonal antibodies were incubated with mouse IgGs of the same class and same dilution as the primary antibodies. Negative control slides for the goat polyclonal antibodies were incubated with goat IgG at the same dilution as the polyclonal antibodies.

\section{Statistical tests}

Statistical tests were carried out using the Statistical Package for the Social Sciences 16.0 (SPSS Inc., Chicago, IL) statistical analysis package. To evaluate whether expression levels varied significantly throughout the menstrual cycle, the non-parametric unpaired MannWhitney $U$ test was used to test for differences between these expression levels versus the expression level in the $M$ phase. The non-parametric Wilcoxon signed-rank test was used to test for differences between steroid-treated explants and controls at a confidence level of $95 \%$.

Table 1 Primary antibodies and conditions used for immunohistochemistry of eutopic endometrium and endometriosis lesions

\begin{tabular}{|c|c|c|c|c|c|c|c|}
\hline Antibody & Species & $\begin{array}{l}\text { Catalog } \\
\text { number }\end{array}$ & IgG class & Dilution & Manufacturer & Incubation & $\begin{array}{l}\text { Antigen } \\
\text { retrieval }\end{array}$ \\
\hline Dnmt 1 & Goat & sc-10222 & $\operatorname{lgG1}$ & $1: 750$ & $\begin{array}{l}\text { Santa Cruz } \\
\text { Biotechnology, } \\
\text { Santa Cruz, CA, USA }\end{array}$ & $\begin{array}{l}2 \text { hours room } \\
\text { temperature }\end{array}$ & $\begin{array}{l}\text { Tris-EDTA } \\
(\mathrm{pH} \mathrm{9.0)}\end{array}$ \\
\hline MBD-2 & Goat & sc-9397 & $\begin{array}{l}\text { Not } \\
\text { specified }\end{array}$ & $1: 500$ & $\begin{array}{l}\text { Santa Cruz } \\
\text { Biotechnology, } \\
\text { Santa Cruz, CA, USA }\end{array}$ & $\begin{array}{l}\text { Overnight } \\
4 \mathrm{C}\end{array}$ & $\begin{array}{l}\text { Tris-EDTA } \\
(\mathrm{pH} \mathrm{9.0)}\end{array}$ \\
\hline 5-MeCyd & Mouse & MCA2201 & $\operatorname{lgG1}$ & 1: 100 & $\begin{array}{l}\text { Abd Serotec, Oxford, } \\
\text { UK }\end{array}$ & $\begin{array}{l}2 \text { hours room } \\
\text { temperature }\end{array}$ & $\begin{array}{l}\text { Citrate } \\
(\mathrm{pH} 6.0)\end{array}$ \\
\hline
\end{tabular}

\section{Results}

\section{DNMT and MBD expression throughout the menstrual cycle}

The relative expression level of DNMT1 was significantly higher in secretory endometrium compared with proliferative $(P=0.02)$ and menstrual endometrium $(P=0.009)$. Expression 
levels of DNMT2 and DNMT3B were not significantly different between the cycle phases. Significantly higher expression levels of MBD2 were observed in secretory endometrium compared with proliferative $(P=0.004)$ and menstrual $(P=0.018)$ endometrium. There were no statistically significant differences in MBD1 and MeCP2 expression throughout the menstrual cycle (Figure 1). Immunoreactivity for DNMT1 (Figure 4A), MBD2 (Figure 4B) and 5-methylcytosine (Figure 4C) was observed in nuclei of epithelial and stromal cells of both proliferative and secretory endometrium.

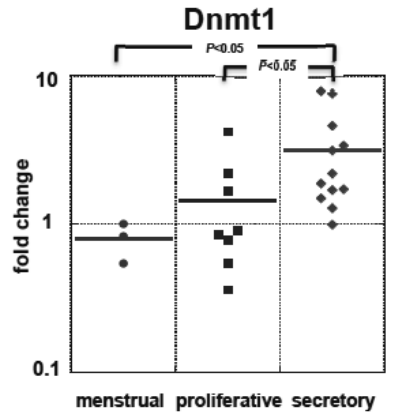

Mbd1

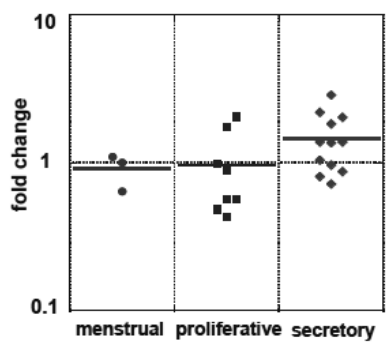

Dnmt2

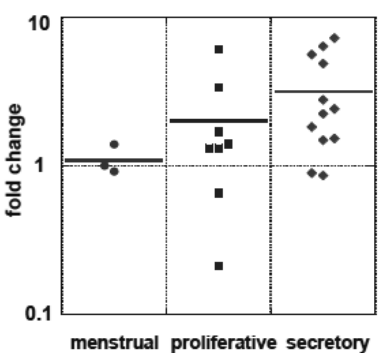

Mbd2

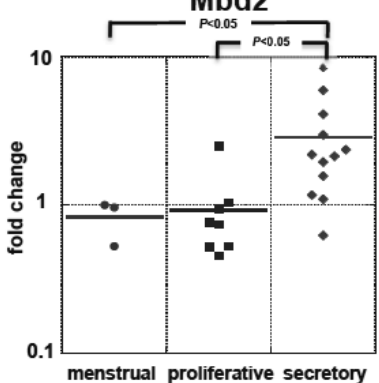

Dnmt3b

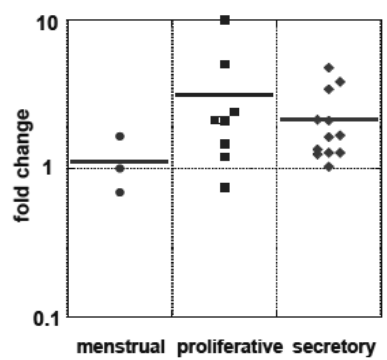

$\mathrm{MeCP}$

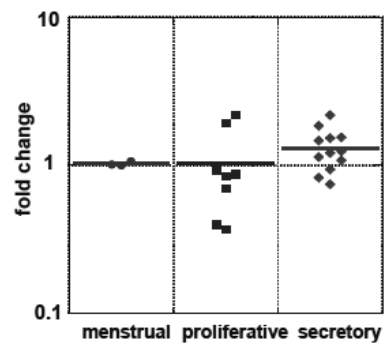

Figure 1 Expression levels of DNMT1, DNMT2, DNMT3B, MBD1, MBD2 and MeCP2 throughout the menstrual cycle.

\section{Expression levels of DNMTs and MBDs in explant cultures}

Because transcript levels of DNMT1 and MBD2 were shown to be upregulated significantly in the secretory phase of the menstrual cycle, hormonal regulation of these genes was hypothesized. Therefore, the effect of cultivation with estrogen (E2) alone or estrogen in combination with progesterone $(E 2+P)$ was assessed in explant cultures of proliferative endometrium. Expression of DNMT1 was significantly upregulated by treatment with E2 + $P(P=0.021)$, but not by treatment with E2 alone $(P=0.086)$. The same phenomenon was 
observed for MBD2: expression levels were shown to be significantly higher when endometrium was cultured with $E 2+P(P=0.038)$, but not after cultivation with $E 2$ alone (Figure 2).

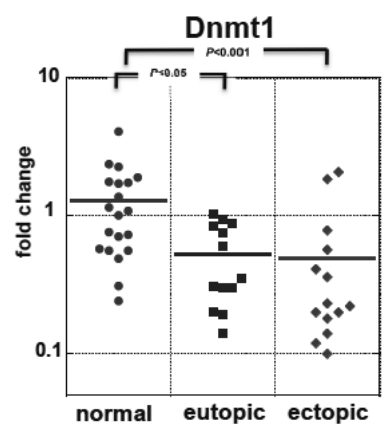

Dnmt2

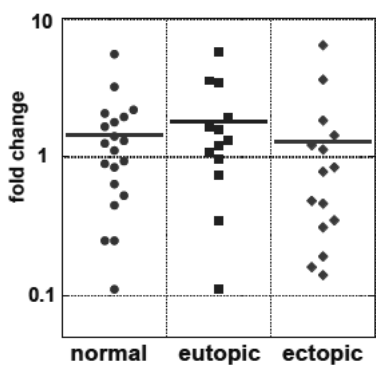

Mbd1

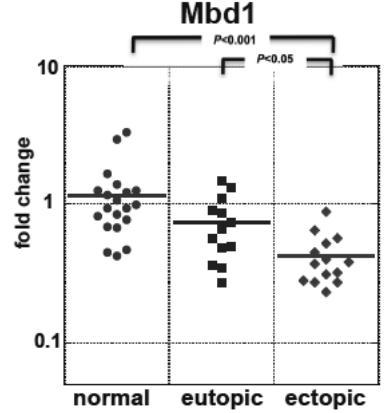

Mbd2

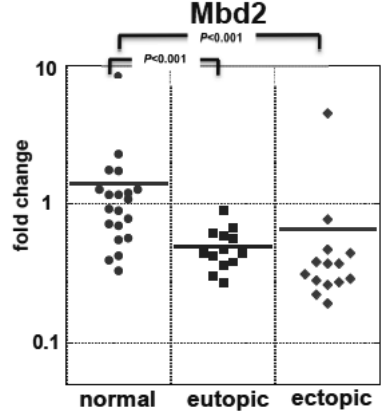

Dnmt3b

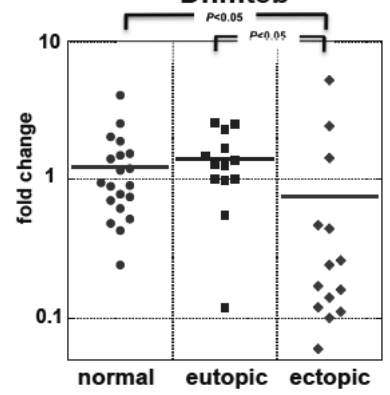

$\mathrm{MeCP}$

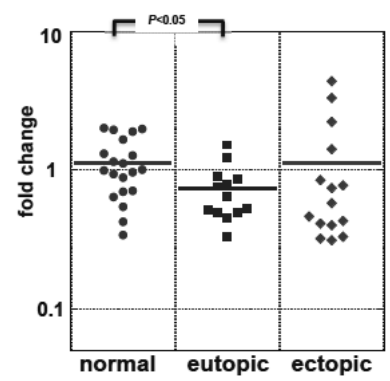

Figure 3 Expression levels of DNMT1, DNMT2, DNMT3B, MBD1, MBD2 and MeCP2 in eutopic endometrium of controls (normal), eutopic endometrium of endometriosis patients (eutopic) and ectopic endometrium of endometriosis patients (ectopic).

\section{Expression levels of DNMTs and MBDs in matched samples of eutopic and ectopic endometrium}

DNMT1 showed significantly lower expression levels in eutopic $(P=0.007)$ and ectopic $(P=0.001)$ endometrium of endometriosis patients compared with eutopic endometrium of controls. Expression levels of DNMT3B did not differ between eutopic endometrium of cases and controls, but were significantly lower in ectopic endometrium compared with eutopic endometrium of cases $(P=0.008)$ and eutopic endometrium of controls $(P=0.002)$. The expression of DNMT2 did not vary between the groups. MeCP2 expression levels were significantly higher in eutopic endometrium of controls compared with eutopic endometrium of cases $(P=0.02)$, but when they were compared with ectopic endometrium no statistically significant difference could be observed. 
A

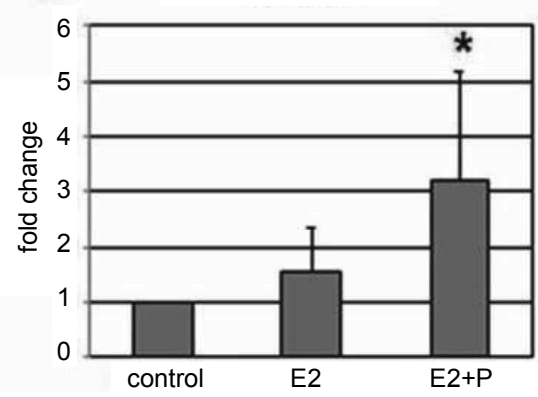

B

Mbd2

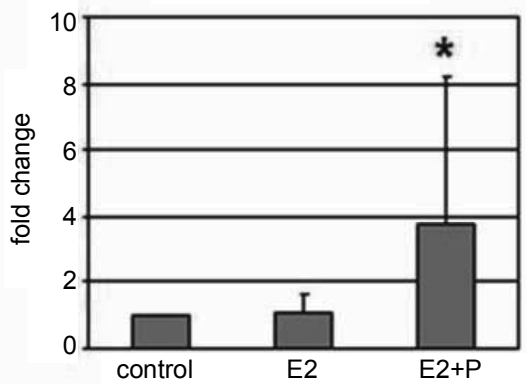

Figure 2 Expression levels of DNMT1 and MBD2 in endometrial explant cultures after cultivation for $24 \mathrm{~h}$ with estrogen (E2) or a combination of estrogen and progesterone (E2+P). Data are presented as means \pm SEM. $* P<0.05$ versus control (uncultured) endometrium.

Expression levels of MBD1 on the other hand did not vary between eutopic endometrium of controls and cases, but were significantly lower in ectopic endometrium compared to eutopic endometrium of cases $(P=0.017)$ and eutopic endometrium of controls $(P<0.0001)$. Finally, significantly lower expression levels of MBD2 were observed in eutopic $(P=0.001)$ and ectopic ( $P=0.0002)$ endometrium of cases compared to eutopic endometrium of controls (Figure 3). Immunoreactivity for DNMT1 (Figure 4A), MBD2 (Figure 4B) and 5methylcytosine (Figure 4C) was observed in epithelial and stromal cells of both eutopic and ectopic endometrium of patients.

\section{Discussion}

\section{DNMT1 and MBD2 expression vary throughout the menstrual cycle}

In the present study, we observed cyclical variations in the expression of DNMT1 and MBD2, with significantly higher expression levels of both enzymes in secretory phase endometrium compared with proliferative and menstrual phase endometrium. Furthermore, we showed that the expression of these genes is regulated by steroid hormones.

Strikingly, our findings contradict the report of Yamagata and coworkers, who found significantly reduced levels of DNMT1, $3 A$ and $3 B$ in the secretory phase of the menstrual cycle. Incubation of cultured proliferative phase endometrial stromal cells in the presence of estradiol and progesterone resulted in significant downregulation of DNMT3A and 3B. 
A

DNMT-1
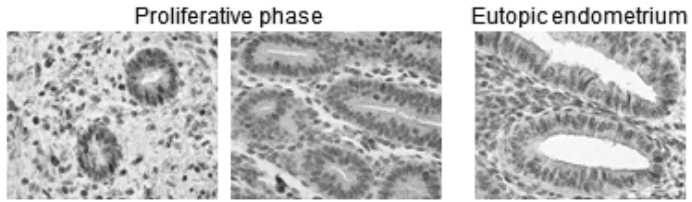

Secretory phase
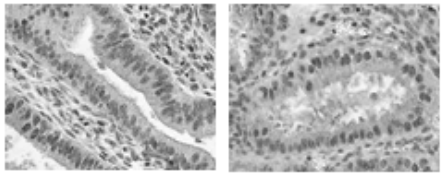

Ectopic lesion

B

MBD2
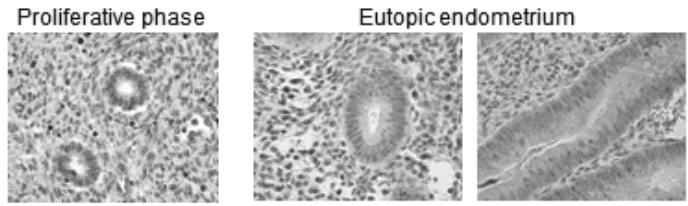

Secretory phase
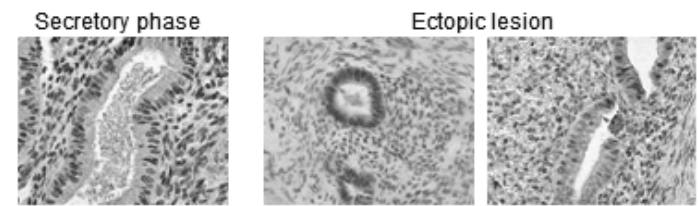

Figure 4 Representative photographs of DNMT1 (A) and MBD2 (B) protein immunostainings in normal endometrium throughout the menstrual cycle (proliferative phase and secretory phase) and in eutopic and ectopic endometrium of endometriosis patients.

C

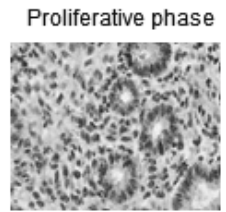

Secretory phase

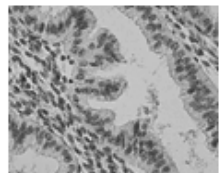

5-MeCyt

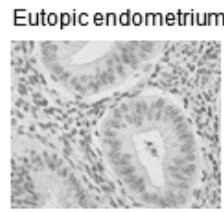

Ectopic lesion

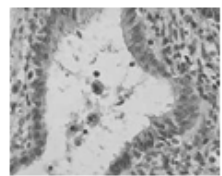

Figure 4 Representative photographs of 5-methyl cytosine (C) immunostainings in normal endometrium throughout the menstrual cycle (proliferative phase and secretory phase) and in eutopic and ectopic endometrium of endometriosis patients. 
The expression of DNMT1 was not influenced under these conditions (13). A possible explanation for this discrepancy could be that the results of these authors were obtained in cultures of isolated endometrial stromal cells, whereas in the present study endometrial tissue cultures were used. Short-term explant cultures have several features which are relevant for understanding the complex intra- and inter-cellular mechanisms of tissue responsiveness to estrogen (16) and progesterone (18). Essential to the short-term explant cultures is the preservation of the tissue architecture, which is a prerequisite for the interactions between the epithelium, stroma, and extracellular matrix. It has been well documented that stromal-epithelial interactions are indispensable for the hormonal response of epithelial cells of the female reproductive tract (19) and that steroid sex hormones regulate epithelial proliferation via paracrine mechanisms requiring the appropriate receptor in the stroma. In culture systems using either isolated endometrial stromal or epithelial cells, the tissue architecture, and thus, stromal-epithelial interaction, is lost. Therefore, results obtained in these culture systems probably do not accurately reflect the in vivo response of human endometrium to steroid hormones.

DNMT1 is considered the maintenance DNMT, since its primary function is to copy an already established DNA methylation pattern after replication. Based on this functional characteristic, it would be expected that DNMT1 expression levels are highest in the proliferative phase of the menstrual cycle. However, in the present study expression levels of DNMT1 in the secretory phase were shown to exceed those in the proliferative phase. Interestingly, it has been shown that DNMT1-depleted isolated ES cells remain viable and proliferative, but die upon induction of differentiation (20-22). Also, targeted deletion of DNMT1 in mouse embryo's proved to be lethal, with embryonic death occurring during or after gastrulation when the pluripotent embryonic stem cells begin to differentiate. These findings indicate a role for DNMT1 not only in proliferating cells, but also in the subsequent differentiation of cells.

The second protein that was shown to be significantly upregulated in the secretory phase is MBD2. There is no evidence for an essential embryonic function for any mammalian methyl-CpG binding protein (23), illustrated by the fact that MBD2 and MeCP2 null mice are viable and fertile and display no overt phenotype $(24,25)$. However, there is evidence for overlapping functions in differentiation and specification of neural stem cells in culture and in postnatal animals (23). Furthermore, it was shown that MeCP2 and MBD2 expression increases during (terminal) differentiation (26), which is in line with our finding of elevated expression levels of MBD2 in secretory phase endometrium.

\section{Reduced expression levels of DNMTs and MBDs in endometriosis}

In the present study we show that expression levels of DNMT1 and MBD2 are significantly lower in eutopic and ectopic endometrium of endometriosis patients compared to eutopic endometrium of controls, whereas MeCP2 expression is lower in eutopic than in ectopic endometrium of endometriosis patients. Finally, expression levels of DNMT3B and MBD1 
are lower in ectopic endometrium compared to eutopic endometrium of both endometriosis patients and controls.

Our findings do not confirm the observations of $\mathrm{Wu}$ and coworkers who found increased expression levels of DNMT1, DNMT3A and DNMT3B in ectopic endometrium as compared to disease free control subjects and eutopic endometrium of women with endometriosis (14). Possible explanations for this discrepancy may be related to the heterogeneous patient population used by $\mathrm{Wu}$ and coworkers (menstrual, proliferative and secretory phase endometrium versus only proliferative phase endometrium in the present study), and the use of isolated endometrial epithelial cells rather than tissue cultures.

As stated above, DNMT1, MBD2 and MeCP2 appear to be indispensable for tissue-specific gene expression and differentiation. The findings obtained in the present study may signify that both eutopic and ectopic endometrium of endometriosis patients have a reduced capacity for differentiation and hence, decidualization and implantation. Circumstantial evidence in support of this notion has been provided by numerous studies: aberrant expression of progesterone receptor (PR) in endometriotic tissues (27-29), the absence of the estradiol inactivating enzyme 17-ß-HSD2 in eutopic and ectopic endometrium of endometriosis patients in the secretory phase of the cycle (30) and altered expression of HOXA10 -a gene that is critical for endometrial decidualization and implantation- in eutopic and ectopic endometrium of endometriosis patients $(31,32)$. Furthermore, levels of the decidualization markers prolactin (PRL) and insulin-like growth factor binding protein-1 (IGFBP-1) are reduced in supernatants from endometrial stromal cells derived from all three types of ectopic lesions and from eutopic endometrium of women with endometriosis (33). Results obtained in a recent study by Aghajanova and coworkers also suggest resistance to full decidualization of endometrial stromal fibroblasts in women with endometriosis (34). Taking all this into account, it is tempting to speculate that reduced capacity for differentiation of endometriotic cell lines and endometrial cells from women with endometriosis may influence the capacity for proliferation and survival of these cells in the ectopic environment maintaining the ectopic endometrial tissue. Moreover, the changes in the expression of DNMTs and MBDs in endometriotic tissue seem to have functional consequences in the endometrium and endometriotic tissue as illustrated by the overexpression of SF-1 (2) and ER2 (1) genes as a result of promoter demethylation, whereas the expression of PR-B is suppressed due to hypermethylation of the promoter (3).

In conclusion, we have shown that expression levels of DNMT1 and MBD2 vary throughout the menstrual cycle. Their anticipated dependence on steroid hormones was confirmed in explant cultures prepared from proliferative phase endometrium tissue. The significant reduction in the expression of various DNMTs and MBDs in ectopic endometrium of endometriosis patients may explain why altered gene promoter methylation has been observed in endometriotic lesions. The fact that these changes in methylation status are also associated with changes in phenotype, i.e. gene expression, supports the notion that endometriosis may be an epigenetic disease. 


\section{References}

1. Xue Q, Lin Z, Cheng YH, Huang CC, Marsh E, Yin P, Milad MP, Confino E, Reierstad S, Innes J, Bulun SE. Promoter methylation regulates estrogen receptor 2 in human endometrium and endometriosis. Biol Reprod 2007;77:681-7.

2. Xue Q, Lin Z, Yin P, Milad MP, Cheng YH, Confino E, Reierstad S, Bulun SE. Transcriptional activation of steroidogenic factor- 1 by hypomethylation of the 5' CpG island in endometriosis. J Clin Endocrinol Metab 2007;92:3261-7.

3. Wu Y, Strawn E, Basir Z, Halverson G, Guo SW. Promoter hypermethylation of progesterone receptor isoform B (PR-B) in endometriosis. Epigenetics 2006;1:106-11.

4. Kim JJ, Taylor HS, Lu Z, Ladhani O, Hastings JM, Jackson KS, Wu Y, Guo SW, Fazleabas AT. Altered expression of HOXA10 in endometriosis: potential role in decidualization. Mol Hum Reprod 2007;13: 323-32.

5. Bird A. DNA methylation patterns and epigenetic memory. Genes Dev 2002;16:6-21.

6. Jones PA, Baylin SB. The epigenomics of cancer. Cell 2007;128:683-92.

7. Lopez J, Percharde M, Coley HM, Webb A, Crook T. The context and potential of epigenetics in oncology. $\mathrm{Br}$ J Cancer 2009;100:571-7.

8. Goll MG, Kirpekar F, Maggert KA, Yoder JA, Hsieh CL, Zhang X, Golic KG, Jacobsen SE, Bestor TH. Methylation of tRNAAsp by the DNA methyltransferase homolog Dnmt2. Science 2006;311:395-8.

9. Nan X, Ng HH, Johnson CA, Laherty CD, Turner BM, Eisenman RN, Bird A. Transcriptional repression by the methyl-CpG-binding protein MeCP2 involves a histone deacetylase complex. Nature 1998;393: 386-9.

10. Jones PL, Veenstra GJ, Wade PA, Vermaak D, Kass SU, Landsberger N, Strouboulis J, Wolffe AP. Methylated DNA and MeCP2 recruit histone deacetylase to repress transcription. Nat Genet 1998;19:187-91.

11. Saito M, Ishikawa F. The mCpG-binding domain of human MBD3 does not bind to $\mathrm{mCpG}$ but interacts with NuRD/Mi2 components HDAC1 and MTA2. J Biol Chem 2002;277:35434-9.

12. Ghabreau L, Roux JP, Niveleau A, Fontaniere B, Mahe C, Mokni M, Frappart L. Correlation between the DNA global methylation status and progesterone receptor expression in normal endometrium, endometrioid adenocarcinoma and precursors. Virchows Arch 2004;445:129-34.

13. Yamagata $Y$, Asada H, Tamura I, Lee L, Maekawa R, Taniguchi K. Taketani T, Matsuoka A, Tamura H, Sugino N. DNA methyltransferase expression in the human endometrium: down-regulation by progesterone and estrogen. Hum Reprod 2009;24:1126-32.

14. Wu Y, Strawn E, Basir Z, Halverson G, Guo SW. Aberrant expression of deoxyribonucleic acid methyltransferases DNMT1, DNMT3A, and DNMT3B in women with endometriosis. Fertil Steril 2007;87:2432.

15. Noyes RW, Hertig AT, Rock J. Dating the endometrial biopsy. Am J Obstet Gynecol 1975;122:262-3.

16. Punyadeera C, Dunselman G, Marbaix E, Kamps R, Galant C, Nap A, Goeij A, Ederveen A, Groothuis P. Triphasic pattern in the ex vivo response of human proliferative phase endometrium to oestrogens. $J$ Steroid Biochem Mol Biol 2004;92:175-85.

17. Delvoux B, Groothuis P, D'Hooghe T, Kyama C, Dunselman G, Romano A. Increased production of 17betaestradiol in endometriosis lesions is the result of impaired metabolism. J Clin Endocrinol Metab 2009;94:876-83.

18. Dassen H, Punyadeera C, Kamps R, Klomp J, Dunselman G, Dijcks F, de Goeij A, Ederveen A, Groothuis P. Progesterone regulation of implantation-related genes: new insights into the role of oestrogen. Cell $\mathrm{Mol}$ Life Sci 2007;64:1009-32.

19. Cunha GR, Cooke PS, Kurita T. Role of stromal-epithelial interactions in hormonal responses. Arch Histol Cytol 2004;67:417-34.

20. Lei $H$, Oh SP, Okano M, Juttermann R, Goss KA, Jaenisch R, Li E. De novo DNA cytosine methyltransferase activities in mouse embryonic stem cells. Development 1996;122:3195-205.

21. Li E, Bestor TH, Jaenisch R. Targeted mutation of the DNA methyltransferase gene results in embryonic lethality. Cell 1992;69:915-26.

22. Tucker KL, Beard C, Dausmann J, Jackson-Grusby L, Laird PW, Lei H, Li E, Jaenisch R. Germ-line passage is required for establishment of methylation and expression patterns of imprinted but not of nonimprinted genes. Genes Dev 1996;10:1008-20. 
23. Martin Caballero I, Hansen J, Leaford D, Pollard S, Hendrich BD. The methyl-CpG binding proteins Mecp2, $\mathrm{Mbd} 2$ and Kaiso are dispensable for mouse embryogenesis, but play a redundant function in neural differentiation. PLoS One 2009;4:e4315.

24. Hendrich B, Guy J, Ramsahoye B, Wilson VA, Bird A. Closely related proteins MBD2 and MBD3 play distinctive but interacting roles in mouse development. Genes Dev 2001;15:710-23.

25. Hutchins AS, Mullen AC, Lee HW, Sykes KJ, High FA, Hendrich BD, Bird AP, Reiner SL. Gene silencing quantitatively controls the function of a developmental trans-activator. Mol Cell 2002;10:81-91.

26. Brero A, Easwaran HP, Nowak D, Grunewald I, Cremer T, Leonhardt H, Cardoso M. Methyl CpG-binding proteins induce large-scale chromatin reorganization during terminal differentiation. J Cell Biol 2005;169:733-43.

27. Prentice A, Randall BJ, Weddell A, McGill A, Henry L, Horne CH, Thomas EJ. Ovarian steroid receptor expression in endometriosis and in two potential parent epithelia: endometrium and peritoneal mesothelium. Hum Reprod 1992;7:1318-25.

28. Bergqvist A. Different types of extragenital endometriosis: a review. Gynecol Endocrinol 1993;7:207-21.

29. Attia GR, Zeitoun K, Edwards D, Johns A, Carr BR, Bulun SE. Progesterone receptor isoform A but not B is expressed in endometriosis. J Clin Endocrinol Metab 2000;85:2897-902.

30. Zeitoun K, Takayama K, Sasano H, Suzuki T, Moghrabi N, Andersson S, Johns A, Meng L, Putman M, Carr B, Bulun SE. Deficient 17beta-hydroxysteroid dehydrogenase type 2 expression in endometriosis: failure to metabolize 17beta-estradiol. J Clin Endocrinol Metab 1998;83:4474-80.

31. Gui Y, Zhang J, Yuan L, Lessey BA. Regulation of HOXA-10 and its expression in normal and abnormal endometrium. Mol Hum Reprod 1999;5:866-73.

32. Taylor HS, Bagot C, Kardana A, Olive D, Arici A. HOX gene expression is altered in the endometrium of women with endometriosis. Hum Reprod 1999;14:1328-31.

33. Klemmt PA, Carver JG, Kennedy SH, Koninckx PR, Mardon HJ. Stromal cells from endometriotic lesions and endometrium from women with endometriosis have reduced decidualization capacity. Fertil Steril 2006;85:564-72.

34. Aghajanova L, Hamilton A, Kwintkiewicz J, Vo KC, Giudice LC. Steroidogenic enzyme and key decidualization marker dysregulation in endometrial stromal cells from women with versus without endometriosis. Biol Reprod 2009;80:105-14. 


\section{Chapter 6}

Is the extreme dysregulation of genes in eutopic endometrium of endometriosis patients the result of aberrant gene promoter methylation?

KJAF van Kaam, B Delvoux, A Romano, T D' Hooghe, GAJ Dunselman, PG Groothuis Submitted 


\section{Abstract}

\section{Background}

Recent reports have provided support for a role of epigenetic mechanisms in the pathogenesis of endometriosis. One of the basic regulatory epigenetic mechanisms is DNA methylation, occurring in genes that harbor a $\mathrm{CpG}$ rich region (CpG island) in their promoter sequence. DNA methylation is commonly associated with complete silencing of a gene. A recent microarray-based study has shown that several genes are more than 100 fold up- or downregulated in the eutopic endometrium of women with endometriosis compared to eutopic endometrium of healthy controls in the window of implantation. We hypothesize that the striking severity of up- or downregulation is the result of gene promoter methylation.

\section{Methods}

Genes that were $>100$ fold up- or downregulated in eutopic endometrium of women with endometriosis were selected based on biological plausibility and investigated for the presence of significant $\mathrm{CpG}$ islands in the promoter region, yielding 10 genes of interest: PRIM2A, TGFB3 EFNB1, TAF6L, SHB, ITGA2, BENE, Rap1GAP, OGG1 and PRB. Genomic DNA and RNA was isolated from eutopic endometrium samples of women with rAFS stage III/IV endometriosis $(n=14)$ and controls $(n=14)$. All samples were obtained in the proliferative phase of the menstrual cycle. Quantitative real-time PCR was used to investigate mRNA expression levels of the genes of interest in eutopic endometrium samples of endometriosis patients $(n=6)$ and controls $(n=6)$. Promoter methylation status was assessed by methylation specific PCR (MSP).

\section{Results}

Both mRNA expression levels and methylation status of the investigated regions of the promoter $\mathrm{CpG}$ island in all genes investigated were not significantly different between the groups.

\section{Conclusion}

Based on the findings in the present study it is not possible to draw any definitive conclusions on the regulation of the investigated genes by (promoter) methylation. We recommend that our hypothesis may be retested in a larger cohort of eutopic endometrium samples, with the use of modern, sensitive, core-region specific techniques for the detection of DNA methylation. 


\section{Introduction}

Endometriosis is a benign, estrogen-dependent disease of the female genital tract that affects millions of women worldwide. Its exact pathogenesis remains enigmatic, but it is thought that genetic factors contribute to the initiation and progression of the disease. One of the approaches in the search for genes causatively related to the pathogenesis of endometriosis is gene expression profiling. Numerous microarray studies have revealed differential expression of varying sets of genes in endometriosis patients. Comparisons have been made between different individuals (eutopic endometrium of affected versus unaffected women) (1-4) or between different tissues from the same individual (eutopic endometrium versus ectopic endometrium) (5-10). The process of regulation of gene expression is highly complex and can take place at many different levels, such as transcription, post transcriptional splicing of RNA, translation and post translational modification of proteins. Epigenetic regulatory processes such as DNA methylation are able to modulate gene expression by interfering with chromatin configuration and subsequent accessibility of the chromatin for transcription factors. The DNA methylation pattern acts as a cell type-specific memory of transcriptional activity and provides a broad range of gene expression rates, varying from high-level expression to complete silencing. Typically, hypermethylation of CpG islands located in the 5'promoter region of genes is associated with gene silencing, whereas hypomethylated regions are associated with enhanced gene activity.

Recent reports support a role for DNA methylation in the pathogenesis of endometriosis. The expression of certain genes such as estrogen receptor-2 (11), steroidogenic factor-1 (12), aromatase (13), HOXA10 (14), progesterone receptor B (15) and E-cadherin (16) were shown to be regulated by promoter hyper- or hypomethylation in eutopic endometrium and ectopic lesions of women with endometriosis.

In 2003, a microarray study by Kao et al. demonstrated that a number of genes were severely (>100 fold) up- or downregulated in eutopic endometrium of women with endometriosis compared to eutopic endometrium of their disease-free counterparts (3) in the window of implantation. Given the striking extent of respective up- or downregulation, we hypothesized that the expression of the genes that have CpG islands in their promoter region is regulated by promoter methylation in these tissues.

\section{Materials and Methods}

\section{Patients and tissue specimens}

Tissues were collected in the Leuven Fertility Clinic (LFC) in Leuven Belgium. This set of patients consisted of 34 women that underwent laparoscopic surgery for infertility with or without pelvic pain in the University Hospital of Leuven. Of these women, 20 had no 
laparoscopically visible endometriosis, whereas 14 women had both laparoscopically (rAFS stage III-IV) and histologically confirmed endometriosis. Eutopic endometrial tissue was obtained from all women by endometrial biopsy after hysteroscopy and before laparoscopy using a sterile Pipelle cannula (Pipelle de Cornier, Paris, France). All biopsies were taken in the proliferative phase of the menstrual cycle. All patients had signed an informed consent, as required by the protocol approved by the Medical Ethical Committee of the University Hospital Leuven. All women had a regular menstrual cycle and were documented not to be on any kind of steroid medication within six months before surgery. Of these samples, 28 were used for analysis, 14 eutopic endometrium samples of endometriosis patients, and 14 eutopic endometrium samples of disease-free controls.

\section{RNA isolation}

RNA was isolated using the TRIzol reagent method (Invitrogen, Calsbad, CA, USA) according to the manufacturer's protocol. RNA quantity and quality was assessed with a spectrophotometer at 260 and $280 \mathrm{~nm}$ wavelengths. For the production of the complementary DNA (cDNA) the iScript cDNA synthesis kit (Bio-Rad, Hercules, CA, USA) was used.

\section{DNA isolation}

Genomic DNA was extracted from endometrium pipelle biopsies by using a proteinase $\mathrm{K}$ (Qiagen, Hilden, Germany) digestion followed by DNA isolation using the Puregene DNA Isolation Kit (Gentra Systems, MN, USA).

\section{Selection of genes}

Genes that were $>100$ fold up- or downregulated in eutopic endometrium of women with endometriosis in the study by Kao et al. were selected based on biological plausibility (involvement in processes such as apoptosis, angiogenesis, cell-cycle regulation, inflammation and adhesion). The promoter sequence of these genes was recovered (Ensembl) and investigated for the presence of significant CpG islands in the promoter region with the aid of appropriate software (CpG Plot, http://www.ebi.ac.uk/ Tools/emboss/cpgplot/). Progesterone receptor B (PRB) was added to the list of genes, because PRB has already been shown to be regulated by promoter hypermethylation in ectopic lesions of endometriosis (15). A summary of the genes investigated and their involvement in different pathways is given in Table 1. 
Table 1 Genes investigated in the present study and their involvement in different pathways *based on results by Kao et al.

\begin{tabular}{|c|c|c|c|c|}
\hline Gene & GenBank ID & Full description & Function & $\begin{array}{l}\text { Up/down in } \\
\text { endometriosis* }\end{array}$ \\
\hline PRIM2A & X74331 & DNA primase subunit p58 & DNA replication & Up \\
\hline TGFß3 & M60556 & Transforming growth factor $\beta 3$ & $\begin{array}{l}\text { Signal transduction, cell } \\
\text { growth, differentiation, } \\
\text { apoptosis }\end{array}$ & Up \\
\hline EFNB1 & L37361 & Ephrin-B1 & $\begin{array}{l}\text { Cell adhesion, } \\
\text { differentiation }\end{array}$ & Up \\
\hline TAF6L & AF069735 & PCAF-associated factor $65 \alpha$ & RNA polymerase & Down \\
\hline SHB & X75342 & $\begin{array}{l}\text { Src homology } 2 \text { domain containing } \\
\text { adaptor protein B }\end{array}$ & $\begin{array}{l}\text { Signal transduction, } \\
\text { apoptosis }\end{array}$ & Down \\
\hline BENE & U17077 & T-cell differentiation protein-like & $\begin{array}{l}\text { Differentiation, apical } \\
\text { trafficking }\end{array}$ & Down \\
\hline ITGA2 & X17033 & Integrin $\alpha 2$ subunit & Cell adhesion & Down \\
\hline Rap1GAP & M64788 & GTPase activating protein & Signal transduction & Down \\
\hline OGG1 & Y11731 & DNA glycosylase & DNA repair & Down \\
\hline PRB & M15716 & Progesterone receptor B & Differentiation & Down \\
\hline
\end{tabular}

\section{DNA modification and methylation specific PCR (MSP)}

Sodium bisulphite modification of DNA samples was carried out using reagents provided in the EZ DNA methylation Kit (Zymo Research, CA, USA). In this reaction, unmethylated cytosines are converted to uracil whereas those that are methylated (5-methylcytosine) are resistant to this modification and remain as cytosine. Subsequently, DNA subjected to bisulphite modification was amplified by PCR with primers specific for methylated and unmethylated DNA (methylation specific PCR). The methylation status of the promoter regions of selected genes was determined by a nested MSP approach, in order to increase the sensitivity of detecting allelic hypermethylation at targeted sequences. Step one of the nested MSP was carried out with primer sets (sense and anti-sense) flanking the CpG rich promoter regions of the 10 respective targeted genes in separate reactions. PCR products of step one were diluted 1:1000 and subjected to the second step that incorporated one set of primers for each gene [labeled unmethylated $(U)$ and methylated $(M)$ ] that were designed to recognize bisulfite-induced modifications of unmethylated $(U)$ and methylated (M) cytosines. Methylation was defined as the presence of (1) only an M band or (2) the presence of both $\mathrm{U}+\mathrm{M}$ bands. If the result was inconclusive, it was omitted from the analysis. Primer sets and PCR conditions for both steps of the nested MSP are listed in Table 2. DNA isolated from normal peripheral lymphocytes from healthy individuals served as a negative methylation control (NL). Normal lymphocyte DNA was treated in vitro with Sssl methyltransferase (New England Biolabs, Ipswich, MA) to create completely methylated DNA at all CpG-rich regions. In vitro methylated DNA (IVD) served as the positive methylation control. 
Table 2 Primer sets and PCR conditions for methylation specific DNA (U: unmethylated DNA; M: methylated DNA)

\begin{tabular}{|c|c|c|c|c|c|}
\hline Primer set & Sense primer & Antisense primer & $\begin{array}{l}\text { Amp } \\
\text { size } \\
\text { (bp) }\end{array}$ & $\begin{array}{l}\text { Annealing } \\
\text { temperature } \\
\left({ }^{\circ} \mathrm{C}\right) \\
\end{array}$ & $\begin{array}{l}\text { No of } \\
\text { PCR } \\
\text { cycles }\end{array}$ \\
\hline PRIM2A flank & 5'-AATTGGTGTGGTGGTTTTGA-3' & 5'-AAAAAAAATAAAACACTAAAAATCAC-3' & 100 & 56 & 35 \\
\hline PRIM2A U & 5'-TGGTGTGGTGGTTTTGATGTTTT-3' & 5'-AACACTAAAAATCACACAAACATACCA-3' & 86 & 60 & 35 \\
\hline PRIM2A M & 5'-GGTGTGGTGGTTTTGACGTTTC-3' & 5'-AAAATCACGCGAACGTACCG-3' & 78 & 60 & 35 \\
\hline TGFß3 flank & 5'-YGTAGGTTGGGAGTTTTTTTTTG-3' & 5'-ТСТСССТССТААТССССС-3' & 129 & 56 & 35 \\
\hline TGF $\beta 3 \mathrm{U}$ & 5'-ATGGTTGTTTITATTGGGTTTTTGT-3' & 5'-CCCCCAATCCCAAAACCA-3' & 84 & 66 & 35 \\
\hline TGF $\beta 3 \mathrm{M}$ & 5'-TCGTTTTTATCGGGTTTCGC-3' & 5'-CCCGATCCCGAAACCG-3' & 78 & 66 & 35 \\
\hline EFNB1 flank & 5'-TAGTGGGAGGTTTGTGAGGTT-3' & 5'-CRAACCCAATCCCATTAATTTTAC-3' & 135 & 56 & 35 \\
\hline EFNB1 U & 5'-GAGGTTTTGTATTGGTTGTAGATTTTT-3' & 5'-AAACCTCAACCAAATAACCCA-3' & 91 & 66 & 35 \\
\hline EFNB1 M & 5'-GTTCGTATTGGTCGTAGATTTTC-3' & 5'-CCTCGACCGAATAACCCG-3' & 85 & 66 & 35 \\
\hline TAF6L flank & 5'-CTGTAGTAAGAGAGGTTGTTTTT-3' & 5'-АСТСАСАСТСАТТСССТСТССС-3' & 193 & 57 & 35 \\
\hline TAF6L U & 5'-GGGAATTTTTAGTGTTATGTGATTGTT-3' & 5'-CCCAATACAACCAATCAACAAACA-3' & 124 & 60 & 28 \\
\hline TAF6L M & 5'-AATTTTTAGCGTTACGTGATCGTC-3' & 5'-CAATACAACCAATCGACGAACG-3' & 119 & 60 & 28 \\
\hline SHB flank & 5'-GTGTGTAGGAGYGGAGAGGTG-3' & 5'-CAACACCRCCCATCCC-3' & 102 & 56 & 35 \\
\hline SHB U & 5'-GGAGAGGTGTGTGTTTATTTTGGTTTT-3' & 5'-CAAACCTAACCCCAAACCACA-3' & 72 & 66 & 35 \\
\hline SHB M & 5'-GAGGTGCGTTATTTCGGTTTC-3' & 5'-CCTAACCCCGAACCGCG-3' & 65 & 66 & 35 \\
\hline BENE flank & 5'-GGTAGGAGGTGATATTTGATAGGT-3' & 5'-AAACAGAAAAAAATAATAAAAAACAA-3' & 158 & 54 & 35 \\
\hline BENE U & 5'-GAGGTGATATTTGATAGGTTGTGTGT-3' & 5'-AATAAAAAACAACACAACCCCCA- $3^{\prime}$ & 140 & 60 & 28 \\
\hline BENE M & 5'-GATATTTGATAGGTTGCGCGC-3' & 5'-AAACAACGCGACCCCCG-3' & 129 & 60 & 28 \\
\hline ITGA2 flank & 5'-GGATAGTTTTTAGAGTGTGTAGGTTT-3' & 5'-CCAACAGAACCCCAAAAAAC-3' & 234 & 57 & 35 \\
\hline ITGA2 U & 5'-TTTAGAGTGTGTAGGTTTTTGTATTTTTTT-3' & 5'-CAAACCCCAAAAAACCACACA-3' & 222 & 50 & 30 \\
\hline ITGA2 M & 5'-TTAGAGTGTGTAGGTTTTCGTATTTTTC-3' & 5'-CAACAACGACAACGACGCG-3' & 120 & 50 & 30 \\
\hline Rap1GAP flank & 5'-GGTAGGGYGGGGGTTTTTT-3' & 5'-CRCCRCTACAACTCTACTCAAATAC-3' & 164 & 56 & 35 \\
\hline Rap1GAP U & 5'-GGGGGTTTTTTTTGTTGTTTTTTGT-3' & 5'-CTACAACTCTACTCAAATACAACCAACA-3' & 150 & 66 & 35 \\
\hline Rap1GAP M & 5'-GGTTTTTTCGTCGTTTTCGC-3' & 5'-AACTCTACTCAAATACGACCGACG-3' & 144 & 66 & 35 \\
\hline OGG1 flank & 5'-GGGGYGTTTAGATGGAATT-3' & 5'-CRCCAATAAAAAATCAAAATAAAC-3' & 141 & 56 & 35 \\
\hline OGG1 U & 5'-GTTTAGATGGAATTTGTTAGTGTTTT-3' & 5'-ATAAACAAACCATTCTAAAACACTCA-3' & 119 & 64 & 35 \\
\hline OGG1 M & 5'-TAGATGGAATTCGTTAGCGTTTC-3' & 5'-GAACCGTTCTAAAACGCTCG-3' & 110 & 64 & 35 \\
\hline PRB flank & 5'-TGACTGTCGCCCGCAGTACG-3' & 5'-CGGCAATTTAGTGACACGCG-3' & 200 & 57 & 40 \\
\hline PRB U & 5'-TGATTGTTGTTTGTAGTATG-3' & 5'-CAACAATTTAATAACACACA- $3^{\prime}$ & 200 & 45 & 40 \\
\hline PRB M & 5'-TGATTGTCGTTCGTAGTACG-3' & 5'-CGACAATTTAATAACACGCG-3' & 200 & 51 & 40 \\
\hline
\end{tabular}

\section{Real-time PCR}

Real-time quantitative PCR was performed with the $A B I$ Taqman Gene Expression system (purchased from Applied Biosystems, Foster City, CA) for PRIM2A, TGFB3, EFNB1, TAF6L, SHB, BENE, ITGA2, Rap1GAP, OGG1 and PRB. Twelve eutopic endometrium samples were used for these experiments: six from women with laparoscopically and histologically confirmed endometriosis and six from disease-free controls. Samples from the same 12 women had also been used for analysis of promoter methylation status by MSP. Primers were designed with the aid of appropriate software (http://primerdepot.nci.nih.gov/) and are listed in Table 3. Human $\beta$ actin was used as house-keeping gene to normalize the differences in the amount of CDNA added to each PCR reaction. Relative quantification of mRNA species was performed using the comparative threshold cycles (CT) method. In brief, CT was used to determine the mRNA level normalized to the average mRNA level in endometrium biopsies. Thus, mRNA levels were expressed as an $\mathrm{n}$-fold difference. For each sample, the gene CT value was normalized using the formula: $\triangle C T=C T$ gene $-C T \beta$ actin. To determine relative expression levels, the following formula was used: $\triangle \triangle C T=\Delta C T$ sample $-\Delta C T$ calibrator. This value was used to plot the gene expression employing the formula $2^{-\Delta \Delta C T}$. 
Table 3 Primer sets used for quantitative real-time (RT) PCR

\begin{tabular}{lll}
\hline Gene & Sense & Antisense \\
\hline PRIM2A & 5'-GAGGTGATTGAGCAGAGGCT-3' & 5'-AGCCAAACTGTCCAAGGC-3' \\
TGF33 & 5'-CACATTGAAGCGGAAAACCT-3' & 5'-AAATTCGACATGATCCAGGG-3' \\
EFNB1 & 5'GCAGATGATGTCCAGCTTGT-3' & 5'-AAGAACCTGGAGCCCGTATC-3' \\
TAF6L & 5'-CTCTTCTCGCTCTGACATGG-3' & 5'-GAGTGTGAGCTGGTGAGTGG-3' \\
SHB & 5'-CTTGGCATCAAAGGGATCTG-3' & 5'-GAAACTGCTCAACAAGTGCG-3' \\
BENE & 5'-GGGGTATACTATGTGGGTGGC-3' & 5'-TGTTCCTCACCATCCCTTTC-3' \\
ITGA2 & 5'-TCACTTGAAGGACCGGAAAA-3' & 5'-CTGGTGTTAGCGCTCAGTCA-3' \\
Rap1GAP & 5'-ACAGGTCTAGTGCCTGAGGG-3' & 5'-CCCTTGGGGTGGACAAG-3' \\
OGG1 & 5'-GAGATGAGCCTCCACCTCTG-3' & 5'-CTTTTGGACCTCGGCTCATC-3' \\
\hline
\end{tabular}

\section{Statistical tests}

Statistical tests were carried out using the Statistical Package for the Social Sciences 16.0 (SPSS Inc., Chicago, IL) statistical analysis package. Promoter methylation frequencies were compared between the groups with the Fisher's exact test. To evaluate whether expression levels of the investigated genes varied significantly between the two groups, the non-parametric unpaired Mann-Whitney U-test was used. All p-values were twotailed and a $\mathrm{p}$ level $<0.05$ was considered to be statistically significant.

\section{Results}

\section{MSP in eutopic endometrium of women with endometriosis versus controls}

Gene promoter methylation in PRIM2A was present in $17 \%(2 / 12)$ of eutopic endometrium samples of controls and completely absent in eutopic endometrium of endometriosis patients $(0 / 12)$, but the difference was not statistically significant $(p=0.48)$. There were no statistically significant differences in methylation status of TGF $\beta 3$, EPNB1, TAF6L, ITGA2, BENE, Rap1GAP, OGG1 and PRB between eutopic endometrium of endometriosis patients and eutopic endometrium of controls. Gene promoter methylation in TGFB3, TAF6L, ITGA2, Rap1GAP and PRB was completely absent in both eutopic endometrium of women with endometriosis and controls. In the case of EPNB1, $100 \%$ of samples in both groups were methylated $(\mathrm{U}+\mathrm{M})(12 / 12$ and $12 / 12$, respectively). BENE showed promoter methylation in $27 \%$ (3/11) of eutopic endometrium of controls and in $31 \%(4 / 13)$ of eutopic endometrium of endometriosis patients (Table 4). MSP for SHB was considered inconclusive, because of an unexplained absence of signal ( $U$ and $M$ bands) in all samples, except in the positive (IVD) and negative (NL) methylation control. 
Table 4 Prevalence of promoter methylation (M) in eutopic endometrium of endometriosis patients and controls

\begin{tabular}{lcc}
\hline Gene & $\begin{array}{c}M \\
\text { endometriosis (\%) }\end{array}$ & $\begin{array}{c}\text { controls (\%) } \\
\text { PRIM2A }\end{array}$ \\
TGFB3 & $0 / 12(0 \%)$ & $2 / 12(17 \%)$ \\
EFNB1 & $0 / 12(0 \%)$ & $0 / 12(0 \%)$ \\
TAF6L & $12 / 12(100 \%)$ & $12 / 12(100 \%)$ \\
BENE & $0 / 5(0 \%)$ & $0 / 12(0 \%)$ \\
ITGA2 & $3 / 11(27 \%)$ & $4 / 13(31 \%)$ \\
Rap1GAP & $0 / 13(0 \%)$ & $0 / 14(0 \%)$ \\
OGG1 & $0 / 12(0 \%)$ & $0 / 12(0 \%)$ \\
PRB & $0 / 12(0 \%)$ & $0 / 12(0 \%)$ \\
\hline
\end{tabular}

\section{Expression levels of investigated genes in eutopic endometrium of endometriosis patients and controls}

Significantly higher expression levels of PRIM2A were observed in eutopic endometrium of endometriosis patients compared to eutopic endometrium of controls $(p=0.008)$ (Figure 1). Expression levels of TGF 33 , EPNB1, TAF6L, SHB, BENE, ITGA2, Rap1GAP and PRB were not significantly different between the groups, although a trend could be observed for higher expression levels of Rap1GAP and PRB in eutopic endometrium of endometriosis patients compared to controls (Figure 1). RT-PCR for OGG1 was considered inconclusive because of a high level of background noise caused by primer dimers, which distorted the melting curve.

\section{Discussion}

Epigenetic regulatory mechanisms such as DNA methylation have been implicated in the pathogenesis of endometriosis, illustrated by the fact that several genes involved in estrogen metabolism were shown to be regulated by promoter methylation in eutopic and ectopic endometrium of endometriosis patients. Hypermethylation of the $\mathrm{CpG}$ rich promoter region is commonly associated with complete silencing of gene expression. To date, several microarray studies have revealed differential expression of genes in the eutopic endometrium of endometriosis patients compared to disease-free controls (1-4). Based on the striking extent of up- or downregulation ( $>100$ fold) of certain genes harboring a significant $\mathrm{CPG}$ island in their promoter region (PRIM2A, TGF 33 , EFNB1, TAF6L, SHB, ITGA2, BENE, Rap1GAP, OGG1 and PRB) in one of these studies (3), we hypothesized that the expression of these genes may be regulated by promoter methylation. 

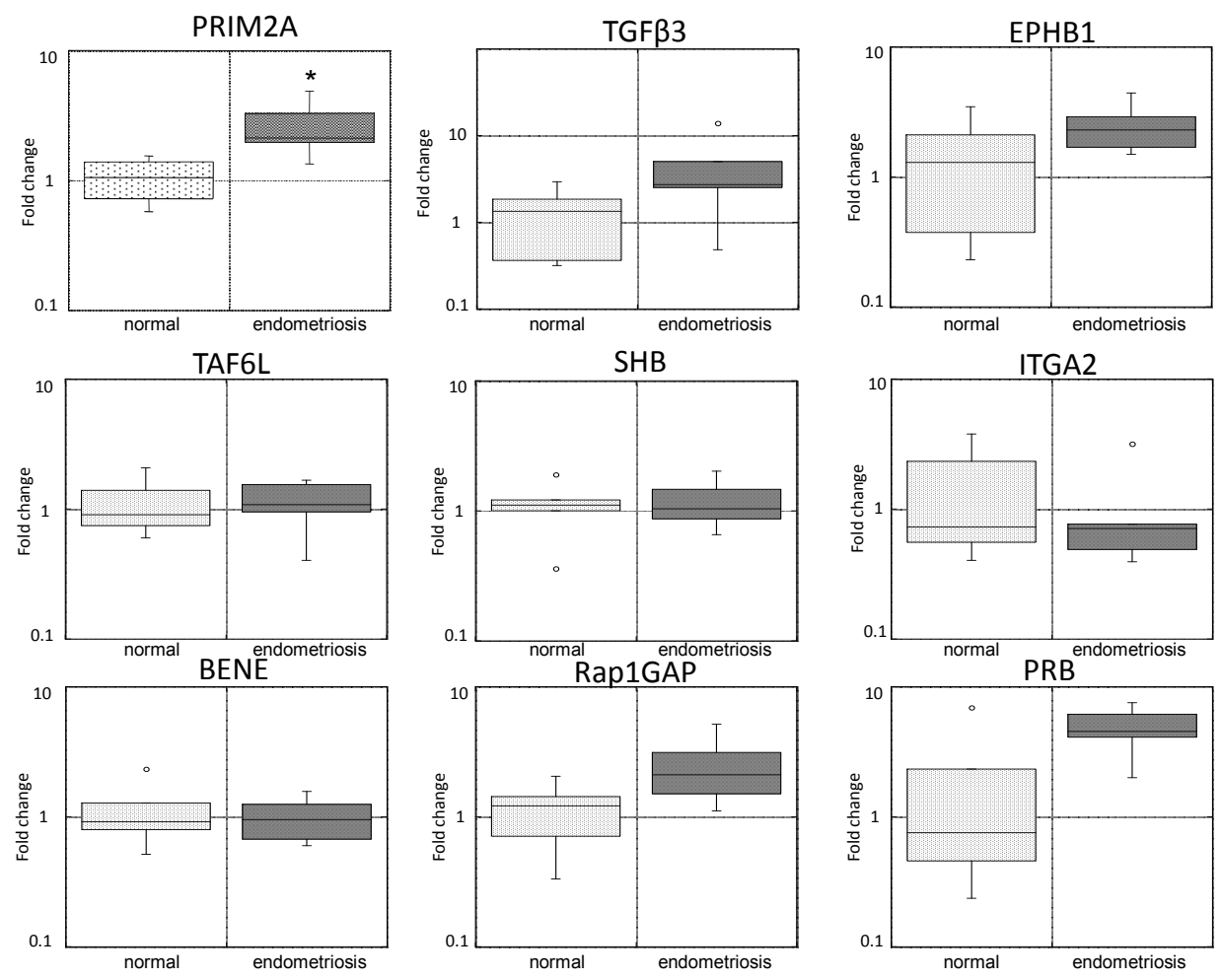

Figure 1 Expression levels of investigated genes in eutopic endometrium of disease-free controls (left) and eutopic endometrium of endometriosis patients (right). ${ }^{*} \mathrm{P}<0.05$ compared to eutopic endometrium of controls.

In the present study, we observed no statistically significant differences in methylation status of the investigated regions of the promoter $\mathrm{CpG}$ island between women with endometriosis compared to controls. In the following section, the interpretation of these data and the methodology used in the present study will be critically discussed within the context of recent and novel insights on the subject of DNA methylation and its exact relation to gene expression.

Not long ago, a rather strict correlation between promoter hypermethylation and gene silencing was assumed. This dogma is currently being revisited, as it has become clear that specific regions within a CPG island ("core regions") are crucial for the regulation of gene expression (17). These core regions are often situated around the transcription start site (TSS) within a CpG island, but can also be observed upstream or downstream of the TSS. Evidence is accumulating that transcriptional silencing depends on the methylation status of these gene-specific core regions within the CpG island, irrespective of the methylation 
status of adjacent CpG sites. A core region may be limited to merely a few CpG dinucleotides, as illustrated by a recent study demonstrating that methylation of only one specific $\mathrm{CpG}$ dinucleotide at the border of the $\mathrm{CpG}$ island is associated with transcriptional silencing of the TTP gene in liver cancer (18). Therefore, the exact location of hypermethylation seems to be the most important factor in determining whether or not a gene is silenced.

Furthermore, regulation of expression by hypermethylation of CpG dinucleotides is not necessarily restricted to the promoter area. It can also be observed in intra-and intergenic regions that may function as alternative promoters (19), in enhancers (i.e. cis-regulatory DNA sequences that increase transcription independent of their orientation and distance relative to the TSS) $(20,21)$, and in bidirectional promoters $(22,23)$. Strikingly, hypermethylation can even regulate expression in promoters without a classical CpG island (i.e. promoters with low CpG density) (24). Moreover, hypermethylation throughout the gene locus by means of long-range interactions with the promoter region has been described within the context of phenomena such as chromatin looping (25) and longrange epigenetic silencing (LRES, i.e. the concept that clusters of genes can be coordinately repressed by epigenetic mechanisms) (26-29).

Because of these newly identified location-related complexities of gene expression regulation by aberrant DNA methylation, data generated by MSP analysis need to be interpreted with extreme caution. The results of bisulfite -based analyses such as MSP are highly dependent on primer design. The most important limitation of MSP in this respect resides in the fact that only 2 to $4 \mathrm{CpG}$ dinucleotides per primer are assessed by this technique. In order to investigate the methylation status of the core region, MSP primers would need to perfectly cover the core region of interest. In the MSP analysis used in the present study, primers were designed without knowledge of the (location of) core regions for the genes investigated. Therefore, it can be concluded that no differences in methylation exist for the $\mathrm{CpG}$ dinucleotides in the promoter area that were covered by the primers used in the present study. However, no conclusion can be drawn on the regulation of these genes by (promoter) methylation, because the core regions crucial for the regulation of gene expression have not been analyzed. Another compromising factor is the lack of confirmation of significant differences in expression levels of the investigated genes by quantitative real-time PCR (except for PRIM2A). This could be due to the fact that no actual differences in expression levels exist, or to the fact that the sample size in the present study is too small to detect these differences.

A great variety of technologies is available for the analysis of DNA methylation, most of which are based on one of three main principles: methylation-sensitive restriction enzymes, bisulphite conversion of unmethylated cytosines and immunoprecipitation of 5methylcytosines (30). The kind of information obtained (qualitative, quantitative, resolution etc.) highly depends on the method chosen. Therefore, it is critical to choose the approach that fits the planned research objectives best. Up until now, MSP has been one of the most widely used methods to detect CpG island methylation (31). It is simple, 
sensitive (to $0.1 \%$ methylated alleles of a given CpG-rich locus) and requires small quantities of DNA, allowing for the study of paraffin-embedded or microdissected tissue samples. In retrospect however, taking the most recent insights on core regions into account, MSP is not the appropriate assay to test our hypothesis. This is mainly because of its low resolution (i.e. its ability to detect only a few CpGs inside the primers) and its inability to quantify methylation at a given locus. A method that would be more suitable for this purpose is pyrosequencing (32). Pyrosequencing provides reproducible and accurate measures of the degree of methylation at several $\mathrm{CpGs}$ in close proximity in combination with a high quantitative resolution. Like MSP, this method requires the coupling of bisulphite treatment of genomic DNA with PCR amplification of the target sequence, but is followed by pyrosequencing as a final step. Pyrosequencing is a sequence-by-synthesis approach (i.e. real-time) that detects luminescence (proportional to the quantity of DNA and number of nucleotides) from the release of pyrophosphate following nucleotide incorporation into the complementary strand. The incorporation of a cytosine is indicative of a methylated residue, whereas the incorporation of a thymine indicates an originally unmethylated cytosine. Thus, the degree of methylation at each $\mathrm{CPG}$ site is determined from the ratio of $\mathrm{C}$ and $\mathrm{T}$. In order to test our hypothesis accurately, this approach needs to be core region- specific, implying that the choice of region analysis is extremely important in this respect.

In summary, based on the findings in the present study it is not possible to draw any definitive conclusions on the question whether the expression of the investigated genes is regulated by (promoter) methylation. We recommend that our hypothesis may be retested in a larger cohort of eutopic endometrium samples, with the use of modern, sensitive, core-region specific techniques with validation of expression levels by qRT-PCR as a first screening test. 


\section{References}

1. Taylor RN, Lundeen SG, Giudice LC. Emerging role of genomics in endometriosis research. Fertil Steril 2002;78:694-8.

2. Giudice LC, Telles TL, Lobo S, Kao L. The molecular basis for implantation failure in endometriosis: on the road to discovery. Ann N Y Acad Sci 2002;955:252-64; discussion 93-5, 396-406.

3. Kao LC, Germeyer A, Tulac S, Lobo S, Yang JP, Taylor RN, Osteen K, Lessey BA, Giudice LC. Expression profiling of endometrium from women with endometriosis reveals candidate genes for disease-based implantation failure and infertility. Endocrinology 2003;144:2870-81.

4. Matsuzaki S, Canis M, Vaurs-Barriere C, Boespflug-Tanguy O, Dastugue B, Mage G. DNA microarray analysis of gene expression in eutopic endometrium from patients with deep endometriosis using laser capture microdissection. Fertil Steril 2005;84 Suppl 2:1180-90.

5. Matsuzaki S, Canis M, Vaurs-Barriere C, Pouly JL, Boespflug-Tanguy O, Penault-Llorca F, Dechelotte P, Dastugue B, Okamura K, Mage G. DNA microarray analysis of gene expression profiles in deep endometriosis using laser capture microdissection. Mol Hum Reprod 2004;10:719-28.

6. Matsuzaki S, Canis M, Pouly JL, Botchorishvili R, Dechelotte PJ, Mage G. Differential expression of genes in eutopic and ectopic endometrium from patients with ovarian endometriosis. Fertil Steril 2006;86:548-53.

7. Borghese B, Mondon F, Noel JC, Fayt I, Mignot TM, Vaiman D, Chapron C. Gene expression profile for ectopic versus eutopic endometrium provides new insights into endometriosis oncogenic potential. Mol Endocrinol 2008;22:2557-62.

8. Hu WP, Tay SK, Zhao Y. Endometriosis-specific genes identified by real-time reverse transcriptionpolymerase chain reaction expression profiling of endometriosis versus autologous uterine endometrium. $J$ Clin Endocrinol Metab 2006;91:228-38.

9. Mettler L, Salmassi A, Schollmeyer T, Schmutzler AG, Pungel F, Jonat W. Comparison of c-DNA microarray analysis of gene expression between eutopic endometrium and ectopic endometrium (endometriosis). J Assist Reprod Genet 2007;24:249-58.

10. Eyster KM, Klinkova O, Kennedy V, Hansen KA. Whole genome deoxyribonucleic acid microarray analysis of gene expression in ectopic versus eutopic endometrium. Fertil Steril 2007;88:1505-33.

11. Xue Q, Lin Z, Cheng YH, Huang CC, Marsh E, Yin P et al. Promoter methylation regulates estrogen receptor 2 in human endometrium and endometriosis. Biol Reprod 2007;77:681-7.

12. Xue Q, Lin Z, Yin P, Milad MP, Cheng YH, Confino E, Reierstad S, Bulun SE. Transcriptional activation of steroidogenic factor- 1 by hypomethylation of the $5^{\prime}$ CpG island in endometriosis. J Clin Endocrinol Metab 2007;92:3261-7.

13. Izawa M, Harada T, Taniguchi F, Ohama Y, Takenaka Y, Terakawa N. An epigenetic disorder may cause aberrant expression of aromatase gene in endometriotic stromal cells. Fertil Steril 2008;89:1390-6.

14. Wu Y, Halverson G, Basir Z, Strawn E, Yan P, Guo SW. Aberrant methylation at HOXA10 may be responsible for its aberrant expression in the endometrium of patients with endometriosis. Am J Obstet Gynecol 2005;193:371-80.

15. Wu Y, Strawn E, Basir Z, Halverson G, Guo SW. Promoter hypermethylation of progesterone receptor isoform $B(P R-B)$ in endometriosis. Epigenetics 2006;1:106-11.

16. Wu Y, Strawn E, Basir Z, Halverson G, Guo SW. Aberrant expression of deoxyribonucleic acid methyltransferases DNMT1, DNMT3A, and DNMT3B in women with endometriosis. Fertil Steril 2007;87:2432.

17. van Vlodrop IJ, Niessen HE, Derks S, Baldewijns MM, van Criekinge W, Herman JG, van Engeland M. Analysis of promoter CpG island hypermethylation in cancer: location, location, location! Clin Cancer Res 2011;17:4225-31.

18. Sohn BH, Park IY, Lee JJ, Yang SJ, Jang YJ, Park KC, Kim DJ, Lee DC, Sohn HA, Kim TW, Yoo HS, Choi JY, Bae YS, Yeom YI. Functional switching of TGF-beta1 signaling in liver cancer via epigenetic modulation of a single CPG site in TTP promoter. Gastroenterology 2010;138:1898-908.

19. Maunakea AK, Nagarajan RP, Bilenky M, Ballinger TJ, D'Souza C, Fouse SD, Johnson BE, Hong C, Nielsen C, Zhao Y, Turecki G, Delaney A, Varhol R, Thiessen N, Shchors K, Heine VM, Rowitch DH, Xing X, Fiore C, Schillebeeckx M, Jones SJ, Haussler D, Marra MA, Hirst M, Wang T, Costello JF. Conserved role of intragenic DNA methylation in regulating alternative promoters. Nature 2010;466:253-7. 
20. Blackwood EM, Kadonaga JT. Going the distance: a current view of enhancer action. Science 1998;281: 60-3.

21. Bulger M, Groudine M. Looping versus linking: toward a model for long-distance gene activation. Genes Dev 1999;13:2465-77.

22. Lin Lin JC, Jeong S, Liang G, Takai D, Fatemi M, Tsai YC, Egger G, Gal-Yam EN, Jones PA. Role of nucleosomal occupancy in the epigenetic silencing of the MLH1 CpG island. Cancer Cell 2007;12:432-44.

23. Shu J, Jelinek J, Chang H, Shen L, Qin T, Chung W, Oki Y, Issa JP. Silencing of bidirectional promoters by DNA methylation in tumorigenesis. Cancer Res 2006;66:5077-84.

24. Domann FE, Rice JC, Hendrix MJ, Futscher BW. Epigenetic silencing of maspin gene expression in human breast cancers. Int J Cancer 2000;85: 805-10.

25. Tiwari VK, McGarvey KM, Licchesi JD, Ohm JE, Herman JG, Schübeler D, Baylin SB. PcG proteins, DNA methylation, and gene repression by chromatin looping. PLoS Biol 2008;6:2911-27.

26. Frigola J, Song J, Stirzaker C, Hinshelwood RA, Peinado MA, Clark SJ. Epigenetic remodeling in colorectal cancer results in coordinate gene suppression across an entire chromosome band. Nat Genet 2006;38: 540-9.

27. Hitchins MP, Lin VA, Buckle A, Cheong K, Halani N, Ku S, Kwok CT, Packham D, Suter CM, Meagher A, Stirzaker C, Clark S, Hawkins NJ, Ward RL. Epigenetic inactivation of a cluster of genes flanking MLH1 in microsatellite-unstable colorectal cancer. Cancer Res 2007;67:9107-16.

28. Rodriguez J, Munoz M, Vives L, Frangou CG, Groudine M, Peinado MA. Bivalent domains enforce transcriptional memory of DNA methylated genes in cancer cells. Proc Natl Acad Sci USA 2008;105: 19809-14.

29. Coolen MW, Stirzaker C, Song JZ, Statham AL, Kassir Z, Moreno CS, Young AN, Varma V, Speed TP, Cowley M, Lacaze P, Kaplan W, Robinson MD, Clark SJ. Consolidation of the cancer genome into domains of repressive chromatin by long-range epigenetic silencing (LRES) reduces transcriptional plasticity. Nat Cell Biol 2010;12:235-46.

30. Jorda M, Peinado MA. Methods for DNA methylation analysis and applications in colon cancer. Mutat Res 2010;693:84-93.

31. Herman JG, Graff JR, Myohanen S, Nelkin BD, Baylin SB. Methylation-specific PCR: a novel PCR assay for methylation status of CpG islands. Proc Natl Acad Sci USA.1996;93:9821-6.

32. Uhlmann K, Brinckmann A, Toliat MR, Ritter H, Nurnberg P. Evaluation of a potential epigenetic biomarker by quantitative methyl-single nucleotide polymorphism analysis. Electrophoresis 2002;23:4072-9. 


\section{Chapter 7}

General Discussion 
Chapter 7 
In this thesis different molecular pathways were studied with regard to their potential involvement in the initiation and progression of severe endometriosis. The relevance and clinical implications of the findings obtained in these studies as well as the future perspectives are discussed in this chapter.

\section{Fibromuscular differentiation and TGF- $\beta$ signaling in deep infiltrating endometriosis}

In the first part of this thesis the origin of smooth muscle (SM) like cells in deep infiltrating endometriosis and the underlying mechanism responsible for the presence of these cells was investigated. We demonstrated that the fibromuscular tissue in deep infiltrating endometriosis lesions expresses multiple markers of SM differentiation, similar to the situation encountered in pathological wound healing and fibrocontractive diseases. In a nude mouse model we showed that the expression of alpha-smooth muscle actin (ASMA) was induced in murine tissue after implantation of human endometrial fragments, suggesting that the presence of SM-like tissue in endometriosis lesions is the result of a reaction of the local environment to the presence of ectopic endometrium.

A small number of studies reported suggestive evidence in favor of the notion that SM like cells in endometriosis lesions result from SM metaplasia of endometrial stromal cells. In one study this was based on positive staining for uterine markers estrogen receptor (ER), PR and oxytocin receptor in differentiated smooth muscle cells in the periphery of endometriosis lesions (1). However, given their location remote from the lesion and their degree of differentiation it is very well possible that these cells are in fact resident smooth muscle cells that were already present before ectopic endometrium arrived at the site. In two other studies, the presence of ASMA positive cells between endometriotic stromal cells led to the assumption that these cells were of uterine origin $(2,3)$. This was later contradicted by a study by Hull and coworkers, using a mouse xenograft model. Fluorescent colocalization of anti-ASMA antibodies and the Hoechst nuclear stain 14 days after transplantation of human endometrial fragments into nude mice revealed that ASMA positive myofibroblasts in central locations (i.e. in the endometrial stroma) in endometriosis lesions were of murine origin, thereby confirming our conclusion that ASMA is induced in local host cells and not in human endometrial stroma (4).

It remains to be fully elucidated whether TGF- $\beta 1$ is indeed (partially) responsible for the fibromuscular reaction observed in deep infiltrating endometriosis. Hull and coworkers investigated endometrial-peritoneal interactions during endometriotic lesion establishment in mouse xenograft lesions (4) using microarrays. One of the four key pathways identified in this study was the TGF- $\beta$ pathway. RNA transcripts of TGF- $\beta$, myofibroblast-associated transcripts such as ASMA as well as ECM components were present in both human and mouse transcriptomes, supporting the importance of this pathway in endometriosis lesion formation. 
With respect to the source that TGF- $\beta$ is derived from in endometriosis, peritoneal macrophages are likely candidates. It has been demonstrated that TGF- $\beta 1$ levels are elevated in peritoneal fluid of women with endometriosis (5) and it has been postulated that this is the result of secretion of TGF- $\beta$ by activated macrophages in the peritoneal fluid. It is known that two major macrophage phenotypes exist, carrying out differential functions and eliciting divergent effects on surrounding cells and tissues (6). Classically activated macrophages (M1) promote inflammation, extracellular matrix (ECM) destruction and apoptosis, while alternatively activated macrophages (M2) demonstrate a more "permissive" phenotype, promoting ECM construction, cell proliferation and angiogenesis. The differentially activated phenotype is induced by cytokines IL4 and IL13 and is thought to play a role in fibrosis, due to the release of profibrotic factors such as interleukin (IL)-1 $\beta$, TGF- $\beta$, fibronectin and matrix metalloproteinases (7). Macrophages in the peritoneal fluid and those that actively infiltrate ectopic lesions display features of alternative activation in both endometriosis patients and mice with experimentally induced endometriosis (8). Furthermore, adoptive transfer of alternatively activated macrophages into a mouse xenograft model dramatically enhanced endometriotic lesion growth, whereas classically activated macrophages significantly reduced growth of ectopic lesions (8). This suggests that the peritoneal environment in endometriosis patients induces the differentiation of macrophage precursors toward an alternatively activated, reparatory phenotype and that the alternative activation of macrophages may be a clue to the heterogeneity in the susceptibility to endometriosis.

\section{TGF- $\beta$ : a target for drug therapy in endometriosis?}

Ultimately, one of the goals of identifying factors involved in the pathogenesis of endometriosis is the development of effective therapeutic strategies, and TGF- $\beta 1$ may be a potential target in this respect. Interestingly, targeted deletion of TGF- $\beta 1$ in nude mice resulted in a significantly smaller amount of ASMA positive murine myofibroblasts in endometriosis lesions and significantly lower weight of endometriosis lesions in total compared to TGF- $\beta 1^{+/+}$mice (9). Furthermore, it has been demonstrated that TGF- $\beta 1$ enhances transmesothelial invasion by immortalized endometrial cells and eutopic endometrial epithelial cells of endometriosis patients in vitro (10) and antagonists of TGF$\beta 1$ signaling significantly inhibited cellular invasiveness. Inhibitors of TGF- $\beta 1$ signaling components may therefore be efficacious in the treatment of endometriosis.

TGF- $\beta$ regulates key mechanisms of tumor development, namely immunosuppression, metastasis, angiogenesis, and proliferation, also making it an attractive target for antitumor therapies. Currently, the majority of the TGF- $\beta$ signaling inhibitors are in the preclinical stage. For example, TGFBR I inhibitors were shown to be effective in inhibiting pancreatic adenocarcinoma cell growth in a mouse xenograft model and in vitro $(11,12)$. So far, the most progress has been made with the TGF beta 2 blocking oligonucleotide trabedersen, that is now being used in clinical studies (13). Intratumoral treatment with 
trabedersen in patients with high-grade glioma is currently evaluated in a randomized controlled phase III study, and phase I/II studies in advanced pancreatic carcinoma, metastatic melanoma, and metastatic colorectal carcinoma are ongoing. At present, an antibody to all three isoforms of human TGF- $\beta$ (GC-1008), a small-molecule inhibitor of the TGF- $\beta$ RI kinase (LY573636), and a vaccine using allogeneic tumor cells have also entered clinical cancer trials (14).

Further studies are required to elucidate the mechanistic actions of (components of) the TGF- $\beta 1$ signaling pathway and its inhibitors on endometriosis lesions before targeting of TGF- $\beta 1$ is contemplated. Moreover, when designing drugs that target TGF- $\beta 1$ signaling one should be aware of undesirable side effects that may arise due to potentially blocking tumor-suppressor activity of TGF- $\beta(15,16)$. Dissection of the TGF- $\beta 1$ signaling pathway may lead to the development of improved therapeutics that target specific TGF- $\beta 1$ signaling components involved in endometriosis without affecting its tumor-suppressor activity.

\section{Suitability of animal models}

Some of the results described above should be interpreted with caution because they were obtained in animal models, most often murine models. Murine models are the most frequently used to study the establishment and evolution of endometriosis in time and characterize key (molecular) events in this dynamic process. This is due to their low cost and the possibility of (1) studying the endometrial lesions at different time intervals and (2) acquiring knowledge about the effect of different drugs or treatment. In addition, a number of genetic knock out models are available, and mice are easy to manipulate genetically. Despite these advantages, it is important to recognize that the murine model presents several important limitations. First, mice lack menstruation and consequently do not develop spontaneous endometriosis. Second, the use of mouse xenograft models (i.e. in which human endometrial tissue is used) implies the use of immunocompromized rodents such as nude mice. This hampers the investigation of an immunoregulatory component involved in the pathogenesis of this disease. Third, endometriosis lesions in mice are small and are not physiologically similar to those found in advanced stages of human disease. Human endometrial tissue transplanted into nude mice only has a limited lifespan, being unable to persist beyond 4 weeks (17) and as a result, cannot acquire characteristics of more advanced stages of endometriosis. Therefore, the extent to which the induced lesions in mice are truly representative of the disease itself, and in particular advance staged disease such as deep infiltrating endometriosis, is debatable.

Some of the limitations named above can be overcome by the use of nonhuman primates, although the use of this model is costly and faced with ethical concerns. Of the nonhuman primates, the baboon (Papio anubis) is the most favorable because of its phylogenetic similarity to humans, its size and similar reproductive anatomy. Baboons are a menstruating species that develop spontaneous endometriosis with ectopic tissue 
morphologically identical to humans and at similar sites (18-20). Endometriosis in baboons can also be artificially induced by injecting autologous menstrual effluent into the pelvic cavity $(21,22)$ mimicking the process of retrograde menstruation. In baboons, it is possible to perform repetitive laparoscopies and collect biological samples before and after the induction of disease, making this model particularly useful for studying the effect of therapeutic interventions. Although the baboon arguably constitutes the most suitable animal model for endometriosis for reasons named above, it presents with a limitation similar to the murine models: minimal to moderate disease is the most common finding in nonhuman primates, whereas severe endometriosis is rarely encountered $(23,24)$. Again, this raises the question whether (artificially induced or spontaneous) endometriosis in nonhuman primates reflects "real" endometriosis, i.e. advanced, symptomatic disease. This may also explain why none of the recently tested drugs that showed effectiveness in reducing the extent of endometriotic lesions in animal models in the preclinical stage has reached the clinic thus far (25-27).

It may be concluded that both rodent and nonhuman primate animal models are invaluable tools for the investigation of specific (early) events involved in the pathogenesis of endometriosis, but it is important to be aware of the relevant disadvantage concerning the extent to which findings obtained in these models can be extrapolated to severe stages of endometriosis in humans. It remains to be determined to what extent the different models are predictive for evaluating clinical efficacy of new therapeutic strategies.

\section{Genetic aberrations in selected candidate genes}

In the second part of the thesis, we investigated the possible association between the presence of single nucleotide polymorphisms (SNPS) with functional consequences at the gene or protein level in two selected candidate genes and the susceptibility for developing deep infiltrating endometriosis. We concluded that no association exists between the presence of the $-509 \mathrm{C} / \mathrm{T}$ polymorphism in the TGF- $\beta 1$ gene or the PROGINS polymorphism in the progesterone receptor gene and deep infiltrating endometriosis. A positive association could be demonstrated between the presence of the $+331 \mathrm{G} / \mathrm{A}$ polymorphism in the progesterone receptor gene and a reduced risk of deep infiltrating endometriosis compared to population controls.

\section{Drawbacks of the candidate gene approach}

At the time when we performed our experiments, the (hypothesis driven) candidate gene study was the mainstay of genetic investigation into the vast majority of complex diseases thought to have a genetic component, but at present substantial criticism is directed at this approach. Lack of replication of genetic associations across different populations is 
the main reason for this criticism. This has also proven to be true for the results obtained in our studies, because they were not consistently replicated in subsequent studies (2834) (Table 1). There are many reasons for the lack of reproducibility encountered in a large number of candidate gene studies. The most important of these is the fact that many candidate gene studies are statistically underpowered. Complex diseases are likely to be caused by multiple (and sometimes numerous) genes, each with an overall small contribution and relative risk. Large sample sizes (typically several thousand cases and controls) are needed in order to detect the expected small effect size of a particular variant, and most candidate gene studies conducted in the field of endometriosis have failed to reach these numbers. Furthermore, genetic associations are often inconsistent across ethnic barriers, due to different frequencies of polymorphic alleles as well as genegene interactions. Therefore, a genetic association, although valid in a specific ethnic population, may not be relevant for individuals of another ethnicity. Candidate gene studies in endometriosis might differ in study population and the definition of the phenotype studied. Ovarian, peritoneal and deep infiltrating endometriosis are often taken together as a group and are not treated as different disease entities with potentially different etiologies- albeit with considerable overlap. As a result, non-replication of association with a particular genetic variant might result from real biological differences between different phenotypes. Conversely, evidence of genetic risk in a homogenous population of endometriosis without subtype investigation is likely to lead to spurious associations. Moreover, problems such as confounding, different types of bias and misclassification are more likely to obscure small- to-moderate relative risks than larger relative risks.

Some of these methodological problems can (in part) be overcome by summarizing data from individual studies in the form of a meta-analysis. The only consistent association revealed by a recent meta-analysis of genetic association studies so far is a positive association between the presence of a phase II detoxifying enzyme GSTT1 polymorphism and the risk of endometriosis. There was a $29 \%$ increased risk of endometriosis in GSTT1 null deletion carriers (35). However, there was evidence of publication bias in this metaanalysis, indicating that the effect size of the GSTT1 deletion may actually be smaller or non-existent (36).

\section{Genome wide association studies in endometriosis: a new era}

The candidate gene approach is a "hypothesis driven" approach, meaning that a gene identified as a candidate is hypothesized to be involved in the risk of developing endometriosis based on biological plausibility and then examined for genetic variants, usually SNPs. However, biological pathways thought to play a role in the development of endometriosis are complex and generally involve a magnitude of genes. It has been argued that incomplete understanding of such pathways renders it likely that variants and genes of possible importance are overlooked by using hypothesis driven techniques. In 


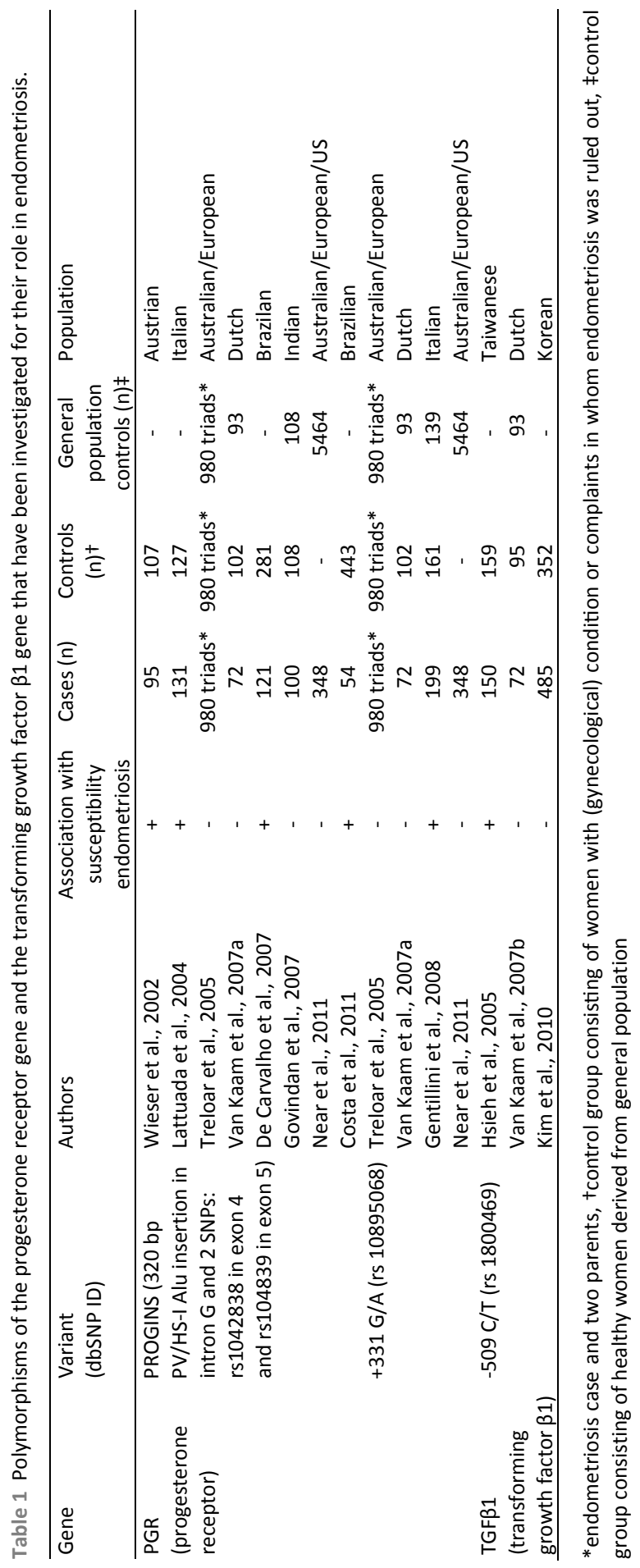


reaction to this, the attention has shifted to high-throughput, non-hypothesis driven strategies such as the genome wide association study (GWAS). Genome wide association studies can be thought of as a large series of candidate gene studies performed in a single experiment on an array based format that capture most, although not all, common variation in the genome. Typically, several hundred thousand to more than 1 million SNPs at a time are studied in this manner. These are evenly spread throughout the entire genome and therefore require no knowledge of genes or biological pathways involved in disease pathogenesis. This type of study has now largely superseded the candidate gene approach and genetic linkage and has proven to be successful in identifying genetic variants that contribute to other complex diseases such as type 2 diabetes and rheumatoid arthritis. The results of the first GWA studies in the field of endometriosis are now emerging. Uno and coworkers found a significant association with a SNP in the tumor suppressor gene CDKN2BAS in a cohort of Japanese women. Furthermore, a possible association was found for a SNP in the linkage disequilibrium (i.e. the non-random association of alleles at two or more loci) block of CDKN2BAS containing WNT4 (37). An even larger genome-wide association study was carried out by an Australian group, who identified a novel locus on chromosome 7p15.2 that was significantly associated with risk of endometriosis in women of European ancestry (38). The identified SNP is located in an intergenic region upstream of the plausible candidate genes NFE2L3 and HOXA10. Interestingly, this group confirmed the previously reported suggestive association for SNPS close to the WNT4 locus in a cohort of British, US and Australian women. WNT4 is important for development of the female reproductive tract (39), ovarian follicle development and steroidogenesis $(40,41)$ and therefore also a plausible candidate gene. Future research should be aimed at elucidating whether variations in these genes truly modify the risk of endometriosis, and the mechanism by which they do so.

In conclusion, considerable debate has arisen over the best strategies to use for the genetic analysis of complex traits such as endometriosis. It is unlikely that any one approach will yield all there is to find in the human genome with regard to disease susceptibility. The advent of new techniques such as GWAS has contributed enormously to the understanding of the genetics of other complex diseases and progress is just beginning to be made in the case of endometriosis. In order to be successful, sufficiently large, well phenotyped case cohorts are required, and international collaborations are essential to replicate initial findings in a second population. Although these measures will lead to increased cost and complexity of studies, only through robust and well-designed experimental procedures we will truly be able to define which pathways contribute to the disease and begin to understand the genetic risks of endometriosis. 


\section{Endometriosis, an epigenetic disease?}

The third part of the thesis addresses the question whether epigenetic regulatory mechanisms, such as DNA methylation, are involved in differential expression of genes in endometriosis patients and in regulating the functional changes in the endometrial that occur throughout the menstrual cycle. Our findings demonstrate cyclical variations in expression levels of epigenetic modulators DNMT1 and MBD2, suggesting that DNA methylation may be involved in endometrial growth and differentiation. Furthermore, the expression of these genes was shown to be regulated by steroid hormones in experiments using endometrial explant cultures. Expression levels of several DNMTs, and MBDs were significantly reduced in ectopic endometrium of endometriosis patients, possibly explaining why altered promoter methylation of certain genes is observed in endometriotic lesions. Finally, we demonstrated that expression levels of a selection of genes that were shown to be markedly up- or downregulated in eutopic endometrium of endometriosis patients in a previous microarray study are not regulated by promoter methylation.

\section{Epigenetic regulatory mechanisms in the endometrium throughout the menstrual cycle}

There is little evidence that differential expression of genes in different phases of the menstrual cycle is under control of DNA methylation. At this point in time, there is more evidence that favors the notion that histone modifications are involved in this process. Modification of histones is an accepted and ubiquitous epigenetic mechanism that allows the transient condensation or relaxation of the chromatin, and therefore controls the accessibility of transcription factors to the DNA for gene transcription. Histone deacetylation, one of the best characterized histone modifications, is associated with gene silencing, whereas histone acetylation is associated with transcriptional activation (42). Histone acetylation is implicated in the vascular endothelial growth factor pathway during angiogenesis (43), and key events in the endometrium such as proliferation, differentiation and decidualization can be influenced in vitro by administration of histone deacetylases (HDAC) and HDAC inhibitors (44-46), suggesting a role for histone acetylation status in these processes.

The endometrium is a dynamic tissue with large numbers of genes whose expression need to be regulated in a controlled manner during the menstrual cycle, implicating that the induced changes need to be (rapidly) reversible. It has been shown that most, if not all, histone modifications are dynamic and rapidly changing. Acetylation, methylation, phosphorylation, and deimination can appear and disappear on chromatin within minutes of a stimulus arriving at the cell surface (47). It is therefore conceivable that histone modifications such as histone acetylation are indeed involved in differential expression of genes throughout the menstrual cycle. Strikingly, preliminary data by Munro and 
coworkers indicate that endometrial global histone acetylation, as determined by western blotting, changed throughout the menstrual cycle and correlated well with expected transcription activity during the different phases (48), whereas expression levels of HDACs and histone acetylases (HATs) are expressed in the human endometrium without cyclical changes (49). This implies that, although it is tempting to speculate that varying expression levels of epigenetic modulators DNMTs, MBDs, HDACs and HATs correlate with DNA methylation or global acetylation status of the endometrium throughout the menstrual cycle, at this point in time there is insufficient evidence to support this notion. More research is needed to elucidate if such a correlation exists.

\section{Correlation between gene expression and promoter methylation in endometriosis}

In line with the above named speculation, our observation of reduced levels of DNMTs and MBDs in ectopic endometrium of endometriosis would be expected to lead to overall reduced levels of DNA methylation in this tissue. Research conducted on the subject so far has revealed three specific gene promoters that are hypomethylated in ectopic endometrium (50-52) and two gene promoters that are hypermethylated $(53,54)$. Recent genome-wide profiling of methylated promoters in endometriosis by Borghese and coworkers demonstrated that the overall methylation profile was highly similar between eutopic endometrium and ectopic endometrium from superficial peritoneal, ovarian and deep infiltrating lesions. It showed promoter regions that were consistently hypomethylated or hypermethylated in all types of endometriosis and others that were specific to one given subtype, but hypomethylation was not more prevalent in ectopic endometrium than hypermethylation (55).

In endometriosis, it is the question whether the aberrant DNA methylation observed in eutopic and ectopic endometrium is the cause or the consequence of the disease. On the one hand, aberrant DNA methylation of gene promoters can be an innate property of the eutopic endometrium, causing changes in gene expression that lead to intrinsic differences (i.e. increased proliferation and survival in the ectopic environment) that contribute to the pathogenesis of this disease. However, it has been shown that expression levels of HOXA10, a gene critical for endometrial decidualization and implantation, are reduced in eutopic endometrium after the induction of endometriosis in mice and baboons (56). This is accompanied by promoter hypermethylation of HOXA10, which is not present in disease- free animals (57). These findings suggest that epigenetic changes in eutopic endometrium may be elicited by external factors such as the presence of ectopic endometrium and therefore represent the result of the disease rather than the cause. In the case of ectopic endometrium, chronic inflammation is thought to play a role in the epigenetic modifications that are observed in this tissue. It is generally known that DNA methylation patterns are influenced by age, diet, toxins, (intra-uterine) environment, the use of medication and chronic inflammation $(58,59)$. It has been postulated that 
repetitive retrograde menstruation elicits a chronic inflammatory response in the local peritoneal environment, leading to aberrant methylation of gene promoters in endometrium after it arrives at ectopic locations, favoring the notion that epigenetic changes arise as a result of the disease.

\section{A short- lived dogma?}

Another striking observation in the study by Borghese and coworkers (55) is that there is no evident correlation between methylation and expression level of nearby genes in ovarian endometrioma cells. This is in apparent contradiction with the current dogma that methylated $\mathrm{CpGs}$ are associated with repression of transcription. However, this observation is not a new one. A recent study by Rakyan and coworkers also reports a negative correlation between DNA methylation and gene expression at promoters with a high, medium or low CpG density (60). Conversely, gene-body methylation was found to positively correlate with gene expression $(43,60,61)$. This may (partially) explain why we didn't observe aberrant promoter methylation in genes that were severely up-or downregulated in eutopic endometrium of endometriosis patients. A recently discovered entity, 5-hydroxmethylation of cytosines $(5 \mathrm{hmC})$, may prove to be of importance in explaining this phenomenon. $5 \mathrm{hmC}$ is particularly enriched at promoters and in intragenic regions (gene bodies) but is largely absent from non-gene regions (62). 5hydroxymethylation peaks at transcription start sites did not correlate with gene expression levels for promoters with intermediate or high CpG content. However, the presence of $5 \mathrm{hmC}$ in gene bodies was more positively correlated with gene expression levels than was the presence of 5 -methylcytosine $(5 \mathrm{mC})$, suggesting that $5 \mathrm{hmC}$ may be more potent than $5 \mathrm{mC}$ in suppressing intragenic transcription (62).

Importantly, the most commonly used technique for DNA methylation mapping, sodium bisulfite treatment of DNA, was shown to be incapable of distinguishing between $5 \mathrm{mC}$ and $5 \mathrm{hmC}(63)$, indicating that significant limitations exist for interpreting data obtained by this technique. Specific methodologies for the detection of $5 \mathrm{hmC}$ are currently being developed (64) allowing for a greater understanding of the temporal and spatial effects that 5 hcM will have on epigenetic regulation.

In conclusion, although indications exist that DNA methylation is involved in the pathogenesis of endometriosis, we are just beginning to understand the complexity of this mechanism. The epigenome of a cell is highly dynamic, being governed by a complex interplay of genetic and environmental factors. As knowledge on the subject deapens, the vision of a strict correlation between promoter hypomethylation on the one hand, and gene up-regulation and promoter hypermethylation and gene down-regulation on the other hand appears to be a simplification and associating methylation with complex phenotypes, especially outside the field of malignancy, has been very difficult (65). However, identifying differentially methylated regions in different types of endometriosis is useful because these may help identifying pathways involved in their (separate) 
pathogeneses. The establishment of specific epigenomic profiles of different types of endometriosis could be used for diagnostic purposes and for the development of new therapeutic strategies. New techniques such as genome-wide arrays for the study of interindividual variations in methylation patterns with locus-specific resolution have been added to the repertoire of investigators only very recently (66) and may prove to be valuable in this respect in the near future. 


\section{References}

1. Barcena de Arellano ML, Gericke J, Reichelt U, Okuducu AF, Ebert AD, Chiantera V, Schneider A, Mechsner S. Immunohistochemical characterization of endometriosis-associated smooth muscle cells in human peritoneal endometriotic lesions. Hum Reprod;26:2721-30.

2. Fukunaga M. Uterus-like mass in the uterine cervix: superficial cervical endometriosis with florid smooth muscle metaplasia? Virchows Arch 2001;438:302-5.

3. Kazakov DV, Ondic O, Zamecnik M, Shelekhova KV, Mukensnabl P, Hes O, Dvorak V, Michal M. Morphological variations of scar-related and spontaneous endometriosis of the skin and superficial soft tissue: a study of 71 cases with emphasis on atypical features and types of mullerian differentiations. J Am Acad Dermatol 2007;57:134-46.

4. Hull ML, Escareno CR, Godsland JM, Doig JR, Johnson CM, Phillips SC, Smith SK, Tavaré S, Print CG, Charnock-Jones DS. Endometrial-peritoneal interactions during endometriotic lesion establishment. Am J Pathol 2008;173:700-15.

5. Oosterlynck DJ, Meuleman C, Waer M, Koninckx PR. Transforming growth factor-beta activity is increased in peritoneal fluid from women with endometriosis. Obstet Gynecol 1994;83:287-92.

6. Stein M, Keshav S, Harris N, Gordon S. Interleukin 4 potently enhances murine macrophage mannose receptor activity: a marker of alternative immunologic macrophage activation. J Exp Med 1992; 176: 287-92.

7. Martinez FO, Sica A, Mantovani A, Locati M. Macrophage activation and polarization. Front Biosci 2008;13:453-61.

8. Bacci M, Capobianco A, Monno A, Cottone L, Di Puppo F, Camisa B, Mariani M, Brignole C, Ponzoni M, Ferrari S, Panina-Bordignon P, Manfredi AA, Rovere-Querini P. Macrophages are alternatively activated in patients with endometriosis and required for growth and vascularization of lesions in a mouse model of disease. Am J Pathol 2009;175:547-56.

9. Johan MZ IW, Robertson SA, Hull ML. Suppression of endometriosis-like lesion development in a TGFB1-/SCID mouse model of endometriosis. In: World Congress on Endometriosis. Montpellier, France, 2011.

10. Liu YG, Tekmal RR, Binkley PA, Nair HB, Schenken RS, Kirma NB. Induction of endometrial epithelial cell invasion and c-fms expression by transforming growth factor beta. Mol Hum Reprod 2009;15: 665-73.

11. Gaspar NJ, Li L, Kapoun AM, Medicherla S, Reddy M, Li G, O'Young G, Quon D, Henson M, Damm DL, Muiru GT, Murphy A, Higgins LS, Chakravarty S, Wong DH. Inhibition of transforming growth factor beta signaling reduces pancreatic adenocarcinoma growth and invasiveness. Mol Pharmacol 2007; 72:152-61.

12. Medicherla S, Li L, Ma JY, Kapoun AM, Gaspar NJ, Liu YW, Mangadu R, O'Young G, Protter AA, Schreiner GF, Wong DH, Higgins LS. Antitumor activity of TGF-beta inhibitor is dependent on the microenvironment. Anticancer Res 2007;27:4149-57.

13. Bogdahn U, Hau P, Stockhammer G, Venkataramana NK, Mahapatra AK, Suri A, Balasubramaniam A, Nair S, Oliushine V, Parfenov V, Poverennova I, Zaaroor M, Jachimczak P, Ludwig S, Schmaus S, Heinrichs $H$, Schlingensiepen $\mathrm{KH}$; Trabedersen Glioma Study Group. Targeted therapy for high-grade glioma with the TGF-beta2 inhibitor trabedersen: results of a randomized and controlled phase Ilb study. Neuro Oncol 2011;13:132-42.

14. Wrzesinski SH, Wan YY, Flavell RA. Transforming growth factor-beta and the immune response: implications for anticancer therapy. Clin Cancer Res 2007;13:5262-70.

15. Jakowlew SB. Transforming growth factor-beta in cancer and metastasis. Cancer Metastasis Rev 2006;25:435-57.

16. Tian M, Schiemann WP. The TGF-beta paradox in human cancer: an update. Future Oncol 2009;5: 259-71.

17. Grummer R, Schwarzer F, Bainczyk K, Hess-Stumpp H, Regidor PA, Schindler AE, Winterhager E. Peritoneal endometriosis: validation of an in-vivo model. Hum Reprod 2001;16:1736-43.

18. Folse DS, Stout LC. Endometriosis in a baboon (Papio doguera). Laboratory animal science 1978;28: $217-9$.

19. D'Hooghe TM, Bambra CS, Cornillie FJ, Isahakia M, Koninckx PR. Prevalence and laparoscopic appearance of spontaneous endometriosis in the baboon (Papio anubis, Papio cynocephalus). Biol Reprod 1991;45:4116.

20. Dick EJ, Jr., Hubbard GB, Martin LJ, Leland MM. Record review of baboons with histologically confirmed endometriosis in a large established colony. Journal of medical primatology 2003;32:39-47. 
21. D'Hooghe TM. Clinical relevance of the baboon as a model for the study of endometriosis. Fertil Steril 1997;68:613-25.

22. Fazleabas AT, Brudney A, Gurates B, Chai D, Bulun S. A modified baboon model for endometriosis. Ann $N$ Y Acad Sci 2002;955:308-17; discussion 40-2, 96-406.

23. D'Hooghe TM, Bambra CS, Isahakia M, Koninckx PR. Evolution of spontaneous endometriosis in the baboon (Papio anubis, Papio cynocephalus) over a 12-month period. Fertil Steril 1992;58:409-12.

24. D'Hooghe TM, Bambra CS, Raeymaekers BM, Koninckx PR. Serial laparoscopies over 30 months show that endometriosis in captive baboons (Papio anubis, Papio cynocephalus) is a progressive disease. Fertil Steril 1996;65:645-9.

25. Guo SW, Olive DL. Two unsuccessful clinical trials on endometriosis and a few lessons learned. Gyn Obstet Invest 2007;64:24-35.

26. Guo SW, Hummelshoj L, Olive DL, Bulun SE, D'Hooghe TM, Evers JL. A call for more transparency of registered clinical trials on endometriosis. Hum Reprod 2009;24:1247-54.

27. Pullen N, Birch CL, Douglas GJ, Hussain Q, Pruimboom-Brees I, Walley RJ. The translational challenge in the development of new and effective therapies for endometriosis: a review of confidence from published preclinical efficacy studies. Hum Reprod Update 2011;17:791-802.

28. De Carvalho CV, Nogueira-De-Souza NC, Costa AM, Baracat EC, Girao MJ, D'Amora P, Schor E, da Silva ID. Genetic polymorphisms of cytochrome P450cl7alpha (CYP17) and progesterone receptor genes (PROGINS) in the assessment of endometriosis risk. Gynecol Endocrinol 2007;23:29-33.

29. Govindan S, Ahmad SN, Vedicherla B, Kodati V, Jahan P, Rao KP, Ahuja YR, Hasan Q. Association of progesterone receptor gene polymorphism (PROGINS) with endometriosis, uterine fibroids and breast cancer. Cancer Biomark 2007;3:73-8.

30. Gentilini D, Vigano P, Carmignani L, Spinelli M, Busacca M, Di Blasio AM. Progesterone receptor +331G/A polymorphism in endometriosis and deep-infiltrating endometriosis. Fertil Steril 2008;90: 1243-5.

31. Near AM, Wu AH, Templeman C, Van Den Berg DJ, Doherty JA, Rossing MA, Goode EL, Cunningham JM, Vierkant RA, Fridley BL, Chenevix-Trench G, Webb PM, Kjær SK, Hogdall E, Gayther SA, Ramus SJ, Menon U, Gentry-Maharaj A, Schildkraut JM, Moorman PG, Palmieri RT, Ness RB, Moysich K, Cramer DW, Terry KL, Vitonis AF, Pike MC, Berchuck A, Pearce CL; Ovarian Cancer Association Consortium; Australian Cancer Study (Ovarian Cancer) (ACS); Australian Ovarian Cancer Study Group (AOCS). Progesterone receptor gene polymorphisms and risk of endometriosis: results from an international collaborative effort. Fertil Steril 2011;95:40-5.

32. Gimenes C, Bianco B, Mafra FA, Rosset V, Christofolini DM, Barbosa CP. The progins progesterone receptor gene polymorphism is not related to endometriosis-associated infertility or to idiopathic infertility. Clinics (Sao Paulo) 2010;65:1073-6.

33. Kim JJ, Choi YM, Choung SH, Yoon SH, Lee KS, Ku SY, Kim JG, Moon SY. Analysis of the transforming growth factor beta1 gene $-509 \mathrm{C} / \mathrm{T}$ polymorphism in patients with advanced-stage endometriosis. Fertil Steril 2010;93:2121-4.

34. Costa IR, Silva RC, Frare AB, Silva CT, Bordin BM, Souza SR, Ribeiro Júnior CL, Moura KK. Polymorphism of the progesterone receptor gene associated with endometriosis in patients from Goias, Brazil. Genet Mol Res 2011;10:1364-70.

35. Guo SW. Glutathione S-transferases M1/T1 gene polymorphisms and endometriosis: a meta-analysis of genetic association studies. Mol Hum Reprod 2005;11:729-43.

36. Tempfer CB, Simoni M, Destenaves B, Fauser BC. Functional genetic polymorphisms and female reproductive disorders: part II--endometriosis. Hum Reprod Update 2009;15:97-118.

37. Uno S, Zembutsu H, Hirasawa A, Takahashi A, Kubo M, Akahane T, Aoki D, Kamatani N, Hirata K, Nakamura Y. A genome-wide association study identifies genetic variants in the CDKN2BAS locus associated with endometriosis in Japanese. Nat Genet 2010;42:707-10.

38. Painter JN, Anderson CA, Nyholt DR, Macgregor S, Lin J, Lee SH, Lambert A, Zhao ZZ, Roseman F, Guo Q, Gordon SD, Wallace L, Henders AK, Visscher PM, Kraft P, Martin NG, Morris AP, Treloar SA, Kennedy SH, Missmer SA, Montgomery GW, Zondervan KT. Genome-wide association study identifies a locus at 7p15.2 associated with endometriosis. Nat Genet 2011;43:51-4.

39. Vainio S, Heikkila M, Kispert A, Chin N, McMahon AP. Female development in mammals is regulated by Wnt-4 signalling. Nature 1999;397:405-9. 
40. Naillat F, Prunskaite-Hyyrylainen R, Pietila I, Sormunen R, Jokela T, Shan J, Vainio SJ. Wnt4/5a signalling coordinates cell adhesion and entry into meiosis during presumptive ovarian follicle development. Hum Mol Genet;19:1539-50.

41. Boyer A, Lapointe E, Zheng X, Cowan RG, Li H, Quirk SM, DeMayo FJ, Richards JS, Boerboom D. WNT4 is required for normal ovarian follicle development and female fertility. Faseb J 2010;24:3010-25.

42. Fuks F. DNA methylation and histone modifications: teaming up to silence genes. Curr Opin Genet Dev 2005;15:490-5.

43. Wang $\mathrm{X}$, Hayes JJ. Acetylation mimics within individual core histone tail domains indicate distinct roles in regulating the stability of higher-order chromatin structure. Mol Cell Biol 2008;28:227-36.

44. Hodges-Gallagher L, Valentine CD, Bader SE, Kushner PJ. Inhibition of histone deacetylase enhances the anti-proliferative action of antiestrogens on breast cancer cells and blocks tamoxifen-induced proliferation of uterine cells. Breast Cancer Res Treat 2007;105:297-309.

45. Sakai N, Maruyama T, Sakurai R, Masuda H, Yamamoto Y, Shimizu A, Kishi I, Asada H, Yamagoe S, Yoshimura $\mathrm{Y}$. Involvement of histone acetylation in ovarian steroid-induced decidualization of human endometrial stromal cells. J Biol Chem 2003;278:16675-82.

46. Uchida H, Maruyama T, Nagashima T, Asada H, Yoshimura Y. Histone deacetylase inhibitors induce differentiation of human endometrial adenocarcinoma cells through up-regulation of glycodelin. Endocrinology 2005;146:5365-73.

47. Kouzarides T. Chromatin modifications and their function. Cell 2007;128:693-705.

48. Munro SK, Farquhar CM, Mitchell MD, Ponnampalam AP. Epigenetic regulation of endometrium during the menstrual cycle. Mol Hum Reprod;16:297-310.

49. Krusche CA, Vloet AJ, Classen-Linke I, von Rango U, Beier HM, Alfer J. Class I histone deacetylase expression in the human cyclic endometrium and endometrial adenocarcinomas. Hum Reprod 2007; 22:2956-66.

50. Xue Q, Lin Z, Cheng YH, Huang CC, Marsh E, Yin P, Milad MP, Confino E, Reierstad S, Innes J, Bulun SE. Promoter methylation regulates estrogen receptor 2 in human endometrium and endometriosis. Biol Reprod 2007;77:681-7.

51. Xue Q, Lin Z, Yin P, Milad MP, Cheng YH, Confino E, Reierstad S, Bulun SE. Transcriptional activation of steroidogenic factor-1 by hypomethylation of the 5' CpG island in endometriosis. J Clin Endocrinol Metab 2007;92:3261-7.

52. Izawa M, Harada T, Taniguchi F, Ohama Y, Takenaka Y, Terakawa N. An epigenetic disorder may cause aberrant expression of aromatase gene in endometriotic stromal cells. Fertil Steril 2008; 89: 1390-6.

53. Wu Y, Strawn E, Basir Z, Halverson G, Guo SW. Promoter hypermethylation of progesterone receptor isoform $B$ (PR-B) in endometriosis. Epigenetics 2006;1: 106-11.

54. Wu Y, Starzinski-Powitz A, Guo SW. Trichostatin A, a histone deacetylase inhibitor, attenuates invasiveness and reactivates E-cadherin expression in immortalized endometriotic cells. Reprod Sci 2007;14:374-82.

55. Borghese B, Barbaux S, Mondon F, Santulli P, Pierre G, Vinci G, Chapron C, Vaiman D. Research resource: genome-wide profiling of methylated promoters in endometriosis reveals a subtelomeric location of hypermethylation. Mol Endocrinol;24:1872-85.

56. Lee B, Du H, Taylor HS. Experimental murine endometriosis induces DNA methylation and altered gene expression in eutopic endometrium. Biol Reprod 2009;80:79-85.

57. Kim JJ, Taylor HS, Lu Z, Ladhani O, Hastings JM, Jackson KS, Wu Y, Guo SW, Fazleabas AT. Altered expression of HOXA10 in endometriosis: potential role in decidualization. Mol Hum Reprod 2007;13:32332.

58. Valinluck V, Sowers LC. Inflammation-mediated cytosine damage: a mechanistic link between inflammation and the epigenetic alterations in human cancers. Cancer Res 2007;67:5583-6.

59. Kurkjian C, Kummar S, Murgo AJ. DNA methylation: its role in cancer development and therapy. Curr Probl Cancer 2008;32:187-235.

60. Rakyan VK, Down TA, Thorne NP, Flicek P, Kulesha E, Graf S, Gräf S, Tomazou EM, Bäckdahl L, Johnson N, Herberth M, Howe KL, Jackson DK, Miretti MM, Fiegler H, Marioni JC, Birney E, Hubbard TJ, Carter NP, Tavaré S, Beck S. An integrated resource for genome-wide identification and analysis of human tissuespecific differentially methylated regions (tDMRs). Genome Res 2008;18:1518-29.

61. Rauch TA, Pfeifer GP. The MIRA method for DNA methylation analysis. Methods Mol Biol 2009; 507:65-75. 
62. Jin SG, Wu X, Li AX, Pfeifer GP. Genomic mapping of 5-hydroxymethylcytosine in the human brain. Nucleic Acids Res;39:5015-24.

63. Jin SG, Kadam S, Pfeifer GP. Examination of the specificity of DNA methylation profiling techniques towards 5-methylcytosine and 5-hydroxymethylcytosine. Nucleic Acids Res;38:e125.

64. Robertson AB, Dahl JA, Vagbo CB, Tripathi P, Krokan HE, Klungland A. A novel method for the efficient and selective identification of 5-hydroxymethylcytosine in genomic DNA. Nucleic Acids Res;39:e55.

65. Feinberg AP. Phenotypic plasticity and the epigenetics of human disease. Nature 2007;447:433-40.

66. Breitling LP, Yang R, Korn B, Burwinkel B, Brenner H. Tobacco-smoking-related differential DNA methylation: 27K discovery and replication. Am J Hum Genet 2011;88:450-7. 


\section{Summary}

Endometriosis is one of the most common benign gynecological conditions with an estimated prevalence of about $10 \%$ in women of reproductive age. It is defined as the presence of functional endometrial glands and stroma at ectopic locations outside the uterine cavity, most often located on the ovaries, the fossa ovarica, the uterosacral ligaments and the pouch of Douglas. Symptoms include dysmenorrhea, dyspareunia, chronic and severe pelvic pain throughout the menstrual cycle, and infertility.

Currently, Sampson's retrograde transplantation theory is the most widely accepted theory regarding the pathogenesis of endometriosis, postulating that reflux of viable endometrial cells takes place through the fallopian tubes during menstruation with subsequent adhesion, implantation and growth on and into the peritoneum and ovary (Sampson, 1927). However, retrograde menstruation is common, and small endometriotic implants are frequently encountered in asymptomatic women of reproductive age. As a consequence, there is a growing appreciation for the notion that mild peritoneal endometriosis should be considered a physiological phenomenon rather than a disease.

In 1990, deep infiltrating endometriosis was introduced as a new distinct entity. Deep infiltrating endometriosis is defined as endometrial glands and stroma infiltrating $>5 \mathrm{~mm}$ under the peritoneal surface. Because deep infiltrating lesions show the strongest association with symptoms such as dysmenorrhea, deep dyspareunia, chronic pelvic pain and painful defecation, this type of lesion is considered a pathological condition, as opposed to superficial peritoneal endometriosis. Moreover, deep infiltrating endometriosis shows morphological similarities to adenomyosis in the uterine wall (i.e. the presence of endometrial glands and stroma inside the myometrium).

As yet, the question why endometriosis develops into a pathological condition in some but not all women has remained largely unanswered. Environmental, genetic and epigenetic factors are thought to play a role in this process. The general aim of this thesis is to gain more insight in the contribution of each of these factors to the initiation and progression of deep infiltrating endometriosis.

An outline of the clinical background and current views on the pathogenesis of endometriosis are described in Chapter 1 . Subsequently, the molecular pathways studied in this thesis are described in more detail. Finally, the aims of the thesis are presented with an outline of the individual chapters.

The first part of the thesis addresses the role of the local environment in the establishment and maintenance of deep infiltrating endometriosis lesions. In Chapter 2, we (1) characterized the fibromuscular tissue present in deep infiltrating endometriosis lesions by using immunohistochemical markers of smooth muscle differentiation, (2) investigated the origin of smooth muscle cells in endometriosis lesions with the aid of a nude mouse model and (3) investigated a possible role for the cytokine transforming 
growth factor- $\beta 1$ (TGF- $\beta 1$ ) in this process by using immunohistochemical markers of TGF$\beta 1$ signaling.

Fibromuscular tissue surrounding human deep infiltrating endometriosis lesions contains myofibroblastic cells that express multiple markers of smooth muscle differentiation, such as alpha-smooth muscle actin (ASMA), desmin and smooth muscle myosin heavy chain (SM-MHC). This resembles the situation encountered in pathological wound healing and fibrocontractive diseases. In a nude mouse model we showed that ASMA expression is induced in the host tissue after implantation of human endometrial fragments, suggesting that the presence of smooth muscle-like tissue in endometriosis lesions is the result of a reaction of the local environment to the presence of ectopic endometrium rather than smooth muscle metaplasia of the ectopic endometrium itself. Immunohistochemical expression of TGF- $\beta$ receptor 1 , TGF- $\beta$ receptor 2 and marker of activated TGF- $\beta 1$ signaling phospho-Smad 2 was more pronounced in the endometrial component of the lesions than in the fibromuscular component, indicating that most TGF- $\beta 1$ signaling apparently occurs in the endometrial tissue and not in the local host cells. Therefore, it is not likely that TGF$\beta 1$ signaling alone is sufficient to account for the excessive fibromuscular tissue in deep infiltrating endometriosis lesions.

In the second part of the thesis we addressed the question whether genetic variants such as single nucleotide polymorphisms (SNPs) with functional consequences in two selected candidate genes influence the susceptibility for developing deep infiltrating endometriosis. In Chapter 3 we evaluated the possible association between the $-509 \mathrm{C} / \mathrm{T}$ polymorphism of the transforming growth factor- $\beta 1$ (TGF- $\beta 1$ ) gene and the risk of developing deep infiltrating endometriosis. We observed no statistically significant differences in the frequency of the $-509 \mathrm{C} / \mathrm{T}$ polymorphism between 72 deep infiltrating endometriosis patients and two separate control groups consisting of 95 gynecological patients without symptoms of endometriosis and 93 healthy females. The $-509 \mathrm{C} / \mathrm{T}$ polymorphism of the TGF- $\beta 1$ gene therefore does not seem to modify the risk of developing deep infiltrating endometriosis.

The possible association between two polymorphisms of the progesterone receptor (PR) gene, PROGINS and $+331 \mathrm{G} / \mathrm{A}$, and deep infiltrating endometriosis was evaluated in Chapter 4. The frequency of the PROGINS polymorphism did not differ between the groups and therefore does not seem to modify the risk of deep infiltrating endometriosis. The frequency of the polymorphic allele $+331 \mathrm{~A}$ was lower in 72 women with deep infiltrating endometriosis (3.0\%) and 40 women with adenomyosis of the uterine wall (2.6\%) compared with 93 healthy females (18.3\%), The presence of the polymorphic allele $+331 \mathrm{~A}$ was associated with a statistically significant reduction of the risk of having the disease phenotype in women with deep infiltrating endometriosis (OR $0.22 ; 95 \% \mathrm{Cl} 0.06$ 0.77) and adenomyosis (OR $0.12,95 \% \mathrm{Cl} 0.02-0.95$ ). Strikingly, the decrease in risk of developing deep invasive endometriosis only reached statistical significance when women with deep infiltrating endometriosis were compared with a general population- based 
control group of healthy females, but not when compared with a control group of 102 gynecological patients without symptoms of endometriosis (frequency of polymorphic allele $+331 \mathrm{~A}: 8.8 \%)$. These findings indicate that a general population-based control group is more suitable for this field of research than a probably biased control group consisting of gynecological patients.

The third part of the thesis addresses the question whether epigenetic regulatory mechanisms such as DNA methylation are involved in the regulation of endometrial growth and differentiation and in differential expression of genes in endometriosis patients. In Chapter 5, we investigated (1) expression levels of epigenetic markers DNA methyltransferases (DNMTs) and methyl-CpG binding domain proteins (MBDs) in human endometrium throughout the menstrual cycle and in matched samples of eutopic and ectopic endometrium of endometriosis patients and (2) hormone responsiveness of DNMT and $\mathrm{MBD}$ expression in explant cultures of proliferative phase endometrium. Expression levels of DNMTs and MBDs were assessed by real-time quantitative PCR.

The results of these experiments showed significantly higher expression levels of DNMT1 and MBD2 in secretory phase endometrium $(n=12)$ compared to proliferative phase endometrium $(n=8)$ and menstrual endometrium $(n=3)$. Expression levels of DNMT1 and MBD2 were significantly upregulated in endometrium treated with $E 2+P$, suggesting a role for DNMTs and MBDs in cyclic growth and differentiation of the human endometrium. Finally, expression levels of several DNMTs and MBDs were significantly lower in endometriotic lesions compared to eutopic endometrium of women with endometriosis and disease-free controls. This may explain why altered gene promoter methylation has been observed in endometriotic lesions and supports the notion that endometriosis may be an epigenetic disease.

In Chapter 6 we tested the hypothesis that severe up- or downregulation of several genes in eutopic endometrium of endometriosis patients in a previously conducted microarray study is the result of promoter methylation. Genes were selected based on biological plausibility and investigated for the presence of significant $\mathrm{CpG}$ islands in the promoter region. Both mRNA expression levels and methylation status of the investigated regions of the promoter CpG island in PRIM2A, TGFB3, EFNB1, TAF6L, SHB, ITGA2, BENE, Rap1GAP, OGG1 and PRB were not significantly different between eutopic endometrium of endometriosis patients and eutopic endometrium of controls. Because of recent and novel insights in DNA methylation and the importance of so-called "core regions" for the regulation of gene expression, our findings do not permit any definitive conclusions on the regulation of the investigated genes by (promoter) methylation. We recommend retesting our hypothesis in a larger cohort of eutopic endometrium samples, with the use of modern, sensitive, core-region specific techniques for the detection of DNA methylation. 
In Chapter 7, the most important findings were summarized and discussed within the context of recent literature. Limitations of the thesis were mentioned, and recommendations for future research were given. 


\section{Samenvatting}

Endometriose is één van de meest voorkomende goedaardige gynaecologische aandoeningen en treft naar schatting ongeveer $10 \%$ van alle vrouwen in de vruchtbare leeftijd. Het wordt gedefinieerd als de aanwezigheid van functioneel endometrium, bestaande uit klierbuisjes en stroma, op ectopische locaties buiten het cavum uteri. Voorkeurslokalisaties zijn de ovaria, de fossa ovarica, de sacro-uteriene ligamenten en het cavum Douglasi. Dysmenorroe, dyspareunie, ernstige en chronische buikpijn en subfertiliteit zijn de belangrijkste symptomen.

Op dit moment is de retrograde transplantatie theorie van Sampson wereldwijd de meest geaccepteerde theorie betreffende de ontstaanswijze van endometriose. Volgens deze theorie vindt er tijdens de menstruatie reflux van vitale endometriumcellen plaats via de tubae naar de buikholte, waarna deze cellen hechten, implanteren en verder groeien op en in het peritoneum ter plaatse. Retrograde menstruatie is echter een veel voorkomend fenomeen, en kleine endometriose laesies worden vaak gezien bij asymptomatische vrouwen in de vruchtbare leeftijd. Hierdoor wordt milde peritoneale endometriose steeds vaker beschouwd als een fysiologisch verschijnsel dan als een ziekte.

In 1990 werd diep invasieve endometriose geïntroduceerd als een nieuwe, separate entiteit. Diep invasieve endometriose wordt gedefinieerd als het voorkomen van endometriale klierbuisjes en stroma $>5 \mathrm{~mm}$ onder het peritoneumoppervlak. Omdat diep invasieve laesies het sterkst geassocieerd zijn met symptomen als dysmenorroe, diepe dyspareunie, chronische pijn in het kleine bekken en pijnlijke defaecatie wordt dit type endometriose als pathologisch beschouwd, in tegenstelling tot oppervlakkige peritoneale endometriose. Ook vertoont diep invasieve endometriose morfologisch gelijkenis met adenomyosis uteri (d.w.z de aanwezigheid van endometriale klierbuisjes en stroma in het myometrium van de uterus).

De factoren die ervoor zorgen dat endometriose zich in de ene vrouw wel tot een pathologische entiteit ontwikkelt en in de andere niet, zijn nog grotendeels onopgehelderd. Zowel omgevingsfactoren als genetische en epigenetische factoren worden verondersteld hierbij een rol te spelen. Het doel van dit proefschrift was om meer inzicht te verkrijgen in de invloed van elk van deze drie factoren op het ontstaan en de progressie van diep invasieve endometriose.

Een overzicht van de klinische achtergrond en huidige inzichten betreffende de pathogenese van endometriose wordt gegeven in Hoofdstuk 1. Vervolgens worden de verschillende moleculaire pathways die onderzocht werden in dit proefschrift in detail beschreven. Tenslotte worden de onderzoeksvragen en een overzicht van de hoofdstukken in dit proefschrift vermeld.

Het eerste gedeelte van dit proefschrift beschrijft de rol van de lokale omgeving bij het ontstaan en de instandhouding van diep invasieve endometriose laesies. In Hoofdstuk 2 werd (1) het fibromusculaire weefsel dat aanwezig is in diep invasieve endometriose 
laesies gekarakteriseerd met behulp van immunohistochemische markers van gladde spiercel differentiatie, (2) de herkomst van gladde spiercellen in endometriose laesies onderzocht in de naakte muis en (3) een mogelijke rol van het cytokine transforming growth factor- $\beta 1$ (TGF- $\beta 1$ ) in dit proces onderzocht met behulp van immunohistochemische markers van TGF- $\beta 1$ signaling.

Het fibromusculaire weefsel dat diep invasieve endometriose laesies omgeeft bevat myofibroblasten die meerdere markers van gladde spiercel differentiatie tot expressie brengen, zoals alpha- smooth muscle actine (ASMA), desmine en smooth muscle myosin heavy chain. Dit komt overeen met de situatie bij pathologische wondgenezing en ziekten die gekarakteriseerd worden door fibrose en contractie van weefsel. In de naakte muis toonden we aan dat de expressie van ASMA wordt geïnduceerd in het gastheerweefsel na de implantatie van humane endometriumfragmenten. Dit suggereert dat de aanwezigheid van gladde spiercel-achtig weefsel in endometriose laesies het gevolg is van een reactie van de lokale omgeving op de aanwezigheid van ectopisch gelokaliseerd endometrium, en niet van gladde spiercel metaplasie van het ectopische endometrium zelf. Immunohistochemische expressie van TGF- $\beta$ receptor 1 , TGF- $\beta$ receptor 2 en phosphoSmad2 (een marker voor actieve TGF- $\beta 1$ signaling) was aanwezig in zowel de endometriale als de fibromusculaire component van de laesies maar was meer uitgesproken in de endometriale component, wat uitwijst dat TGF- $\beta 1$ signaling hoofdzakelijk plaatsvindt in het endometrium en niet in het gastheerweefsel. Het is daarom onwaarschijnlijk dat de hoeveelheid fibromusculair weefsel in diep invasieve endometriose laesies verklaard wordt door TGF $\beta$ signaling alléén.

Het tweede gedeelte van het proefschrift behandelt de vraag of genetische varianten zoals single nucleotide polymorphisms (SNPs) met functionele consequenties in twee geselecteerde kandidaatgenen de vatbaarheid voor het ontwikkelen van diep invasieve endometriose beïnvloeden. In Hoofdstuk 3 werd de mogelijke associatie tussen het $509 \mathrm{C} / \mathrm{T}$ polymorfisme van het TGF- $\beta 1$ gen en het risico op het ontwikkelen van diep invasieve endometriose onderzocht. Er waren geen statistisch significante verschillen in de frequentie van het $-509 \mathrm{C} / \mathrm{T}$ polymorfisme tussen 72 diep invasieve endometriose patiënten en twee separate controlegroepen bestaande uit 95 gynaecologische patiënten zonder symptomen van endometriose en 93 gezonde vrouwen. Het -509C/T polymorfisme van het TGF- $\beta 1$ gen lijkt daarom het risico op diep invasieve endometriose niet te modificeren.

De mogelijke associatie tussen twee polymorfismen in het progesteron receptor (PR) gen, PROGINS en +331G/A, en diep invasieve endometriose werd onderzocht in Hoofdstuk 4. De frequentie van het PROGINS polymorfisme verschilde niet tussen de groepen en lijkt daarom het risico op diep invasieve endometriose niet te beïnvloeden. De frequentie van het polymorfe allel $+331 \mathrm{~A}$ was lager in 72 vrouwen met diep invasieve endometriose (3.0\%) en in 40 vrouwen met adenomyosis uteri (2.6\%) vergeleken met 93 gezonde vrouwen (18.3\%). De aanwezigheid van het polymorfe allel $+331 \mathrm{~A}$ was geassocieerd met 
een statistisch significante reductie van het risico op het hebben van het fenotype diep invasieve endometriose (OR $0.22 ; 95 \% \mathrm{Cl} 0.06-0.77$ ) of adenomyosis uteri (OR $0.12,95 \% \mathrm{Cl}$ 0.02-0.95). Opmerkelijk was dat deze afname in risico op het ontwikkelen van diep invasieve endometriose alleen statistische significantie bereikte wanneer vrouwen met diep invasieve endometriose werden vergeleken met een controlegroep met gezonde vrouwen uit de algemene populatie, maar niet wanneer zij vergeleken werden met een controlegroep bestaande uit 102 gynaecologische patiënten zonder symptomen van endometriose (frequentie polymorfe allel +331A: 8.8\%). Dit geeft aan dat een controlegroep die representatief is voor de algemene populatie geschikter is voor dit type onderzoek dan een controlegroep bestaande uit gynaecologische patiënten, omdat bij deze laatste groep het risico op de introductie van bias verhoogd is.

Het derde gedeelte van dit proefschrift behandelt de vraag of epigenetische mechanismen zoals DNA methylering betrokken zijn bij de regulatie van groei en differentiatie in het endometrium en bij de differentiële expressie van genen in endometriose patiënten. In Hoofdstuk 5 onderzochten we (1) de expressie van de epigenetische markers DNA methyltransferases (DNMTs) en methyl-CpG-binding domain proteins (MBDs) in humaan endometrium gedurende de menstruele cyclus en in eutopisch en ectopisch endometrium van endometriose patiënten, en (2) het effect van behandeling met de steroïd hormonen estradiol (E2) en progesteron (P) op de expressie van DNMTs en MBDs in explant kweken van proliferatief endometrium. De expressie van DNMTs en MBDs werd onderzocht met behulp van kwantitatieve real-time PCR (qRT-PCR).

De expressie van DNMT1 en MBD2 was significant hoger in secretoir endometrium $(n=12)$ dan in proliferatief $(n=8)$ en menstrueel endometrium $(n=3)$. Daarnaast werd de expressie van DNMT1 en MBD2 significant ge-upreguleerd in endometrium dat behandeld was met een combinatie van E2+P, wat een rol voor DNMTs en MBDs bij de cyclische groei en differentiatie van het humane endometrium suggereert. Tenslotte was de expressie van verschillende DNMTs en MBDs significant lager in ectopische endometriose laesies dan in eutopisch endometrium van endometriose patiënten en controles zonder endometriose. Dit zou kunnen verklaren waarom veranderingen in promoter methylering van bepaalde genen gezien worden in ectopische endometriose laesies. Ook wordt het idee dat endometriose een epigenetische ziekte zou kunnen zijn door deze resultaten ondersteund.

In Hoofdstuk 6 werd de hypothese getest dat de sterke up- of downregulatie van genen in eutopisch endometrium van endometriose patiënten in een eerder uitgevoerde microarray studie het gevolg is van methylering van de promoter. De door ons onderzochte genen werden geselecteerd op basis van biologische plausibiliteit en de aanwezigheid van een significant CpG eiland in de promoter van het gen. Zowel de expressie van mRNA als de methyleringsstatus van de onderzochte gebieden in het promoter CpG eiland van de genen PRIM2A, TGFB3, EFNB1, TAF6L, SHB, ITGA2, BENE, Rap1GAP, OGG1 en PRB was niet significant verschillend tussen eutopisch endometrium 
van endometriose patiënten en eutopisch endometrium van controles. Vanwege recente nieuwe inzichten op het gebied van DNA methylering en het belang van zogenaamde "core regions" voor de regulatie van genexpressie is het op basis van deze resultaten helaas niet mogelijk om definitief een uitspraak te doen over de regulatie van deze genen door (promoter) methylering. Hiertoe bevelen we het opnieuw testen van onze hypothese aan met gebruikmaking van moderne, sensitieve, core region-specifieke technieken voor de detectie van DNA methylering aan in een grotere groep eutopische endometrium samples.

In Hoofdstuk 7 worden de belangrijkste bevindingen samengevat en bediscussieerd in de context van recente literatuur. De beperkingen van onze studies en aanbevelingen voor toekomstig onderzoek worden vermeld. 


\section{Dankwoord}

Dit proefschrift zou nooit het daglicht hebben gezien zonder de steun van een groot aantal mensen. Een aantal hiervan wil ik graag in het bijzonder bedanken.

Professor Evers, aan de zijlijn bewaakte u scherp de voortgang van het wetenschappelijk proces. Ook al was u voornamelijk op de achtergrond aanwezig, toch stond $u$ op cruciale momenten klaar met raad en daad en hebt u ervoor gezorgd dat de vaart erin bleef. Veel dank voor de mogelijkheden die u me hebt geboden.

Dr. Dunselman, beste dr. D., uw toewijding aan vrouwen die lijden aan "de gevreesde ziekte" is ongeëvenaard. Ik heb veel plezier beleefd aan de discussies die ik met u voerde over het onderwerp, en heb er ontzettend veel van geleerd. Uw opmerkingen als clinicus bij de basaal wetenschappelijke stukken waren dan ook onmisbaar. Daarnaast hebt u niet alleen oog voor de mens achter de patiënt, maar ook voor de mens achter de promovendus, en dat is iets heel waardevols. Veel dank voor alles.

Dr. Groothuis, beste Patrick, toen ik als $4^{\mathrm{e}}$ jaars student bij jou de kamer op kwam wandelen om te praten over een wetenschapsstage kon ik niet vermoeden dat het uiteindelijk in dit proefschrift zou uitmonden. Jij was de spil van de endometriumgroep en als zodanig ben je voor mij en voor dit onderzoek van onschatbare waarde geweest. Altijd, maar dan ook altijd, kon ik bij je aankloppen voor advies of een brainstormsessie maar ook om te klagen over een experiment dat mislukt was of om even het weekend door te nemen. In jouw ogen was niets onmogelijk, en die positieve instelling was vaak precies wat ik nodig had als ik het weer eens somber inzag! Ook na je vertrek ben je betrokken gebleven bij het onderzoek, en was je steeds bereid om indien nodig van Oss naar Maastricht af te reizen. Dat je niet meer betrokken bent bij het Maastrichtse endometriose onderzoek is -en blijft- absoluut een gemis. Heel veel dank voor alles wat je voor me gedaan hebt!

Jacqueline Schouten, ik weet niet wat ik zonder jou had gemoeten. Honderden immuno's en minstens zoveel coupes later ligt het boekje er nu eindelijk, en dat is net zo goed jouw verdienste. Ontzettend bedankt voor je hulp en voor de gezelligheid op het lab!

Ook de overige leden van de toenmalige endometriumgroep, Rick, Christa, Helen, Chamindie en alle stagiaires wil ik hartelijk bedanken voor de samenwerking en de altijd gezellige werksfeer. Ayşe Demir, bij jou ben ik mijn carrière op het lab begonnen. Het beeld van dat A4-tje met de slogan "Laat uw menstruum niet zomaar wegvloeien" zal voor altijd op mijn netvlies gegrift blijven! Dank je wel voor de leuke en leerzame tijd. 
Medewerkers van de afdeling Pathologie. Als iets te ingewikkeld voor me was of ik gewoonweg de ingrediënten voor PBS niet kon vinden kon ik altijd rekenen op jullie hulp. Dank jullie wel voor het scheppen van de praktische randvoorwaarden waarbinnen ik mijn onderzoek kon uitvoeren (en voor jullie geduld als ik het PCR-hok weer eens een halve dag bezet hield).

Toen huisvesting binnen de afdeling Pathologie niet langer mogelijk was kon ik gelukkig al snel worden "geadopteerd" door de afdeling Moleculaire Celbiologie. Een aantal mensen in het bijzonder maakten dat ik mij daar al snel thuis voelde.

Andrea Romano, beste Andrea, jij hebt de afgelopen jaren eigenlijk voor mij gefungeerd als vice-copromotor en daar ben ik je erg dankbaar voor. Veel dank voor alle discussies, je adviezen en voor je waardevolle inbreng bij de artikelen. Mijn Italiaans is veel minder goed dan jouw Nederlands, maar ik waag toch een bescheiden poging: molto grazie!

Bert Delvoux, beste Bert, dank je wel voor al het praktische werk dat je voor me hebt gedaan, voor het oplossen van allerlei ad hoc problemen, het produceren van streeploze figuren en niet te vergeten voor het archiveren van alle gegevens op de computer en in je labjournaal (waarschijnlijk omdat je al voorzag dat het niet goed zou komen met die paar vodjes in de zak van mijn witte jas!). Daarnaast was het bij jullie vooral erg gezellig en hadden jullie de beste koffie van de UNS50 en omstreken. Dank jullie wel voor alles, zonder jullie had ik dit niet tot een goed eind kunnen brengen!

Dr. Ton Hopman, veel dank voor de hulp bij het krassen van de paraffinecoupes voor de methyleringsexperimenten en voor uw constructieve opmerkingen.

Dr. Bert Smeets en Rob Jansen, destijds behorend bij de vakgroep Populatiegenetica, dank jullie wel voor het belangeloos ter beschikking stellen van de samples voor de controlegroep van onze polymorfisme-studies.

Eveneens veel dank aan professor D'Hooghe en dr. Kyama van het Universitair Medisch Centrum Gasthuisberg te Leuven voor het ter beschikking stellen van de gematchte samples van eutopisch en ectopisch endometrium voor het epigenetica gedeelte van dit proefschrift.

Professor Beets-Tan, dr. de Die-Smulders, professor van Engeland, professor Fauser en dr. ir. Voncken, hartelijk dank voor het plaatsnemen in de beoordelingscommissie en voor het kritisch lezen van het manuscript.

Stafleden, collega-assistenten en collega's van verloskamer, verpleegafdelingen, poli en secretariaat van de afdeling Obstetrie en Gynaecologie van het MUMC te Maastricht en het VieCuri Medisch Centrum te Venlo: dank jullie wel voor de fijne samenwerking in de afgelopen jaren. Mijn afscheid van de gynaecologie ging gepaard met gemengde gevoelens. Het is dan ook nog steeds een heel mooi vak! Ik wil jullie heel hartelijk 
bedanken voor de waardevolle ervaring die ik bij jullie heb opgedaan. Uit het oog betekent in dit geval zeker niet uit het hart.

Lieve collega's van de afdeling IVF en het IVF-lab : Germaine, Laurence, Carla, Cecile, Marie-José, Erna, John, Josien, Edith, Aafke, Marijke, Marij, Roel, Inge, Marion, Myriam, en PGD-afgevaardigden Marion D. en Jos, het was een voorrecht om in zo'n klein, hecht team te mogen werken. Het feit dat het IVF- team in Maastricht zulke lovende recensies ontving was voor een heel groot deel aan jullie te danken. De samenstelling van het team is in de afgelopen jaren aanzienlijk veranderd, maar ik kijk nog steeds met enige weemoed terug naar die tijd. Keep up the good work (en jullie kunnen het goed)!

Annemiek Nap, we hebben maar heel kort samengewerkt op de IVF, maar hebben daarna nog menig congres bezocht samen, waarvan Australië absoluut het hoogtepunt was. Dank je wel voor de gezelligheid! Celine Lardenoije, ook jij bent helaas maar kort mijn collega IVF-arts geweest, maar ik heb steeds bewondering gehad voor je dappere keuze. Ewka Nelissen en Aisha de Graaff, mijn opvolgers, jullie hebben de IVF alweer verlaten en zijn inmiddels beiden in opleiding tot gynaecoloog. Ik kan maar één ding zeggen: hou vol, ook jullie boekje gaat eens af komen. En dan gaan we heel hard feest vieren!

Nieuwe collega's van de afdeling klinische genetica in het MUMC te Maastricht, jullie hartelijke ontvangst gaf me meteen het gevoel dat ik in een warm nest terecht was gekomen. Veel dank daarvoor, en voor het vertrouwen dat jullie in mij hebben gesteld!

Lieve vrienden en vriendinnen, gelukkig kon ik altijd bij jullie terecht voor de broodnodige afleiding en ontspanning buiten de wetensjap om. Regelmatig heb ik tegen jullie gezucht en gesteund over het boekje, vaak kwam het nooit meer af, heel lang was het bijna af, maar nu kan ik dan eindelijk volmondig zeggen: het is af! Dank jullie wel voor de talloze latte macchiato's, etentjes, lunchafspraken, terrasjes, saunadagjes, shopmiddagjes, kroegavonden en opbeurende woorden als ik weer eens in een promotie-dipje zat. Het schrijven van een proefschrift gaat, zeker in de laatste fase, helaas gepaard met enige mate van (zelfverkozen) sociaal isolement. Vanaf nu heb ik gelukkig weer meer tijd, dus laten we snel weer eens iets plannen!

Lieve Janneke, alweer 9 jaar geleden werd ik jouw collega op de IVF. Het feit dat de afdeling onder ons "bewind" voor het eerst tot beste IVF-afdeling van Nederland werd uitgeroepen vind ik best veelzeggend over onze samenwerking! Die samenwerking groeide uit tot vriendschap en ook buiten het werk hebben we inmiddels menig succesje gedeeld samen. Je hartelijkheid, gevoel voor humor en consciëntieusheid zijn onvolprezen en ik ben heel trots op hoe je het doet als gynaecoloog. Ik ben blij dat je vandaag mijn paranimf wilt zijn. 
Lieve Natasja, toen we 13 jaar geleden allebei terecht kwamen in de Maastrichtse endometriumgroep, jij als stagiaire en ik als wetenschapsstage-student, klikte het meteen. In vele rosé-en-bitterbal sessies op het terras of in de kroeg hebben we al heel wat lief en leed gedeeld, zowel wetenschaps- als niet wetenschapsgerelateerd! Dank je wel voor je vriendschap, en voor het feit dat je me vandaag als paranimf terzijde wilt staan.

Lieve Bas, ik heb bewondering voor hoe je je door de afgelopen periode heen hebt gevochten. Ik heb er dan ook alle vertrouwen in dat je je plek gaat vinden. Ik ben trots op je!

Lieve pap en mam, ook al hadden jullie hooguit een vaag idee van waar ik nu precies mee bezig was daar in het laboratorium, jullie waren altijd even belangstellend en betrokken. Dank jullie wel voor jullie onvoorwaardelijke liefde en steun en voor de stabiele thuisbasis die jullie me gegeven hebben. Zonder jullie was ik in vele opzichten niet geweest waar ik nu ben!

Lieve Tjipke, ik ken niemand die zo positief is en zo goed kan relativeren als jij! Je hebt de gave om overal het goede in te zien, en dat is bewonderenswaardig. Dank je wel voor je steun en je rotsvaste vertrouwen in mij. Ik ben blij dat jij bij me hoort, ik hoop dat we nog heel lang samen mogen genieten! 


\section{Curriculum Vitae}

Kim van Kaam werd op 15 september 1977 geboren te Sittard. In 1995 behaalde ze cum laude haar gymnasiumdiploma aan het gymnasium van het toenmalige Bisschoppelijk College Sittard (thans: Trevianum scholengroep). In datzelfde jaar ving zij aan met de studie Geneeskunde aan de Universiteit Maastricht. Tijdens haar coschappen volgde zij een wetenschapsstage met als onderwerp de pathogenese van endometriose bij de vakgroepen Gynaecologie en Pathologie, met als begeleiders dr. A.F.P.M. de Goeij, dr. P.G. Groothuis en dr. G.A.J. Dunselman. Tevens volgde zij een keuze co-schap Obstetrie en Gynaecologie in het Onandjokwe Lutheran Hospital, Ondangwa, Namibië. Na het behalen van het artsexamen in 2001 werkte zij van december 2001 tot juni 2003 als arts-assistent niet in opleiding bij de afdeling Obstetrie en Gynaecologie in respectievelijk het Laurentius Ziekenhuis te Roermond en het Elkerliek Ziekenhuis te Helmond. Vervolgens werkte zij van juni 2003 tot oktober 2007 als IVF-arts/onderzoeker op de afdeling Obstetrie en Gynaecologie van het Maastricht Universitair Medisch Centrum. Tijdens deze periode werd aangevangen met het promotieonderzoek zoals beschreven in dit proefschrift. Het onderzoek werd uitgevoerd binnen het Maastrichtse onderzoeksinstituut GROW, School for Oncology and Developmental Biology, bij de afdeling Gynaecologie en Obstetrie. In oktober 2007 startte zij met de opleiding tot gynaecoloog. Deze werd aangevangen in het VieCuri Medisch Centrum te Venlo (opleider: dr. J.J. van Beek) en vanaf oktober 2009 voortgezet in het Academisch Ziekenhuis Maastricht (opleider: prof. dr. G.G.M. Essed, vanaf oktober 2010 prof. dr. R.F.P.M. Kruitwagen). In 2011 besloot zij haar carrière voort te zetten bij de afdeling klinische genetica. Per 1 september 2011 is zij gestart met de opleiding tot klinisch geneticus in het Maastricht Universitair Medisch Centrum (opleider: dr. C.E.M. de Die-Smulders). 
Color figures

143 


\section{Figures chapter 2}
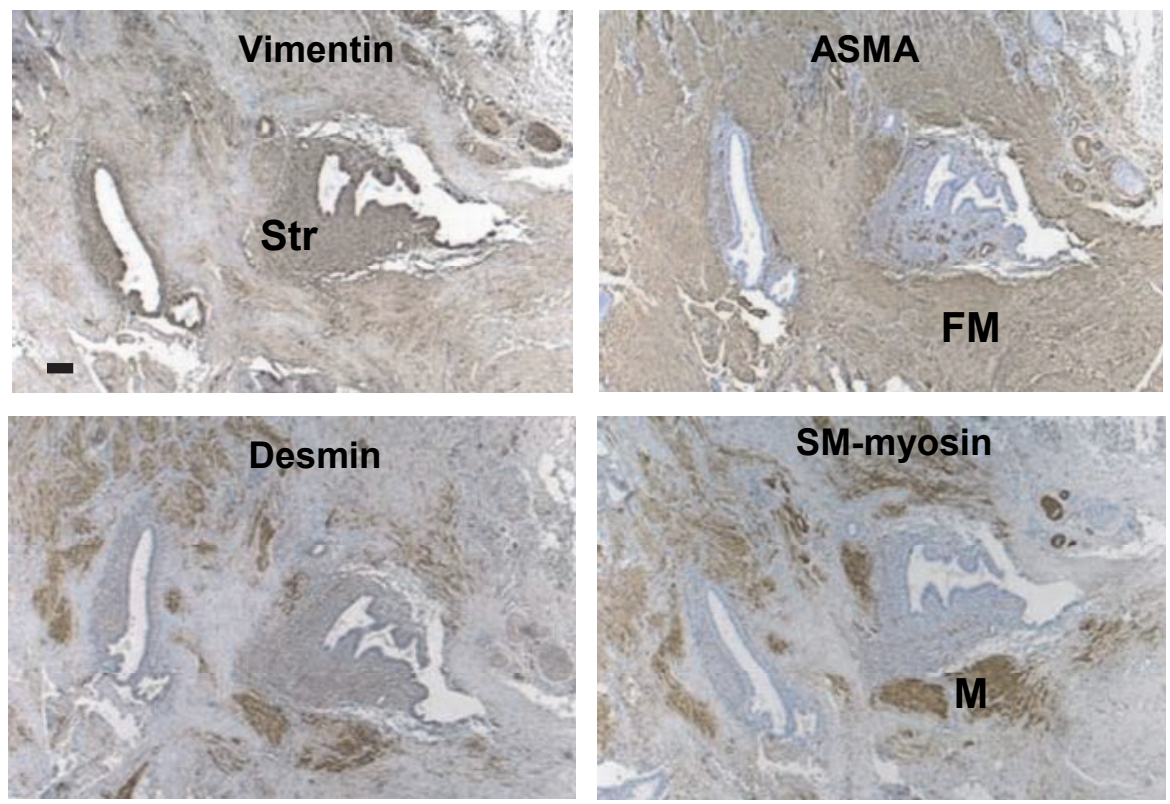

Figure 1 Representative photographs of deep-invasive endometriotic lesions stained with antibodies against vimentin, alpha-smooth muscle actin (ASMA), desmin and smooth muscle myosin heavy chain (SM-myosin). Vimentin staining is strong in the stroma (Str) of the ectopic endometrium, whereas the cells surrounding the lesion (FM) are positive for ASMA. Some areas (M) are also positive for desmin and SM-myosin; most likely resident smooth muscle cells. Scale bar $=100 \mu \mathrm{m}$. 

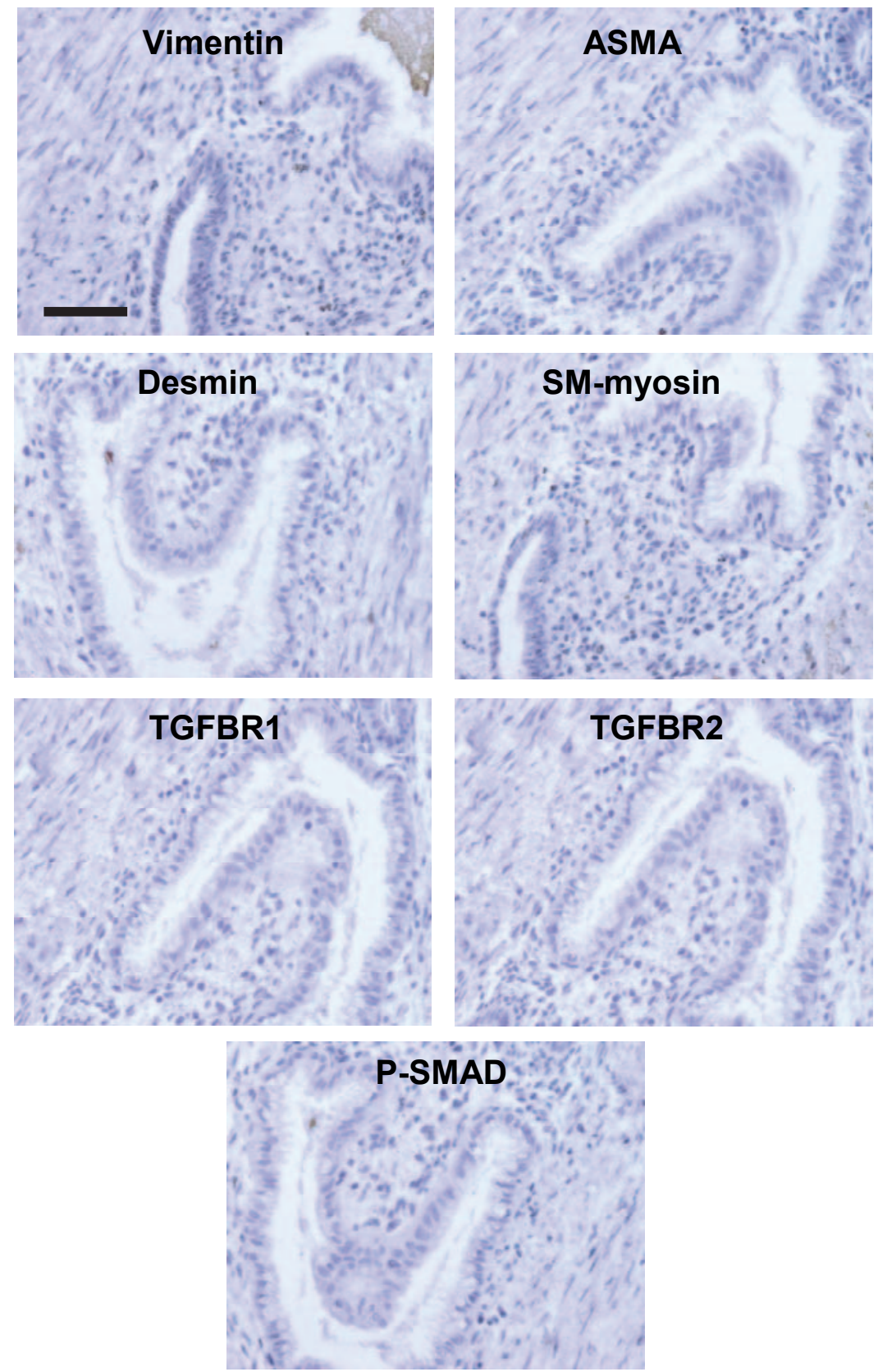

Figure 3 Representative photographs of the negative controls for the vimentin, ASMA, desmin, SM-myosin, TGF- $\beta$ receptor 1 and 2 and phosphorylated Smad immunostainings. Scale bar $=100 \mu \mathrm{m}$. 

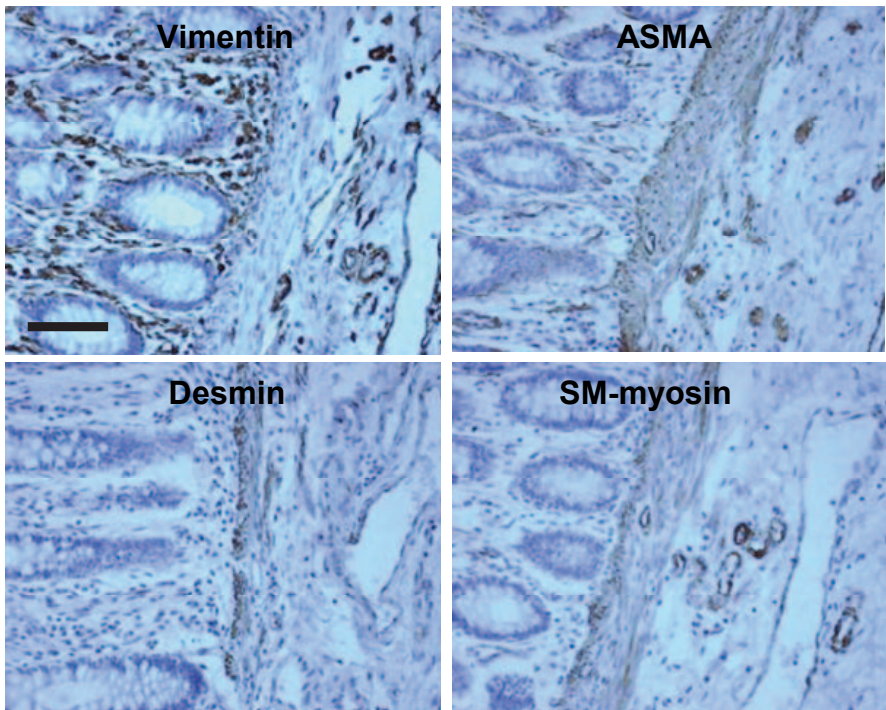

Figure 4 Immunostaining of vimentin, ASMA, desmin and SM-myosin in submucosal connective tissue of the large bowel. Scale bar $=100 \mu \mathrm{m}$.
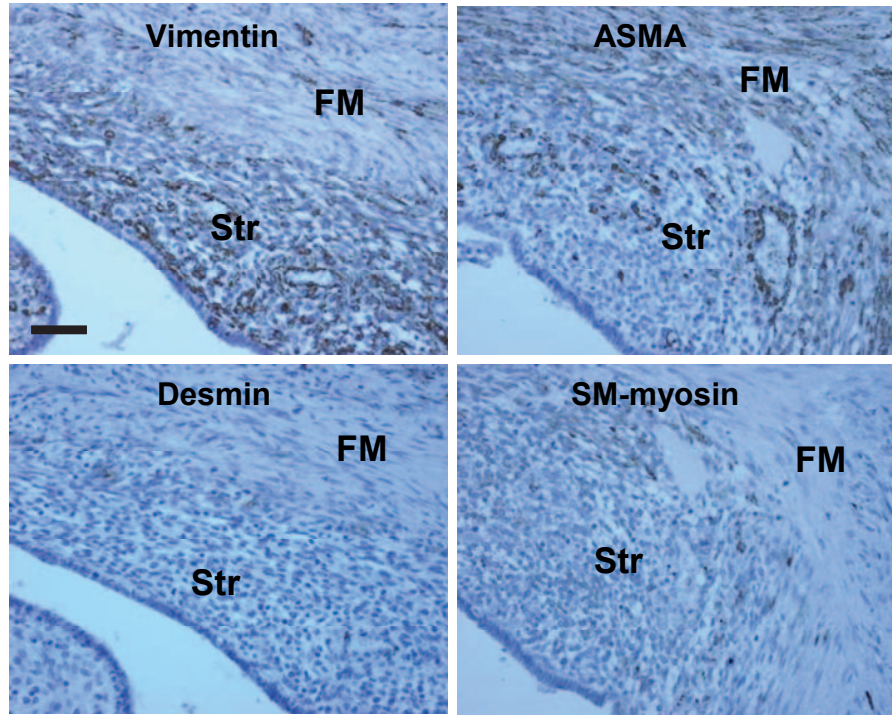

Figure 5 Higher magnification photographs of an endometriotic lesion in the sigmoid, with fibromuscular tissue, stained for vimentin, ASMA, desmin and SM-myosin. Str = stroma in ectopic lesion, FM = fibromuscular tissue. Scale bar $=100 \mu \mathrm{m}$. 

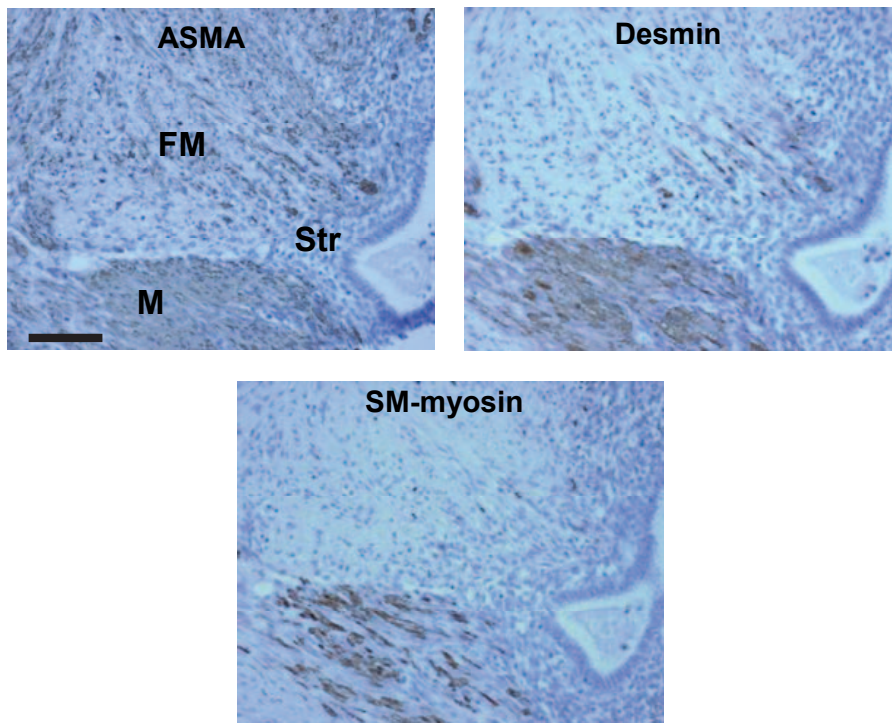

Figure 6 Difference in fibromuscular tissue and structures that are most likely resident smooth muscle cells. The sections were stained for ASMA, desmin and SM-myosin. Str = stroma in ectopic lesion, FM = fibromuscular tissue, $M=$ visceral muscle. Scale bar $=100 \mu \mathrm{m}$.
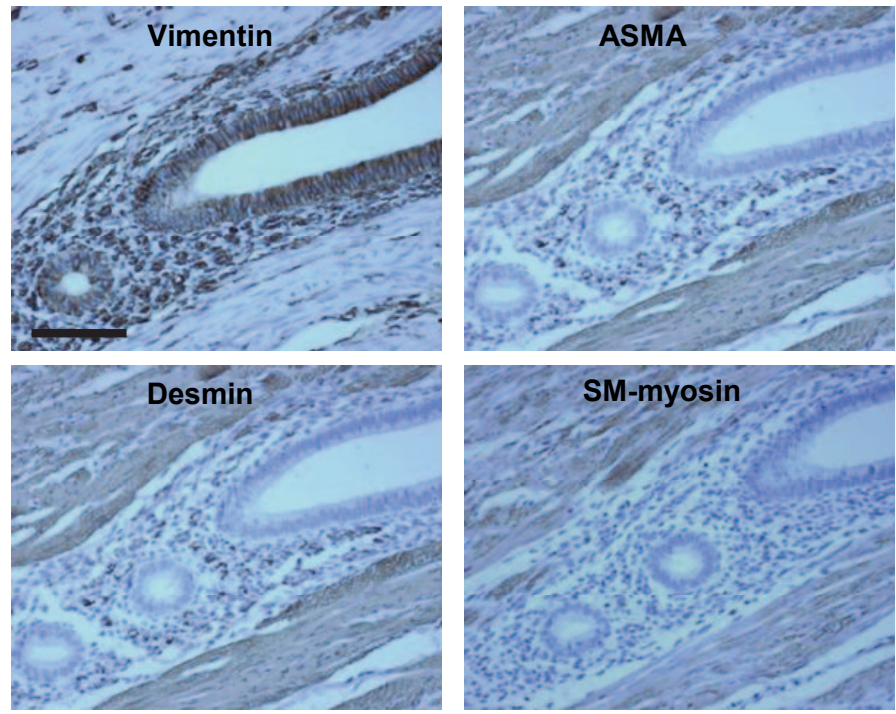

Figure $7 \mathrm{~A}$ lesion in the visceral muscle of the colon wall. The stroma is positive for vimentin and ASMA, whereas the muscle cells are positive for ASMA, desmin and SM-myosin. Scale bar $=100 \mu \mathrm{m}$ 


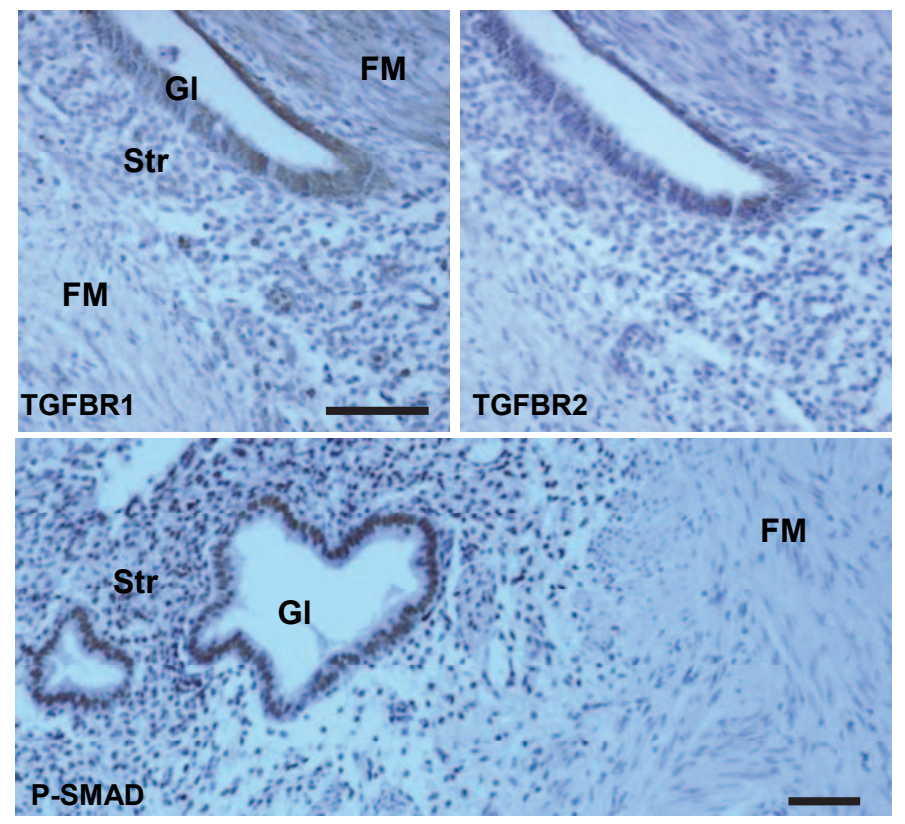

Figure 9 Representative photographs of immunostaining for TGF- $\beta$ receptor 1 and 2 and phosphorylated Smad in deeply infiltrating endometriosis. Str = stroma in ectopic lesion, FM = fibromuscular tissue, $\mathrm{Gl}=$ gland in ectopic lesion. Scale bar $=100 \mu \mathrm{m}$ 


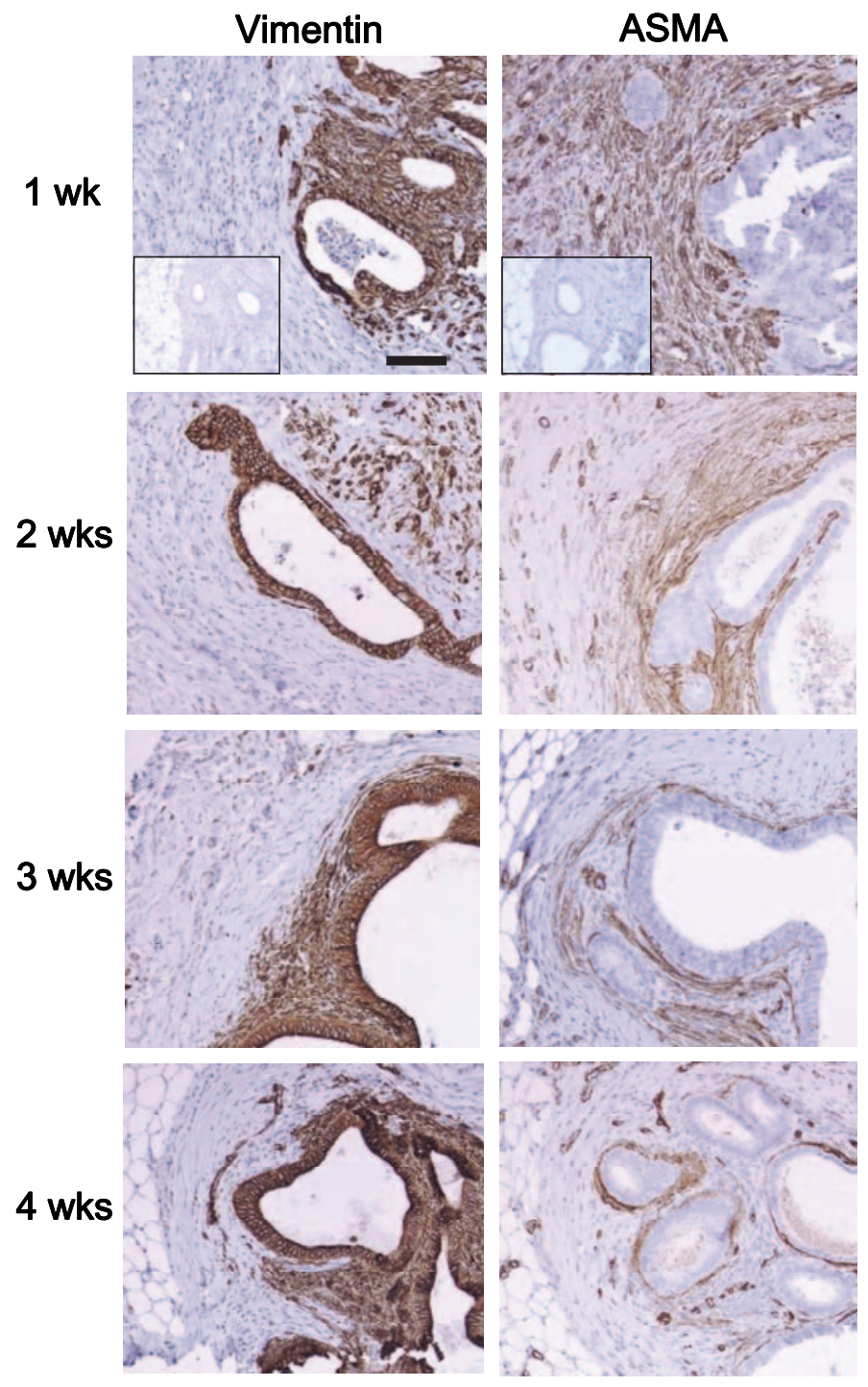

Figure 10 Vimentin and ASMA expression in endometriotic lesions generated through the subcutaneous transplantation of human endometrium in nude mice. Lesions were collected weekly for four weeks. The vimentin antibody is human-specific, which demonstrates that the ASMA expression is strongly enhanced in the host cells. Negative controls for the vimentin and ASMA stainings are shown in the inserts. Scale bar $=100 \mu \mathrm{m}$ 
Figures chapter 4

\section{Non-carriers}

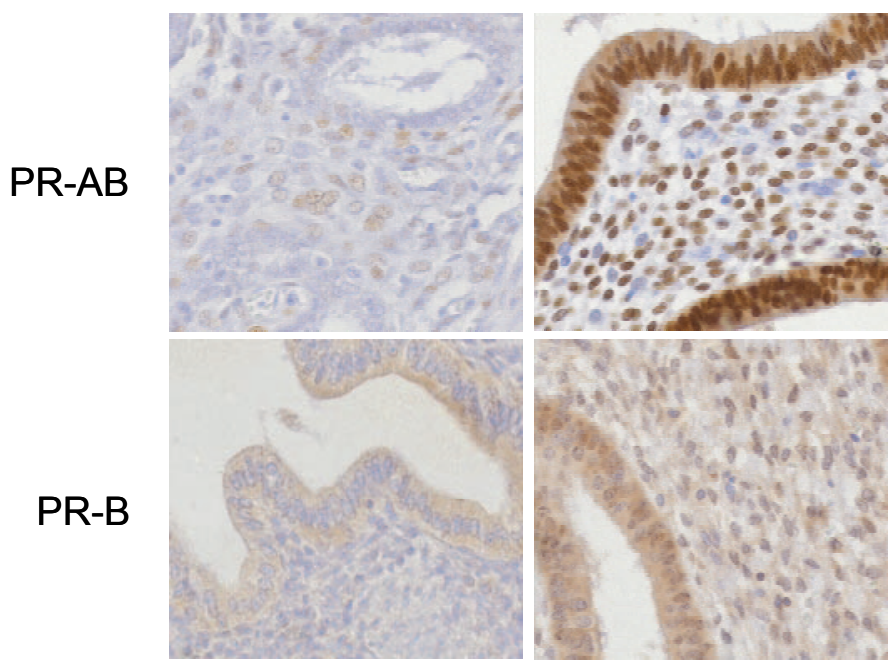

Figure 3A Representative examples of heterogeneous expression of PR-A/B and PR-B protein in endometriotic lesions in non-carriers (patients carrying neither the $+331 \mathrm{~A}$ nor the PROGINS polymorphic allele)

\section{PROGINS}

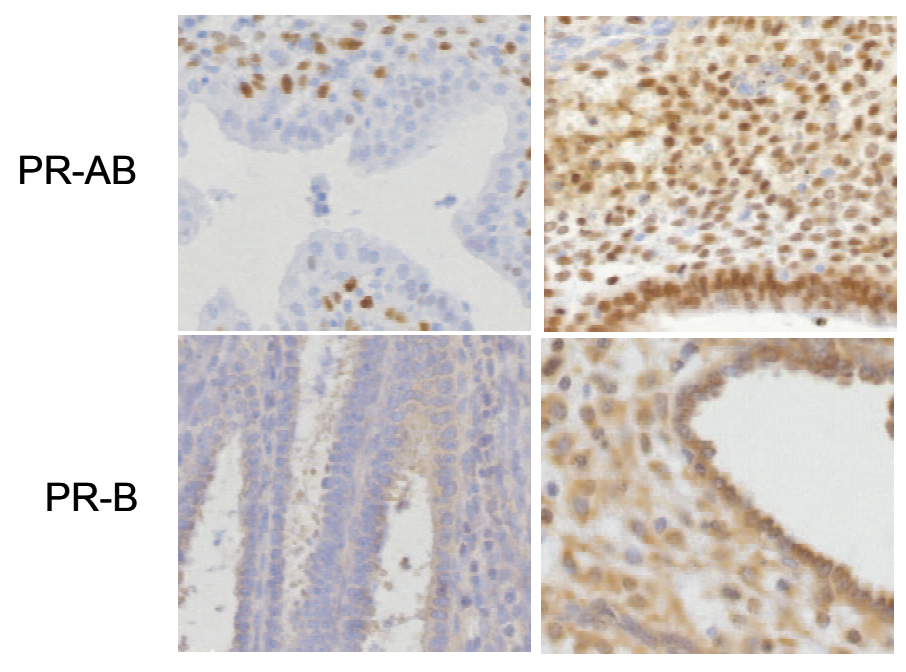

Figure 3B Representative examples of heterogeneous expression of PR-A/B and PR-B protein in endometriotic lesions in patients carrying the PROGINS polymorphic allele. The left panel shows weak expression of PR-A/B and PR-B, whereas the right panel shows strong expression. 


\section{$+331 \mathrm{GA}$}

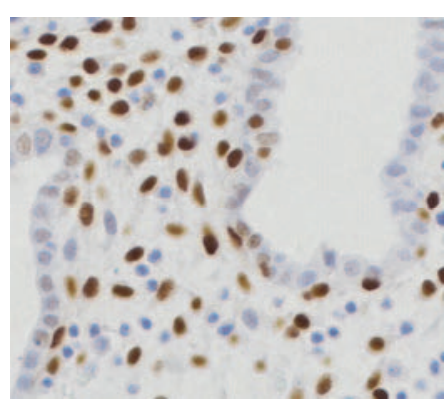

PR-AB

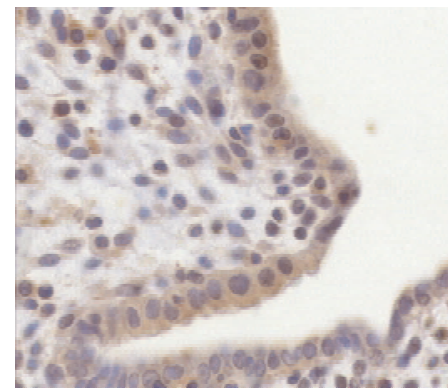

PR-B

Figure $3 C$ Representative examples of strong staining for PR-A/B and PR-B in endometriotic lesions of patients carrying the $+331 \mathrm{~A}$ polymorphic allele. 









$$
\begin{aligned}
& \text { ( MIX } \\
& \text { Paper from } \\
& \text { FSC responsible sources }
\end{aligned}
$$

